\title{
A PHOTOGRAPHIC INQUIRY INTO REGGIO INSPIRED NATURAL OUTDOOR ENVIRONMENTS IN ONTARIO EARLY LEARNING SETTINGS \\ by
}

Tanya Farzaneh, Bachelor of Child Development, Seneca College,

Toronto, Ontario, 2013

\author{
A Major Research Paper \\ presented to Ryerson University \\ in partial fulfillment of the \\ requirements for the degree of \\ Master of Arts \\ in the program of \\ Early Childhood Studies
}

Toronto, Ontario, Canada, 2015

(C) Tanya Farzaneh, 2015 


\section{AUTHOR'S DECLARATION FOR ELECTRONIC SUBMISSION OF A MRP}

I hereby declare that I am the sole author of this MRP. This is a true copy of the MRP, including any required final revisions.

I authorize Ryerson University to lend this MRP to other institutions or individuals for the purpose of scholarly research

I further authorize Ryerson University to reproduce this MRP by photocopying or by other means, in total or in part, at the request of other institutions or individuals for the purpose of scholarly research.

I understand that my MRP may be made electronically available to the public. 


\title{
ABSTRACT \\ PHOTOGRAPHIC INQUIRY INTO REGGIO INSPIRED NATURAL OUTDOOR ENVIRONMENTS IN ONTARIO EARLY LEARNING SETTINGS
}

\author{
Master of Arts, 2015 \\ Tanya Farzaneh \\ Early Childhood Studies \\ Ryerson University
}

This qualitative study explores the translation of Reggio principles in 20 Ontario natural outdoor early learning settings. Through visual research methods, digital images revealed the translation of the following principles: the image of the child, the environment as a third teacher and the hundred languages of children in the outdoor environments. Moreover, nature was a predominant element in two ways. First, nature was incorporated in the curriculum and natural spaces. Second, half the sites committed to connecting children to nature through frequent excursions in local green areas.

This research positions the potential for practice in creating outdoor early learning spaces by merging both the principles of nature-based education and Reggio inspired pedagogy, in considering compatibility with the Ontario Early Years Framework. This research addresses the current gaps in the literature pertaining to quality outdoor environments, and provides recommendations for a proposed Outdoor Pedagogy for the Early Years.

Key Words: Reggio inspired, pedagogy, outdoor environments, nature-based, visual research methods 


\section{Acknowledgements}

I would like to express my gratitude to my MRP supervisor Dr. Rachel Langford for her ongoing support, encouragement and advice from the conception of this study to the final submission of this paper. Thank you for allowing me to combine my passion and interests and encouraging the use of visual research methods. Thank you Dr. Marni Binder for your feedback and support as my second reader.

I very special thanks to all the site participants that so graciously allowed me into their outdoor environments to photograph their extraordinary work and for sharing their spaces, stories and love of Reggio and nature. This continues to enthuse me to the possibilities of practice and what can be imaginable outdoors in every early learning environment in Ontario.

I express deep gratitude and thanks to Dr. Diane Kashin as my mentor and friend who inspired me over two decades ago and continues to challenge and support my professional growth and instill a love of lifelong learning. It was her belief and encouragement in me that I returned back to school.

I express thanks to my place of employment Seneca College for providing me an environment that supports professional development. In particular June Williams for her enduring support in my educational endeavors. To the wonderful passionate colleagues at Seneca College ECE Lab School and faculty, each day you inspire me to grow, learn and embrace our work enthusiastically.

I warmly thank Maria Montuoro for being a supportive friend and colleague and providing a critical sounding board to discuss this paper and all things related to ECE. I express appreciation to Nicole Bontoft- Pierce for all your help and support especially those late nights.

Lastly, I thank my friends and family for their ongoing support, encouraging words and love. I am grateful to the outdoors, the trees and lakes and our summer cottage for providing me perseverance and belief that every child should grow up in and with nature for all the beauty and wonder it embodies. 


\section{Dedication}

This paper is dedicated to my beautiful children Nikki, Natalie and Kameron who I have enjoyed sharing my love of nature with, particularly at our family lake cottage. Thank you for sharing in the sense of wonder, love and appreciation for all it offers. May you always find peace and solace in nature and always know to return home to it. To my late mother Dorothy who saw the beauty in all living things. Through your eyes, we saw the wonder and astonishment of nature and now your love of flowers; trees and hummingbirds reside in my children and me. To children everywhere may you find a place in nature and experience its sense of awe, wonder and beauty. May you grow to love, honor and protect it always.

All of this is a great forest. Inside the forest is the child. The forest is beautiful, fascinating, green, and full of hopes; there are no paths. Although it isn't easy, we have to make our own paths, as teachers and children and families, in the forest. Sometimes we find ourselves together within the forest, some- times we may get lost from each other, sometimes we'll greet each other from far away across the forest; but it's living together in this forest that is important. And this living together is not easy (Malaguzzi, 1994 p. 2.). 


\section{Table of Contents}

Chapter One: Introduction .............................................................................................................................. 1

Purpose Statement ..................................................................................................... 4

Theoretical Framework........................................................................................... 5

Chapter Two: Literature Review ......................................................................................................... 8

Reggio Emilia Approach .................................................................................................... 8

Nature -Based Education ........................................................................................................... 17

Chapter Three: Methodology ................................................................................................ 26

Data Collection Methods ................................................................................... 30

Data Analysis ................................................................................................................................ 35

Chapter 4: Findings ........................................................................................................................................... 45

Environment as the Third Teacher ............................................................................ 48

The Atelier as an Expression of the Hundred Languages of Children .................. 58

The Image of the Child as Competent................................................................................. 65

Nature as the Third and Infinite Teacher........................................................................... 73

Chapter Five: Discussion.......................................................................................................................... 80

Limitations \& Future Considerations ........................................................................................ 94

References ............................................................................................................................................................... 121 


\section{List of Tables}

Table 1. Number of Environments Found in Sites ........................................................... 35

Table 2. Evidence for the Environment as the Third Teacher ............................................. 38

Table 3. Evidence of the Hundred Languages of Children ................................................... 39

Table 4. Evidence of the Image of the Child ................................................................ 40

Table 5. Evidence of Nature as the Third and Infinite Teacher ........................................... 41

Table 6. Connecting Reggio Principles to Codes......................................................................... 46 


\section{List of Figures}

Figure 1. Data Analysis: This image shows some of the data analysis process..................... 36

Figure 2. Provocations: To illicit the testing of inclines. ................................................... 46

Figure 3. Climbing Logs: Cluster of logs constructed to represent the image of the child as

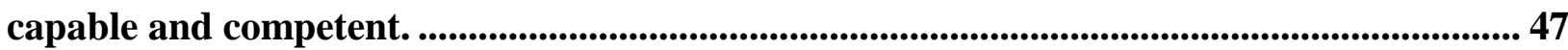

Figure 4. Evidence of the environment as the third teacher: Observed elements that were

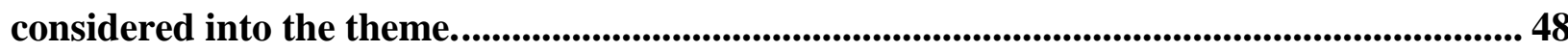

Figure 5. Evidence of choice: A variety of options for children to use. .................................. 49

Figure 6. Aesthetic considerations: Materials are displayed with aesthetics in mind......... 50

Figure 7. Invitations to learning: Provocation placed to invite children to learn through

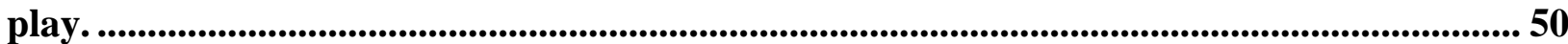

Figure 8. Real tools and natural materials: The children are offered real tools to create impressions with hammers and natural items.............................................................................. 51

Figure 9. Spaces to gather: This photo shows a space for a large group to gather and engage.

Figure 10. Small cozy spaces: An example of a small cozy areas for children to explore in.52

Figure 11. Décor: An example of items used to decorate and add beauty to the space........ 53

Figure 12. Art: Artwork used to add aesthetic value and honor the children's work. ........ 54

Figure 13. Natural Art: Natural objects displayed as art to acknowledge the beauty of

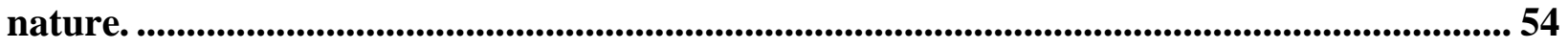

Figure 14. Movement: Fabric hung on a tree adds movement to the space......................... 55

Figure 15. Reflections: Reflective surfaces used through spaces to add interesting

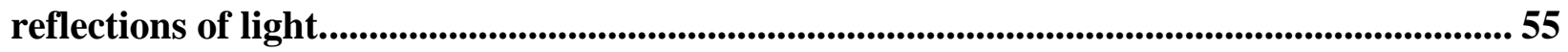

Figure 16. Shadows: Structures designed to cast interesting shadows are added to the

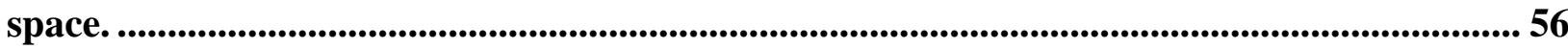

Figure 17. Sound. An example of items hung to create sounds in the wind. ....................... 56

Figure 18. Textures: Natural materials used to create a variety of textured surfaces in the

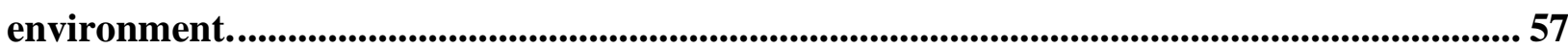

Figure 19. Evidence of the Atelier: The hundred languages of children............................. 58

Figure 20. Dramatic Dwellings: An example of a structure that allows for dramatic play opportunities. 
Figure 21. Mud Kitchens: A kitchen setup for children to engage in dramatic play. 60

Figure 22. Sensory exploration: Multiple provocations set up for the use of sand and sensory play. 61

Figure 23. Water Wall: Tubes and funnels set up to allow for testing theories with water. 62 Figure 24. Loose parts: This image shows free standing structures created with loose parts.

Figure 25. Large loose parts: Large logs and branches offered to children for the use in creative construction. 63

Figure 26. Small loose parts: A collection of small loose parts to enhance children's play. 64

Figure 27. Music: An example of a homemade music atelier using household materials to

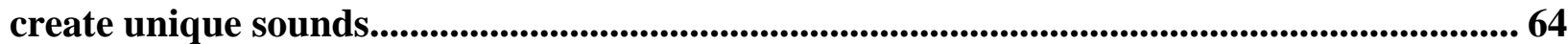

Figure 28. Evidence of the image of the child: Elements considered for the theme. ............ 65

Figure 29. Tree stumps: Tree stumps of varied heights for climbing and balancing on...... 66 Figure 30. Tires: A number of tires set up to present a physical challenge for the children.

Figure 31. Real tools: An example of real tools provided for the children's use. 67

Figure 32. Competency: A variety of materials provided which demonstrate children's

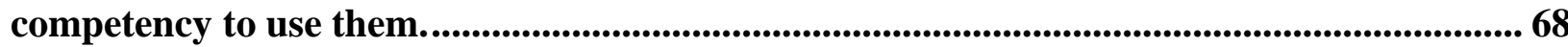

Figure 33. Boulders: Large boulders in the environment to challenge children. 68

Figure 34. Watering cans: A large selection of watering cans accessible for children's use.

Figure 35. Balancing: Long logs presented as an opportunity to explore balance. .............. 69

Figure 36. Large building: A structure created with large loose parts.................................. 70

Figure 37. Concrete materials: Metal kitchenware provided for the children to engage with.

Figure 38. Climbing structures: Nature based climbing challenge in place of a commercial climbing structure. 71

Figure 39. Self-help tasks: A manual water pump for children to get their own water

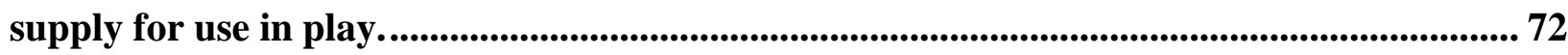

Figure 40. Evidence of nature as the third and infinite teacher emerged ............................. 73 Figure 41. Trees on a walk: Large trees spotted on the route children follow on walks...... 75 
Figure 42. Forest Trees: Trees in a forest children visit off site......................................... 75

Figure 43. Water access: Offsite water source visited by children on walks......................... 75

Figure 44. Local creek: A natural water source the children are taken to for explore........ 75

Figure 45. No-mow zone: An area adjacent to a site with natural growth for children's

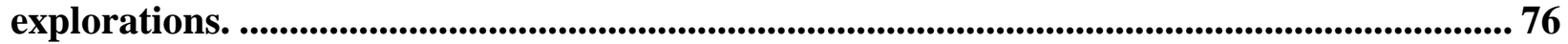

Figure 46. Gardens: One example of a garden bed within the outdoor learning

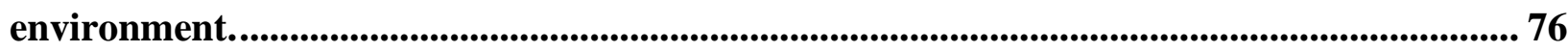

Figure 47. Bird feeders: A bird feeder placed within the environment to invite more nature in.

Figure 48. Cutting herbs: A provocation using nature provided to children to encourage

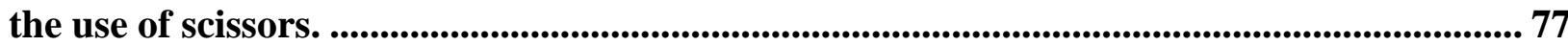

Figure 49. Bringing nature to Children: An exploration of insects .................................... 78

Figure 50. Natural playscapes: A playscape replaces a traditional outdoor structure. ....... 78

Figure 51. New outdoor pedagogy: The combination of approaches builds on one another to create a new pedagogy

Figure 52. A proposed Ontario outdoor pedagogy for the early years: A pedagogy

embracing Reggio principles and nature-based education in Ontario.

Figure 53. Hundred Languages Poem (Gandini, 2012. p. 3.) 


\section{List of Appendices}

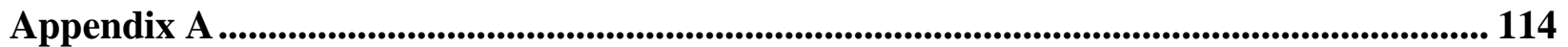

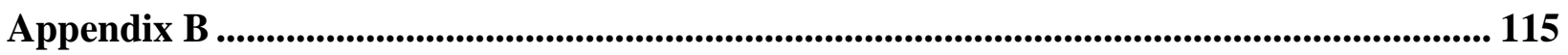

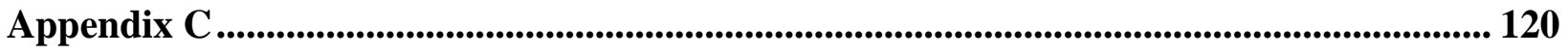




\section{Chapter One: Introduction}

The landscape of early childhood education is changing. The how, why, and what early childhood educators do with young children has been gaining the attention of the public, the government, and educational professionals over the last several decades. As societal needs change, the social phenomenon of childhood evolves. The fundamental question of how best to support children's learning has led to advances in government policies, protocols, and early learning frameworks nationally and provincially. New theories, philosophies, and methodologies for supporting young children's learning have directly influenced the need to address pedagogical practices within the early learning sector. Elliot (2010) suggests that the current trend in the early years has led to the implementation and design of policies, curricula, and frameworks aimed at increasing outcomes and offering optimal learning experiences for all children.

This paper focuses on three changes in the ECEC landscape evident in Ontario. First, the Ontario Early Years division has undergone several changes over the last decade, beginning with the Government launch of its Best Start Plan in 2004 (Best Start Panel on Early Learning, 2007). More recently, a resource guide aimed at improving quality and consistency across the province of Ontario, entitled: How Does Learning Happen? A Pedagogy for the Early Years (HDLH) was introduced in 2014. The HDLH guide calls on educators to reflect, research and co-construct new pedagogical practices (Ontario Ministry of Education, 2014). The document serves as a resource for educators to question and challenge long-held beliefs in early years pedagogy. "Pedagogy is the understanding of how learning takes place and the philosophy and practice that supports that understanding of learning" (Ontario Ministry of Education, 2014, p. 5). Pacini-Ketchabaw (2010) maintains that it is through discussion, asking questions and engaging in reflection of practices that we can create shifts in pedagogical thinking.

Historically in the field of early childhood education, developmental psychology has dominated and dictated practice through various theories and models (Elliot, 2010). The challenge educators currently face is how to move away from the conceptualization of linear, sequential stages in children's learning, towards a more holistic and complex view of teaching and learning (Elliot, 2010). Miller (2007) describes

Holistic education is on relationships: the relationship between linear thinking and intuition, the relationship between mind and body, the relationships among 
various domains of knowledge, the relationship between the individual and the community, the relationship to the earth, and our relationship to our soul (p.13).

Opportunities to engage in dialogue about new ideas about learning and teaching practice are presented in the HDLH guide in the form of reflection questions. The guide outlines essential pedagogical foundations intended to support educators in creating optimal conditions and environments for learning in the early years. Ministry of Education (2014) outlines the following four foundations of learning:

Belonging: the sense of connectedness and relationships with others

Well-being: physical and mental health, self-care, and self-regulation

Engagement: exploration of the world through play-based inquiry

Expression: being heard and listened to through various forms of expression

The HDLH guide is based on current research that addresses the existing need for educators to engage in critical thinking and embrace a new type of pedagogy within the early years sector (Ontario Ministry of Education, 2014). It draws from a variety of educational perspectives on teaching and learning including those from the pedagogies of the pre-primary schools of Reggio Emilia, Italy (hence force referred to as Reggio Emilia or Reggio). Indeed, Reggio Emilia principles of teaching and learning are referred to throughout the HDLH resource guide. These principles include the view of the child as competent, family, and educators as capable and competent, the environment as a third teacher, and the need for reflective and collaborative practice through pedagogical documentation (Ontario Ministry of Education, 2014). These theories challenge the Universalist view that children develop the same everywhere, as the key principles of Reggio offer a new approach to pedagogical thinking.

Secondly, Reggio has been at the forefront of influencing change all over the world as educators; administrators, and policy makers draw inspiration from this progressive educational movement. For decades the schools of Reggio have been recognized for their innovations in early childhood education (Edwards, Gandini \& Foreman, 2012). These innovations have influenced and changed the pedagogical practices of educators, and inspired change in the conceptualization of how children learn and how to facilitate it. Reggio has evolved into a "distinctive and innovative set of philosophical and pedagogical assumptions, methods of school organization and principles of environmental design that, taken as a unified whole, we are calling the Reggio experience" (Edwards et al., 2012. p. 6). 
The recent introduction of the HDLH resource in Ontario has incorporated key principles inspired by current theories and pedagogy in education, including those found in the principles of Reggio (Ontario Ministry of Education, 2014). These principles have had a significant impact on how educators conceptualize children, the role of the teacher and the environment as a third an important teacher within the classroom are discussed throughout the HDLH guide. The HDLH guide encourages educators to explore their current practice and re-consider these principles.

The third change evident in the Ontario ECE landscape has been influenced by the significant decline in children's play outdoors. Kasten (2005) contends there is a new type of childhood, in which children spend less time outdoors, with lower expectations to interact with nature and the natural world. According to Childcare Canada (n.d.) there has been a recent growth in the pedagogy of embracing outdoor learning environments as more than spaces for leisure, but rather as places that has the potential for the highest level of play, development, and learning. Consequently, it is an important time for practitioners, government, and researchers in the early years sector to re-evaluate approaches to outdoor learning spaces.

At the same time there is a global movement, particularly active in North America, in which educators, parents, and communities have gained an increased interest in connecting or reconnecting children to nature. This movement is a call to return children to nature and natural spaces (Moore, 2014). The fundamental shift may be the result of changes to childhood landscape in which schools have significantly moved away from emphasizing the outdoors, resulting in decreases in children's direct experiences with nature. As a result, Frumkin (2014) proposed that there is a natural call to reframe childhood, in what Richard Louv (1995) calls the nature movement, or integrating nature into childhood.

Nature play can be defined as "a designated area in an existing or modified outdoor environment where children of all ages and abilities play and learn by engaging with, and manipulating, diverse natural elements through sensory, fine and gross motor experiences" (Moore 2014, p. 13). Nature play and learning spaces comprising primarily of natural elements such as plants, trees, fallen trees, hollowed out logs, stones, water and dirt offer endless opportunities for explorations and discoveries. Experiences in nature support children's developing sense of love for the earth and help them to create an emotional bond with it. Adults have a responsibility to promote nature play and support the development of environmental stewardship in children (Frumkin, 2014; Moore, 2014). Explorations and hands on connections 
with nature facilitate the development of the whole child, encompassing a holistic model of education that integrates body, mind, and spirit (Moore, 2014).

Despite these advances, it appears the attention and value placed on outdoor play is still limited in early learning pedagogy. Childcare Canada (n.d) argues that outdoor play is often seen as an opportunity for children to release energy, with little consideration for the potential for space and learning.

The Ontario Early Years HDLH guide acknowledges the importance of connecting children to nature and providing meaningful experiences both inside and outside the classroom (Ontario Ministry of Education, 2014). However more guidelines, discussion, and a reconceptualization are needed to assist educators in establishing an outdoor pedagogy of natural spaces. The HDLH resource guide embodies several principles similar to those found in the Reggio philosophy. In considering these two significant changes occurring across Ontario, namely the introduction of the HDLH resource guide, influenced by Reggio-inspired pedagogy, and the importance of connecting children to nature and natural spaces, it appears timely for research to focus on outdoor learning environments in Ontario.

\section{Purpose Statement}

The introduction of the HDLH resource guide, the influences of Reggio-inspired pedagogy, and the movement to connect children to nature and natural spaces, suggests a confluence of ideas to examine in relation to outdoor learning environments. More specifically this study explores the question of whether or not Reggio principles, which underline the HDLH resource guide, are consistent and compatible with the descriptors of outdoor education. To achieve this, this study explores the elements and characteristics of a sample of Reggio-inspired natural outdoor learning environments in Ontario. This research also has the potential to impact educators' perceptions of the significance of natural Reggio-inspired outdoor learning environments. Equally, it can support educators in examining their beliefs and the potential of natural spaces for meeting children's diverse needs. While much research has explored Reggio pedagogy indoors, there is limited research that has explored the translation of Reggio principles in the outdoors context. This study addresses this gap.

In addition, this study contributes to a deeper understanding of the possibilities of space in the pedagogy of outdoor natural learning environments for educators, policy makers, and licensing bodies. This research has the potential to initiate a discussion about the need to 
establish an outdoor pedagogy, and how Reggio pedagogy can transform spaces and better meet children's holistic needs in nature-based settings. Last, this research contributes to the movement in connecting children to nature through an outdoor pedagogy in the early years.

The focus of this study is to examine the translation of the principles of Reggio in identified Reggio-inspired outdoor natural early learning environments, through the use of visual research methods. The visual data collected seeks to answer the following research questions: How does Reggio-inspired practice translate in outdoor natural learning environments? Can photos illustrate the potential for Reggio-inspired pedagogy in Ontario nature based outdoor environments? Themes extracted from photo images provide evidence for the presence of Reggio principle outdoors. This research develops recommendations or suggestions for practice based on the findings and proposes a way of conceptualizing a pedagogy for the outdoors that combines Reggio principles and beliefs and values held by natural outdoors advocates.

\section{Theoretical Framework}

This study employs a constructivist framework for exploring Reggio inspired natural outdoor learning environments throughout Ontario. Through visual research methods, photographs were used to explore if the principles of Reggio can be translated in outdoor environments. Creswell (2014) describes constructivism (often associated with interpertivism) as seeking to understand the world we live in. Constructivism is based on the individual construction of knowledge with the interaction of the environment (Gibson, 2009), and is the process of individuals developing subjective meaning in objects. Rather than starting with a theory, constructivist researchers generate knowledge and theories through the process of meaning- making (Creswell, 2014). Cotty (1998) as cited in Creswell (2014) discusses constructivism in the following way: humans construct knowledge within the world they are interpreting, thus researchers seek to understand the context and setting of the participants through visiting and gathering information. Finally, the process of research is inductive, as the researcher generates meaning from the collection of data in the field. Constructivist researchers focus on specific contexts in which people work and live to better understand and make meaning (Creswell, 2013). This theoretical framework is well suited to answer the research question as it involved fieldwork in twenty early learning settings, and added to the understanding and construction of meaning of outdoor Reggio environments.

The theoretical framework of constructivism was evident in the choice of visual research 
methods, which is the use of various visual materials to generate knowledge and explore research questions. Visual research methods can be used in the production, organization and interpretation of images (Prosser, 2007). Photos captured allowed for the construction of meaning as the interpretation of image data supports the development of new knowledge. Weber (2008) describes visual research methods as valuable, as images capture the indescribable and provide the ability to draw attention to things in novel ways. The collection of data through numerous sites, in the form of images, allows for the generation of meaning from the data. The choice of visual research methods and the use of photography served to provide evidence for the translation of Reggio principles into practice. Photos taken and selected at the participant sites offered the opportunity to make meaning and construct knowledge. Through this lens, this study sought to better understand and capture the elements and characteristics of Reggio-inspired natural outdoor learning environments, and determine whether the principles of Reggio can translate outdoors.

Constructivist researchers often recognize that their background and beliefs may shape their interpretation of data. Creswell (2013) suggests that the researcher positions him or herself within the study, allowing for reflexivity. As a researcher I recognize that I bring my own experience and assumptions that may influence the interpretation of data. Within a constructivist framework, the goal of the research is not to make a universal claim but rather to construct knowledge based on the photos as they are taken, selected, and analyzed to make meaning. Measures to ensure accuracy and authenticity as well as reflexivity will be discussed in subsequent chapters.

I am aware that my own experiences and background inform and shape my interpretations. My own subjectivity was taken into consideration as I reflected on my own personal teaching philosophy influenced by the principles of Reggio-inspired practice. Through a constructivist framework, I aim to make meaning through existing research as well as the images taken and selected for analysis. Taken together, the images coupled with Reggio theory informed the analysis and meaning making of the data.

My personal interest in pedagogical practice and philosophy guided my research. Over the past 20 years I have practiced as an Early Childhood Educator within a laboratory teaching school in a local college in Ontario. I have explored a variety of pedagogical beliefs and how they relate to my own personal teaching practice. In the early part of my career, many of the 
dominant pedagogical influences left me feelings disingenuous and questioning authenticity. That changed when I was introduced to the Reggio Philosophy more than thirteen years ago. The principles of the Reggio approach resonated with my core teaching values and beliefs. For me, the principles of Reggio-inspired practice have served as a compass, and ignited a renewed passion for teaching and learning. More recently I have been introduced to the Forest School movement and the concept of ecological education that both appear to run parallel in similarities to the principles of Reggio. These parallels of practice have acted as a provocation for this inquiry.

As an educator inspired by the principles of Reggio, pedagogical documentation has served to allow me to deepen my understanding of children and their learning, and provided the space for my inquiry. Therefore, visual research methods presented themselves as a natural method into the inquiry of natural outdoor environments. Additionally, photography is a hobby of mine, although I have no professional or practical training and do not intend to position myself as an expert in photography. However, I have always been drawn to the beauty of images and how the lens can aid define, frame, and assist my understanding and meaning-making.

I am aware that my experience and own pedagogical beliefs may shape the interpretation of the data. As a precaution, data collections was shared and validated by my research supervisor to ensure accuracy and authenticity. 


\section{Chapter Two: Literature Review}

The purpose of this literature review is to provide an overview of a large subset of current literature in the field of early childhood education in relation to Reggio-inspired natural outdoor learning environments. I examined this literature with the aim of clarifying some of the concepts in my research questions: How does Reggio-inspired practice translate in outdoor natural learning environments? Can photographs illustrate the potential for Reggio-inspired pedagogy in Ontario nature based outdoor environments?

A comprehensive search of databases in early childhood education, published peerreviewed journals, books, government publications, relevant organizational literature, and a large collection of published and unpublished works, provided definitions of Reggio pedagogy and principles, nature-based education and outdoor natural environments. The theories identified in the review were used to guide my research, and provided a theoretical framework for data collection and analysis. Specifically, this literature review examined the history, philosophy and principles embodying both Reggio pedagogy as well as the current literature on nature-based education philosophy in early childhood education.

The scope of the review was limited to published and unpublished works in English, primarily in North American context, from early 1990 to 2015. Due to the nature of the two areas of exploration, namely Reggio-inspired pedagogy and nature-based education, published works from Europe were included in my North American search. The intent of this review was to focus on recently published works, however a significant body of literature was drawn from original writings in Reggio philosophy, notably one book that became a primary resource. This is in part due to the fact that most publications draw directly from this source. In addition, I expanded my search to include several publications addressing the interest in the Reggio philosophy in the Canadian context.

\section{Reggio Emilia Approach}

The pre-primary schools of Reggio Emilia began in the small city located outside Milan, Italy. The first school was established after World War II as parents began to build the school left from the rubble of the war-torn city. The parents of this community rejected the conventional school of the past and wanted for their children a different type of school where children would acquire critical thinking and collaboration skills (Gandini, 2012). The sense of purpose and 
community inspired Loris Malaguzzi, an educator from a neighboring town, to join the collaborative efforts in building the first public preschool in Reggio Emilia thereafter called Reggio (Gandini, 2012).

Upon joining the community efforts, Loris Malaguzzi was instrumental in establishing the philosophical foundation and pedagogical beliefs of the preschools of Reggio (Gandini, 2012). During the early 1960's, Malaguzzi focused on developing a distinctive philosophy and approach to teaching and learning (New, 2000). Malaguzzi was a seminal thinker and embraced a complex system of theory influences from Dewey, Piaget, Vygotsky, Gardner, and Hawkins among others in the construction of a new progressive education philosophy known as Reggio (Gandini, 2012; Dodd-Nufrio, 2011; Fu, Stremmel \& Hill, 2002).

Lella Gandini, the North American Liaison for the Dissemination of the Reggio Emilia Approach and former colleague of Malaguzzi, was responsible for the translation of many of his ideas, that are found in The hundred languages of children: the Reggio Emilia experience in transformation. This book became a primary source of literature capturing the views and conceptual thinking of Malaguzzi. Here he discussed the early history of Reggio and the many influences that shaped the development of his philosophy. These theorists include Dewey, Piaget, Vygotsky and Hawkins.

John Dewey (1859-1952), a progressive educator in the United States, believed in a child-centred curriculum. Dewey held that education is based on meaningful experiences and conditions that promote growth and learning (Dewey, 1963). Disputing most traditional methods of teaching, Dewey discussed the significance of the educator in providing optimal conditions for learning, including the educator's tone, choice of words, materials and equipment offered, along with the freedom for children to pursue his or her own meaningful curriculum and directives (Dewey, 1963). Dewey claimed that education must take into account the internal factors and motivators for learning that are part of the experience; "[the] most important attitude that can be formed is the desire to go on learning" (Dewey, 1963 p. 20). Education, according to Dewey, is not a preparation for future citizenship, but rather involves significant and meaningful experiences in the present, and therefore education should ensure present, worthwhile experiences (Dewey, 1963). In turn, this creates positive attitudes to learning and sets the premise for future meaningful engagement: "educators should view teaching and learning as a continuous process of reconstruction of experiences" (Dewey, 1963, p. 39). 
Malaguzzi was also influenced by Piaget's focus on how children think and develop knowledge within the environment, a theory now known as constructivism (Marion, 2015). Piaget believed that children learn best when actively involved in building knowledge, and therefore need opportunities for problem solving and inventing (Gandini, 2012). Further, he believed that children move gradually through stages of development as they interact, assimilate, and accommodate new ideas (Marion, 2015). Children, according to Piaget, progress through each stage by actively constructing and building on previous knowledge through their interactions with the environment. Constructivists believe children are curious, active learners eager to investigate and discuss findings (Marion, 2015). Malaguzzi agreed with the image of the self-motivated child, but disputed Piaget's notion of the egocentric child who constructs knowledge in isolation.

Building on Piaget's theories, Malaguzzi drew on Vygotsky's theory that learning is situated in social interactions and co-constructed with others (Fraser, 2000). Vygotsky too believed that children actively construct knowledge. However, differing from Piaget, Vygotsky believed that learning was relevant to experience, and that thought and language work together to form ideas and actions (Gandini, 2012). Vygotsky's theories emphasize that learning takes place in a social context and are enriched by the support of others (Gandini, 2012; Fraser, 2000). In particular, he highlighted the significance of the adult, or knowledgeable other, in scaffolding what is commonly referred to as the theory of the zone of proximal development (Gandini, 2012; Fraser, 2000). According to Vygotsky's theories, there is a space or zone where learning occurs. At one end is the child's current ability while at the other is what the child could learn with the help of a knowledgeable other (Marion, 2015). The adult's role is to establish where the child currently is, and support the child in accomplishing the new task and learning.

Finally, Malaguzzi drew on American academic David Hawkins' focus on the significance of adults' engagement in the process of learning. A professor of philosophy at Boulder University, Hawkins and his wife, an early childhood educator, established a progressive environmental education program heavily situated in active hands-on explorations. Fundamental to Hawkins's philosophy of learning was the significance of teacher as learner, who engages with children in active inquiry (Hall, 2012). Hawkins proposed that educators need to demonstrate a sense of wonder, curiosity and engagement alongside children, which he referred to as "messing about" (Gandini, 2012, p. 49). According to Hawkins, the environment is 
significant to the learning process and should include enticing, provoking, everyday materials, and loose parts both recycled and natural to support children in inquiry and investigation (Hall, 2012). Messing about requires active participation of both adults and children to play, test, and build theories with materials. Through this process, adults learn, experience, and understand the complexities of exploring, testing and creating ideas like children. Through this the role of the adult is viewed as a co-constructor of knowledge, an inquisitive researcher, as well as creator of knowledge.

\section{Reggio Principles}

Educators draw inspiration from the Reggio approach, intended to be adapted for each context. Building on the early foundations of the philosophy of Reggio, those working with Malaguzzi such as Edwards, Gandini and Rinaldi continued to add to and refine the philosophy. For the purpose of this literature review, Reggio principles relevant to this study will be discussed as articulated by these later Reggio thinkers. These principles include the role of the teacher as a researcher, pedagogical documentation, the image of the child as competent, the hundred languages of children, and the environment as a third teacher. Reggio texts refer to educators as teachers, therefore the terms educator and teacher will be used interchangeably.

The role of the teacher in Reggio is multifaceted and responds to the changing times, and needs of children, families, and culture (Edwards, 2012). The role of the teacher is based on "all aspects of the organization, environmental design, pedagogy and curriculum-on the explicit nature of children as learners" (Edwards, 2012, p. 148). The teacher holds and supports the image of the child as competent, honors the hundred languages of children and places significance on the environment as a third teacher. The role of the teacher involves active participation, being fully attentive and listening to children, and sharing in meaning and decision-making. Active listening contributes to developing relationships with children, understanding and supporting inquires, and establishes the emerging curriculum.

In Reggio teachers are seen as researchers, active initiators, constructing knowledge of children, and learners engaging in continuous reflective practice (Rinaldi, 2012). This notion of the teacher as researcher sets the premise for a process of inquiry and lifelong professional renewal. In Reggio the teacher is the researcher, and pedagogical documentation is treated as teacher research. Pedagogical documentation, which is a visual representation of children's learning, communicated to other teachers, families, and children. It supports teacher research as a 
method of communicating, and as a means of making teacher and child learning visible. Documentation makes visible the processes of the individual child as well as those of the whole group. Teachers engaging in pedagogical dialogue offer their perspectives to others, creating a space or interpretation, reflection, debate, ongoing learning, and potentials for change. Through an awareness of teaching practice, there is greater potential to promote change, as pedagogical documentation allows us to create space for discussion and debate (Dahlberg, 2012).

The educators of Reggio conceptualize the role of the teacher beginning with the image of the child rather idealized in pair with the image of the teacher (Edwards, 2012). Both are constructed as strong, powerful and equal contributors to the process of learning, and as active contributors to the culture and community in the classroom (Rinaldi, 2012). Children are considered citizens in the classroom, with rights and decision-making power. The expectation in Reggio is that teachers must not only think of children as strong and capable, but also act in ways that represent this conceptualization (Edwards, 2012). "It's necessary that we believe that the child is very intelligent, that the child is strong and beautiful and has very ambitious desires and requests. This is the image of the child that we need to hold" (Malaguzzi, 1994, p.1.). In this image, the child is constructed as being full of potential, with innate curiosity and desire to build relationships with others, while constructing knowledge in the environment (Edwards, 2012).

Children are believed to possess relational, sensory, and cognitive resources that change and evolve as each child has a natural receptivity towards materials, others, and the environment (Rinaldi, 2012). Therefore, the child enters into a relationship with the environment to construct knowledge and make meaning (Rinaldi, 2012). Through this relationship with materials, children begin to construct a personal language from direct interaction with the environment, materials, and one another (Edwards et al., 2012). In Reggio, this is often referred to as the hundred languages of children. The hundred languages of children is a metaphor representing the potentials of children, their knowledge-building and creative capacities. Fiore (2013) describes the hundred languages of children as infinite sensorial, relational, and affective intelligences. "The hundred languages of children can include the use of words, language, pottery, movement, art explorations such as clay, paint, mark making, building, sculpting, designing, light and shadow, mirrors to engage in perspective to drama and music. The hundred is the child's way of expressing, sharing, knowing and understanding" (Fiore, 2013 p. 2). This declaration was further given meaning with a poem written by Loris Malaguzzi referring to the image of the child and 
their infinite possibilities and supports educators in defining the image of the child.

No way. The hundred is there

The child

is made of one hundred.

The child has

a hundred languages

a hundred hands

a hundred thoughts

a hundred ways of thinking

of playing, of speaking.

A hundred always a hundred

ways of listening

of marveling, of loving

a hundred joys,

for singing and understanding

a hundred worlds

to discover

a hundred worlds

to invent

a hundred worlds

to dream.

The child has

a hundred languages

(and a hundred, hundred, hundred more)

but they steal ninety-nine.

The school and the culture

separate the head from the body.

They tell the child

to think without hands

to do without head 
to listen and not to speak

to understand without joy

to love and marvel

only at Easter and Christmas.

They tell the child:

to discover the world already there

and of the hundred

they steal ninety-nine.

They tell the child

That work and play

reality and fantasy

science and imagination

sky and earth

reason and dream

are things

that do not belong together.

And thus they tell the child

that the hundred is not there.

The child says:

No way. The hundred is there.

Loris Malaguzzi, Translated by Lella Gandini (Edwards et al., 2012. p. 3).

The poem further draws attention to the role of the school and the environment in honoring children's multiple languages and providing a means to explore them freely. Reggio schools and teachers hold a strong belief in the environment as a third teacher. According to this viewpoint, the environment is seen as an educator that can provide relevance, purpose, and that invites learning and engagement. The principle of the third teacher supports the premise that children can create meaning and make sense of their world by living and learning in complex, rich environments. The principles of Reggio strongly support the notion that children have a right to environments that support the development of their many languages (Gandini, 2012). 
The atelier has become another fundamental principle in relation to Reggio, due to its significance both concretely as well as figuratively. The atelier, as described by Malaguzzi, is the school's studios or laboratories, rich in space, materials and possibilities (Gandini, 2012). Often thought of as an art studio, the atelier hosts more than art projects. It is a place for making meaning and representing thinking. It is a space for research, made available to children for manipulating and exploring visual languages in addition to building theories and messing about (Gandini, 2012). Ateliers are viewed as opportunities within the classroom for children's constructions and representations of thinking and knowledge.

Malaguzzi explains "The atelier [...] generating complexity and new tools for thought. It has allowed for rich combinations and creative possibilities among different symbolic languages of children" (Gandini, 2012, p. 49). The atelier or ateliers address the children's multiple ways of knowing and expressing. Through the atelier, children have opportunities to express their ideas. To children it is a space to construct, build, and create and represent meaning. Along with the large atelier, smaller ateliers around the classroom allow children the opportunity to transfer skills in small spaces.

Cooper (2012) communicates the role of the atelier as a rich environment for both children and adults. "The choice of the atelier was a strong declaration of the importance given to expression, creativity, aesthetics as natural fibers within education, and the broad human search for understanding and meaning" (Cooper, 2012, p. 298). Both the interior and exterior schools of Reggio are designed as places of research for children and adults. They offer opportunities for interaction, autonomy, exploration, and communication (Gandini, 2012). Continuity between the outdoors and indoor flow with the large windows that allow for natural light, leading to an array of outdoor possibilities within the gardens (Fiore, 2013; Gandini, 2012).

The environment as a third teacher evokes interest and sparks child-initiated investigations, that are organized around the idea of "expect the unexpected", often referred to as the emergent or negotiated curriculum within the Reggio context (Strong-Wilson \& Ellis, 2007, p. 42). These provocations are intended to provoke interest, and in turn set the premise for new emerging curriculum. In creating spaces for children, attention to the messages and invitations contained within inspire children in the creation and construction of knowledge. "Beautiful spaces are a testament to beautiful processes" (Copper, 2012, p. 301). Thoughtful, purposeful, and meaningful considerations to detail embody the design (Gandini, 2012; Strong-Wilson \& 
Ellis, 2007). There are several design principles fundamental to environments in Reggio space, including softness, aesthetics, transparency, active learning and collaboration, flexibility and adaptation, reciprocity and relationships, outdoors, and multi-sensorial experiences (Gandini, 2012, p. 324).

However, equal importance is given to the design of spaces for social engagement and collaborations. In Reggio, the space allows a focus on the social constructions of knowledge through social constructivism. It is the design of space that contributes to the social and collective use of the environment and choices made within it. Gandini (2012) proposes that adults must think about the quality and instructive influence of space, in order to foster collaboration within it.

\section{Interpretations of Reggio}

To embrace Reggio is not a matter of uprooting their work into another context, but rather involves critical reflection and engagement in adapting, re-inventing, and envisioning the potentials of practice into a new context (Fu et al., 2002). Reggio is not a model with the intention of being replicated. The educators from Reggio stress the challenges others might face in interpreting and reinventing the philosophy in their own context (Dodd-Nufrio, 2011).

This dynamic educational approach, which is constantly questioning itself, changing and inventing new ways of understanding [...] can't easily be captured and presented by only one person and with only one language. The challenge is for all of us who want to offer children in our own context and community the best opportunities to experience learning with pleasure and to continuously find new ways to translate ideas, reinvent them and invent new ones (Gandini, 2012. p. 21).

This translation of practice is often realized through the incorporations of principles within the environment, as well as through curriculum. Building on these principles, Fraser (2000) explores the translation of Reggio in Canadian context. She describes the application of the theories of Reggio, particularly influenced by Dewey, as applied in the classroom. Fraser descriptions of Canadian Reggio-inspired classrooms as including child-led investigations based on children's direct and inborn curiosity and freedom to pursue interests that are integrated into the design of the classroom. Children are presented with real, concrete materials to explore and make meaning. This is grounded in real experiences and materials that are open-ended, or what 
Dewey referred to as "real, familiar, direct and straight forward materials", such as carpentry tools and dishware to dramatize real personal experiences (Fraser, 2000, p. 7). This use of real, interesting, and legitimate materials creates interest and motivation for learning.

The Reggio environment, also influenced by Piagetian theories, supports a children's exploration and offers a rich stimulating environment designed to initiate child-led inquiry and investigations (Fraser, 2000). Further, Piaget's theories continue to add to the principles of Reggio, particularly to the image of the child as a meaning-maker and constructor of knowledge. The view of the child as inquisitive, curious, active, and as a discoverer and generator of knowledge is demonstrated in the rich, varied, and challenging environments created for children (Fraser, 2000).

In Reggio environments, there is a delicate balance between children's free and active explorations and structure (Strong-Wilson \& Ellis, 2007). Space can provide structure and communicate the invitations presented to the child. In these structures of space, the educator may support children's interest and provide provocations to surprise, elicit, or initiate further inquiry. Provocations can take the form of enticing contents such as transparent materials; natural items, or loose parts, and serve to add life to the classroom (Strong-Wilson \& Ellis, 2007).

The design of the environment provides a window into the educational philosophies held and the values placed within it. Attention to small details and the use of intelligent and beautiful materials speak respectfully to children's capabilities and aesthetic awareness (Strong-Wilson \& Ellis, 2007). Aesthetics play an important role as the use of beauty, colour, natural light, mirrors, and reflection set the stage for pleasant learning experiences.

As many continue to be inspired by the work of Reggio in the early years, much attention is given to the environment as a third teacher in the indoor context, particularly within the Reggio literature. A limited range of literature addresses the outdoor learning environment in Reggio context and explores the outdoor learning environment, an environment rich with potential and full of possibilities.

\section{Nature-Based Education}

North American interest in nature-based education has resulted in extensive literature on the many facets of the topic. These include, but are not limited to, nature and play, benefits of connecting children to nature, and the developmental gains inherent in natural outdoor environments. Further, there is extensive literature describing the detrimental affects of 
excluding nature from the lives of children.

As the landscape of childhood has changed, connecting children to the natural world becomes more relevant and necessary in today's society. O'Brien (2009) reports concern over the decline of children's access and engagement in outdoor natural environments or green spaces, and what has been termed by Richard Louv (1995) as 'nature deficit disorder' within our society. Although not a medical diagnosis, it has gained attention as serious issue-affecting children today. Children today tend to lack contact with nature, due to increased safety concerns and to overly programmed activities. O’Brien \& Murray (2007) suggest that children today experience increased screen time, less physical free play, and more structured activities, resulting in less time outdoors.

Concurrently, there is increased awareness among educators to connect children to nature and natural spaces. This may be motivated by statistical evidence suggesting that children are spending less time in natural areas (Moore, 2014). Engaging in and with nature is a valid and important element of learning in the early years. Moore (2014) claims that connecting children to nature and facilitating learning in nature have become educational necessities. It is important to note that the value of natural spaces in education is not a new idea, as educational theorists such as Froebel, Dewey, Montessori, Steiner, Rousseau, and Malaguzzi have all emphasized that experiences in nature support children's development and wellbeing (Ernest, 2014).

Nimmo and Hallett's (2008) study of children's gardens revealed that nature and natural environments hold endless possibilities for learning that provoke children's innate curiosity and a desire to investigate. Nature offers children countless opportunities to explore, connect, and learn through multi- sensory experiences. The approach of nature play is to enhance freedom of expression, as children explore spaces creatively with materials and with others to shape, build, and construct new ideas in and with nature. Outdoor natural spaces are a recent trend and allow for the highest level of play in development and learning (Childcare Canada, n.d.). These spaces offer a magnitude of learning opportunities and challenges that support children's development in all domains. MacEachren (2013) contends that being outdoors provides distinct learning opportunities and benefits for diverse learners.

Gleave \& Cole- Hamilton's (2012) propose that there is a growing body of literature that suggests the numerous benefits of engaging in natural outdoor play, such as developmental gains in cognitive abilities, physical skills, and social skills. This contributes to children's developing 
sense of self and belonging to the nature world. Nature play supports the development of the whole child and touches upon all areas of development. Children engage in contact with living organisms, develop empathy, care, and cognitive skills with regards to environmental conditions with each passing season (Herrington \& Lesmeister, 2006; Moore, 2014). Swarbrick, Eastwood \& Tutton's (2004) study on Forest School suggests that experiences in the outdoors are rich opportunities for nurturing growth in all areas of development. According to Forest School Canada (2014), children benefit from improvements to health and to their overall development. These may include increased motor development, improvement in communications skills, selfesteem, and the promotion of risk-taking, improving concentration skills. Kenny (2009) confers that natural outdoor environments such as those found in forest schools provide children with numerous developmental and educational advantages.

Frost (1992), as cited in Fjortoft (2001), introduced the concept of natural playscapes including natural features such as boulders, terrains, and hills. He claimed that green spaces enrich children's play and offer a wide range of learning opportunities. Fjortoft's (2001) experimental study explored the benefits of natural environments on children's development. Results demonstrated that children who played in flexible, natural landscapes more frequently, appeared to have improved motor fitness, balance and coordination than their counterparts.

Another study, conducted by Waller (2007) in Wales, explored pedagogical considerations outdoors, and explored whether children benefited from regular contact in wild environments in contrast to typical playground equipment. The data revealed first, children's play in natural environments was stronger and involved, as children's play was creative and social. Second, educators reported more quality time, stronger interactions, and a better understanding of the children within the natural environment.

Extensive research outlines the benefits of nature to children's outcomes, health, and development (Gleave \& Cole-Hamilton, 2012). Furthermore, connecting children to nature supports children in creating a lasting connection and a sense of love and care for the environment, both now and in the future (Moore, 2014). This connection is crucial for this generation and generations to come. Moore (2014) suggests that children need to grow up in nature to understand it and develop a love and care for it. Children cannot care for, protect, or love what they have not experienced, and therefore it is essential to begin developing a connection to nature in the early years (Moore, 2014). Frumkin (2014) contends that children 
need opportunities to develop an emotional innate bond with nature; they need to see the beauty of nature and be fascinated by it.

Moore (2014) argues that educators play a crucial role in connecting children to nature and natural spaces in the early years. Educators must begin to explore and challenge their scope of practice to include play in and with nature. Frances Kuo (n.d.) as cited in Frumkin (2014) posits that two strategies need to be pursued in connecting children to nature: one is to bring children to nature through natural areas and green spaces, and the other is to bring nature to children through curriculum and natural outdoor environments. Learning through and in nature is an educational essential, and educators need to explore opportunities to attract children to local natural settings and reintegrate nature into children's lives and hearts (Frumkin, 2014). Waller (2007) proposes that children benefit from learning both in natural outdoor settings as well as in natural wild environments.

\section{Ecological Identity and Stewardship}

Sobel (1995) noted educator and author, recommends connecting classrooms to communities and opportunities to experience the local ecosystems that are present in every schoolyard, a practice commonly referred to as place-based education (as cited in Weise, 2012). Connecting children to nature involves looking beyond the schoolyard fence, so that children can experience, feel, see, and touch nature with their heart and soul. Sobel (1995) proposes that place-based education is the process of using the local community to teach different subjects across the curriculum. The emphasis is on hands-on, real world experiences that can help students create ties to their local communities. Sobel (1995) argues that the need for children to develop a connection with nature is significant to the early years, rather than educating them about environmental tragedies, which can create a sense of hopelessness or fear in young children.

Pelo (2008) an American educator and writer, agrees that in developing an ecological identity in their local places, children are encouraged to forming a relationship, love, and respect for their planet. She believes our work as educators is to give children a sense of place, in order to blend their identities with the place (Pelo, 2008). Pelo (2008) proposes that understanding place as part of our identity shapes and opens children to broader sensual experiences, as well as to an emotional and conscious connection to the earth. Through the use of local natural grounds, adjacent natural parks, green spaces, and forest, children's sense of home and connections to the 
local environment is strengthened. Pelo (2008) proposes walking the land requires frequent visits to the same places; children come to know them and experience them in all seasons creating lasting connections.

\section{Outdoor Natural Spaces}

There is a need to address quality outdoors learning environments that place nature at their core. Merewether (2015) proposes that outdoor environments should be thoughtful educational environments with vast opportunities provided to meet children's diverse needs. Herrington \& Lesmeister (2006) contend that outdoor learning areas must be flexible, manipulative, and must offer children the ability to modify and extend learning through combining areas and materials.

In designing these spaces, children's places and places for children are to be considered. Cadwell (2003) conceives that children's places are created by children, and involve the investment of deeply inventive energy. The creation of their own worlds becomes a source of meaning and belonging for the children (Cadwell, 2003). Moore (1996), as cited in Cadwell (2003), states that exploration of the natural environments intensifies friendship, and stimulates social interactions, independence, and autonomy. Through rich, meaningful, and deliberate environments, children can find place and belonging, and stronger interactions with others (Cadwell, 2003).

The range of spaces offered should accommodate children's different needs and interests (Herrington \& Lesmeister, 2006). Merewether's (2015) study included children's perspectives, and found that outdoor environments must provide spaces for social interactions as well as for intimacy, by featuring partially closed areas. Outdoor spaces must provide opportunities for dramatic play, by allowing the freedom to move in unencumbered ways. Large open spaces for dramatic play, using natural elements and loose parts, enhance the potential for imaginary play opportunities and enrich children's creativity and inspiration (Merewether, 2015).

Haas \& Ashman's (2014) study of outdoor environments found that playgrounds converted into natural spaces with a higher degree of naturalness offer rich possibilities in play and development. As educators explore the notion of connecting children to nature, the examination of natural spaces and outdoor nature environments is warranted. Natural play areas

can include adventure play, children's gardens, play zoo, forest kindergartens, as well as nature- 
based preschools, natural outdoor playgrounds, and parks (Moore, 2014, p. 21). These areas may include multi- purpose lawns, meadows, woodlands, landforms, forest, and aquatics that offer children a variety of multi-sensorial elements that excite or soothe while engaging the learner. Nature Schools and Forest School programs offer a wide range of possibility in providing naturebased curriculum and environments to children.

The form of nature-based early childhood institutions has existed for more than one hundred years in forest kindergarten and preschool nature schools. Nature Schools and Forest School programs are a relatively new concept in North America. The Forest School movement began in Scandinavia and has spread across the world, recently emerging in Canada (Forest School Canada, 2014). The first school in Canada opened in 2008, and subsequently several schools and nature programs have launched throughout Canada (Forest School Canada, 2014). The primary focus is connecting children to nature, and learning in and through engagement with nature. The defining features of Forest School include nature focus, extensive time, and regular, consistent engagement in nature and natural areas (Moore, 2014).

Forest School Canada (2014) notes that Forest Schools are run within a variety of urban, suburban, rural, and natural setting that include local forests, creeks, meadows, prairie, grasslands, mountains, shorelines, woodlands adjacent to or on school grounds, outdoor classrooms, natural playscapes built using natural and sustainable materials, and municipal, provincial, and national parks. Variants to the structure of Forest Schools can include full and part time programs, ranging from preschool and nursery to multiple grade levels and after school initiatives.

The Forest School and Nature School approach to learning encompasses a variety of progressive educational philosophies that are complimentary to those found in Reggio. These include a holistic, play-based curriculum model that builds on children's interests and capabilities within a socially constructed environment. Further, the curriculum capitalizes on children's innate motivation and curiosity while developing an understanding of and appreciation for the natural world (Forest School Canada, 2014; Slade, Lowery \& Bland, 2013). At Forest School, children have the freedom to explore, play, build, create, imagine, and use their senses to experience the outdoor environment and engage with one another. Sustainability is woven into the culture of the classroom, and nature becomes the third teacher (Forest School Canada, 2014). Loose and natural open-ended materials support children's inquiry. Forest School philosophy 
and pedagogical practices are deeply rooted in emergent, inquiry, and constructivist theories of learning, where the teacher's role is that of supporting and co-creating knowledge.

These principles align closely with those of Reggio, playing a complimentary role in the building of pedagogy. Further, these principles could also be applied to outdoor learning environments comprising of nature or nature-based settings. The Forest School approach to ecological literacy and nature-based education provides an excellent model, which warrants recognition by early learning settings in the adaptation of some key pedagogical practices. The Forest School movement can be seen as offering possibilities of practice, adding to educators' concepts of outdoor educational programs.

\section{Limited Studies Connecting Reggio to the Outdoors}

Despite extensive literature on the pedagogies and implementation of Reggio practice, and the growing literature on the significance of nature play, limited literature has drawn links between these pedagogical practices. Despite similarities and parallel belief systems, little research has attempted to link them. The few studies that have examined their compatibilities are discussed here. My study intends to contribute to this emerging body of literature.

Weigand (2011) contends that much attention has been given to the inspirational work of Reggio, and more specifically to the significance of indoor environment as a space for childinitiated curriculum. In her qualitative case study in Toronto, Weigand explored parallels between environmental critical place-based learning and a Reggio inspired emergent curriculum in the indoor and outdoor context. The study revealed the complimentary nature of these approaches as well as the possibilities, benefits, and challenges as expressed by educators.

A study by Maynard, Waters and Clement (2013) included eight early years teachers supported in exploring Reggio inspired projects in natural outdoor environments. The study sought to include Reggio-inspired pedagogy in the form of child- led investigations and interests supported by the facilitation of the teachers. First, the study found that the teachers practiced more child-initiated/ centred approaches, and suggested that this was in part related to the outdoor context. Secondly, teachers expressed difficulty in letting go, and seemed concerned with meeting curricular outcomes with the "real work" of the indoor classroom.

In an additional study, Maynard \& Waters (2007) examined the environment and drew on the forest school philosophy of the strong capable child, emergent curriculum, and partnerships of learning. Through interviews and observations, the study explored educators' pedagogical 
practice with regards to natural outdoor settings. The study revealed that the educators were more likely to "let go", appear laid back, and follow a child-initiated philosophy while outdoors. Maynard \& Waters (2007) proposed that the green environment and natural elements have a calming, restorative effect on children and adults, as adults are more inclined to support and guide children's play in natural outdoor settings. The study revealed that significant changes to teacher beliefs were required to make the shift towards viewing the importance of outdoor pedagogical practice.

In contrast, a study by Ernest (2014) used interviews to explore 46 Reggio-inspired educators' beliefs in the use and access to natural outdoor learning environments. Results indicated that educators found the use of nature and the outdoors to be effective learning environments. Although educators in this study viewed the outdoor environment as a significant place for inquiry, they also indicated a need to reduce barriers and improve access to these environments. Ernest (2014) suggested a need to focus not on changing educator's beliefs, but rather on reducing barriers to natural outdoor environments.

Nimmo and Hallett's (2008) study provided a discussion of the Reggio-inspired gardencentred school and child-care centre in New Hampshire. The program emphasized the importance of the garden as a place for free child- initiated play and opportunities for children to learn through their senses. Further, they stressed the significance of risk and flexible approaches through an ongoing process of caring for the garden. Additionally, Nimmo and Hallett (2008) proposed that the garden and green spaces promoted social, open-ended, imaginative and cognitive play.

\section{Summary}

This literature review attempted to locate studies about Reggio-inspired outdoor environments, natured-based outdoor sites, or connections between these two pedagogical approaches. In general, early childhood education has not explored the prospect of the Reggioinspired outdoor natural environment. The lack of existing studies suggests a need to address this gap in research, and explore the topic of Reggio-inspired outdoor learning environments in Ontario. Despite extensive literature in both Reggio-inspired educational practices, and the call to return children to nature, few studies have made connections that bridge together these two fundamental shifts in the early years.

Play in and with nature allows for spontaneous, self-initiated explorations and sensory 
learning. The government of Ontario's document, How Does Learning Happen? A Pedagogy For the Early Years makes reference to the significance of designing outdoor spaces to engage children's natural curiosity and provide meaningful sustained engagement (Ontario Ministry of Education, 2014). Further, it recommends daily encounters and opportunities to connect children to nature. However, there are no guidelines or suggestions as to how to make these connections. More information and discussion is needed in identifying the essential requisites for connecting children to natural outdoor environments as an effective part of curriculum and pedagogy for the early years.

This chapter sought to complete a comprehensive literature review of the principles of Reggio-inspired practice and the theories that support this pedagogy. The body of literature on the influence of Reggio pedagogy has direct impact on the changing landscape of early childhood education. The principles as reflected in Ontario's HDLH guide encourage educators to re-conceptualize practice through an examination of beliefs. This literature review discussed the imperative need to introduce nature back into childhood. Similar pedagogical principles can be found in the Reggio and the Forest School philosophy and pedagogy of nature-based education, both heavily situated in social constructivist theories. Few studies make the connections to these two pedagogical practices or explore the possibilities of one complimenting and building upon the other. This literature clearly outlines the lack of research in this area, missing the opportunity to bring the literature together and to further explore these pedagogical perspectives in Ontario. This review addresses the significance of the present study in exploring Reggio-inspired natural outdoor early learning environments in Ontario, and whether Reggio inspired practice can translate into natural outdoor learning environments.

The proceeding chapter will discuss the methodology for this study, and its suitability for the study's purpose. This section will address how the chosen methods addressed my research questions: how does Reggio-inspired practice translate in outdoor natural learning environments? Can photographs illustrate the potential for Reggio inspired pedagogy in Ontario nature-based outdoor environments? 


\section{Chapter Three: Methodology}

This chapter begins by exploring the methodology I employed to answer my research questions: how does Reggio-inspired practice translate in outdoor environments? The nature of my question warranted a qualitative methodology. Differing from quantitative research, I chose a qualitative research methodology that focuses on the meaning participants create in their social world (Nielson, 2011). Creswell (2014) defines "qualitative research as an approach for exploring and understanding the meaning individuals or groups ascribe to a social or human condition" (p. 4). Historically, qualitative research designs have been developed in the social sciences and humanities disciplines (Creswell, 2014). Qualitative research compliments the constructivist theoretical framework used within this study.

Methodologies provide a framework so that logical links exist throughout the entire research plan (Jackson, Drummond \& Camara, 2007). In designing a study, research questions attempt to answer the how and why of a particular process or phenomena (Trainor \& Graue, 2014). Creswell (2014) states: "The process of research involves the emerging of questions and procedures, data typically collected in the participants setting, data analysis inductively building from particulars to general themes and the researcher making interpretations of the meaning of the data" (p. 4).

Qualitative research methods can include participant or non-participant observation, focus groups, field notes, reflexive journals, structured or unstructured interviews or semistructured interviews, and the analysis of documents and materials (Nielson, 2011). This analysis may include the use of visual text such as photographs that represent aspects social life (Jackson et al, 2007). As my research employs photographs as a method of data collection, the following literature will examine the use of photography in the context of visual research methods. Further, a discussion considers the strengths and drawbacks of the use of visual research methods, as well as its compatibility with the focus of my research study.

The use of visual research methods has developed over the last several decades (Rose, 2013). Photos have a long history in social research, and visual-based research has also been described as visual anthropology and visual ethnography (Mason, 2005). This interest has spread across disciplines to include sociology, anthropology, psychology, and education (Buckingham, 2009). Rose (2013) defines visual research methods as methods that utilize various forms of visual material to generate evidence and explore research questions. Prosser (2007) describes 
visual research as "concerned with the production, organization and interpretation of imagery" (p.13). Visual research methods use visual materials in the production of data; these methods are varied in the type of visual material used and the procedures for data collection and analysis (Manson, 2005).

Visual research methods include the use of photographs, time-lines, diagrams, films, video and or photo diaries, collages, and drawings. These methods are diverse in both the forms of visual materials used and the procedures the materials are subjected to (Rose, 2013). Approaches to visual research methods differ in how the data is generated (Cope, 2014). Data may be generated by the researcher, created by participants, or involve pre-existing visual materials for analysis (Manson, 2005). Subsequently, the visual materials can be theorized, contextualized, and analyzed differently across research designs (Rose, 2013).

In today's society, images are predominant; they are readily available and help us construct knowledge regarding our lives and the environment around us (Rose, 2007). Rose (2013) contends that this growth in visual research is somehow related to the increasing significance of visual images in today's society. Rose (2007) proposes that images are a unique source of data that can be used as a transparent representation of participants' experiences. Many researchers in the social sciences agree that photographs are a unique source of evidence (Rose, 2007). Sears \& Cairns (2010) contend that photographs have strong documenting power and allow the viewer to gain first hand access to the subject of study.

Over the last several decades, visual research has played an important role in educational research (Prosser, 2007). Prosser (1998) contends that visual research "is an approach based on the commodity of the visual world. Images allow us to make statements which cannot be made by words" (p. 38). Prosser (2007) argues that visual research as seen as qualitative inquiry positions visuals as a form of observation, which is typically used as a major method in qualitative studies. Visuals offer observable and tactile information that leads to an understanding of the experiences of those studied. Rose (2007) suggests that photographs can be a transparent representation of participants' lives and experiences. Prosser \& Schwartz (1998) argue that the strength in photo data is the ability to produce images that are subtle and overlooked.

Rose (2013) contends that the strength of photo research is that it offers meaning of the visual and incorporates visual, aural, and textual representations of the environment, which can 
further create understanding and knowledge. Rose (2007) asserts that photos capture the textures and the feel of places, and carry many visual representations. The strength of photos is the potential to address details visually that would take pages to define. Photos can show the elusive qualities of a space, while offering a varied set of sensorial experiences (Rose, 2007).

"Photographs are never merely visual, but in fact conjure up synesthetic and kinesthetic effects. For the visual provokes other sensory responses. The textures and tactile, smell, atmosphere and sounds among other sensorial responses” (Edenson, 2005 as cited in Rose, 2007, p. 248.).

Becker (2003) as cited in Rose, (2013) suggests that photos offer a general statement of the specifics of people, places and events, while offering a lush and textured portrait of the participants' experiences. Images can be especially effective in describing the indescribable. Banks (2008), as cited in Rose (2013), contends that photos have the ability to offer the sensory and ambiance as part of the experience of environments. Pink (2006) advocates for visual research methods as they place significance on the richness and unique relation to the sensory in generated data.

Rose (2013) argues that visual research methods are highly effective in obtaining evidence that other qualitative methods, such as in interviews or surveys, cannot. She contends that visual research reveals the inner and often taken for granted works of the everyday (Rose 2013). In addition, photographs can become a tool to assist the researcher in exploring deeper aspects of behaviours. "In this way visual research methods are often used to uncover the explicit knowledge in everyday practice" (Rose, 2013. p. 28). Thus, visuals can act as a window to exploring such practice and allow researchers to reflect on fieldwork and their relation to the field (Rose, 2013). Prosser (2007) argues that visual-based methodologies can inform educational practices. In this, visual research methods gives importance to what is visually seen rather than what is measured, written, or spoken (Prosser, 2007). It allows the research to slow down in the act of seeking information, which makes this method effective for the analysis of data (Prosser, 2007).

Despite the strengths in using visual methods for research, it has been criticized on several grounds. For the last 100 years social research has adopted a scientific objective approach that has marginalized visual research methods, and as a result the academic community places more emphasis on words, with a limited role of images in research (Prosser, 1998). Pink (2006) calls for the end of hierarchies of image and words, and the need to move away from 
contesting the validity of images as valid methods of qualitative research. Prosser (1998) argues that visual research methods are often underrated and under-applied in research, as they are viewed as distractions from real research. Furthermore, he argues that a common dichotomy in the academic world is that photos are often viewed as an acceptable means to record data, but objectionable as a way of obtaining knowledge (Prosser, 1998). Manson (2005) contends that image-based research needs to be as recognized as other conventional methods (Manson, 2005). Pink (2006) convenes that visual research methods are a suitable alternative method for research, and that photographs are equally meaningful as other data.

Prosser \& Schwartz (1998) argue that image-based research is often discounted, as it may not offer an unbiased view. However, Pink (2006) argues that images should not be viewed as neutral means of documentation. She contends that images do not simply serve to record data, but also to create new knowledge that is socially constructed. Buckingham (2009) argues that most handbooks on visual research suggest that visual images are always constructed and not objective means for documenting reality.

Pauwels (2010) argues that visual research is an ill- defined methodology, despite its growing popularity and quality of re-inventing traditional methods. Pauwels (2010) states there appears to be a lack of agreed upon, unified methodological frameworks. He argues that visual research methods can lead to an over-emphasis of casual and natural variables and relationships. Therefore, Pauwels (2010) calls for a more methodological grounding through an integrated approach.

Prosser \& Schwartz, (1998) propose that a well-structured research plan is needed as justification for establishing the validity of data and inferences. The approach should include rationale, site and sample selection, researchers' role, data collection methods, management, analysis and trustworthiness. Rose (2007) considers there is a lack of clear methodological frameworks for the use of visual research methods in the social sciences. She suggests that, in order to counter this, a critical approach to interpreting data should follow certain criteria. Firstly, images are to be taken seriously, as legitimate data having validity on their own. Secondly, researchers must consider the socially specific context, in looking at and interpreting photos (Rose, 2007). She also argues that photo documentation is one way in which image-based research becomes a meaningful representation, through researchers' interpretations, and a valid form of research. Therefore, researchers' interpretations are offered as evidence to answer the 
research question. Rose (2007) attributes the strength in photo documentation to the careful, systematically conceptualized link between the photos taken and theory. To strengthen this approach, Suchar (1997) as cited in Rose, 2007) discusses the significance of shooting scripts and the use of questions to guide the photo shoot. These questions are used to elicit and support the reasoning for the photos that are taken. Prosser \& Swartz (1998) propose that the interpretation of any photo requires a theoretical framework, which provides logic for sorting and organizing data. It is the theory that makes sense of the photos, which in turn makes the data worth communicating (Prosser \& Schwartz, 1998). Lastly, some researchers believe that visuals are central to the dissemination of results, whereas others contend that visuals should be omitted in the final research paper (Manson, 2005).

Despite the criticisms of visual methods for research outlined above, its strengths provide sufficient reasons to use this method. This inquiry intends to use photos as the primary source of data collection, in order to offer rich representations of the chosen environments. The strengths of photographs highlighted in the literature, such as their carrying observable, sensorial, and affective qualities, are believed to add depth and richness to the understanding of data. Further, photographs can potentially make transparent the hidden and implicit practices within the environments. It is believed that visual research methods are the best approach in the construction of knowledge to provide evidence of the translation of Reggio-inspired practice into outdoor environments.

Consistent with this project's constructivist theoretical framework, photo data will be used to understand and make meaning of the participant sites. Images will be shared in photo documentation, providing a direct relationship with and first-hand access to the research methods, data, and analysis. The photo documentation is believed to be a complementary approach, as it aligns with the Reggio practice of pedagogical documentation. Having explained the choice of visual research methods, the following section offers a detailed overview of the methods of data collection employed within this study.

\section{Data Collection Methods}

The following section will provide a detailed systematic description of the visual research methods in the collection of data to assist in answering the research questions: how does Reggioinspired practice translate in natural outdoor learning environments? 


\section{Sample}

This study included 20 Reggio- inspired natural outdoor early learning sites in South-western Ontario. The sample of participant sites comprised a wide range of early learning settings, including a parent-co-op home forest school playgroup, childcares and centres for early learning; licensed and privately-owned, municipality-run Forest School programs, Full Day Kindergarten sites within various school boards, a non-for-profit public access playground, a travelling pop-up lab school, and several local college and university laboratory early learning sites. My intent was to have a representative sample of environments from various parts of Ontario. I believe this added to the richness and diversity of the data. Data was collected from all sites and data collection ended when saturation became evident.

\section{Recruitment Process}

The recruitment process primarily involved the use of social media and pre-existing connections to professional bodies. A flyer (see Appendix: A) was distributed through professional affiliations and social media networks such as Facebook and Twitter, as an open call for early learning centres to share their Reggio-inspired natural outdoor learning environments for this research study. A flyer distributed on a Facebook page associated with several professional on-line learning communities was used, including contacts made through previous school and professional affiliations such as the Bachelor of Child Development Facebook page, the Reggio Collaborative online group, and the York Region Nature Collaborative. There was no personal relationship with people on these media sites other than online discussions and posting related to Reggio- inspired practice and/or nature-based education. However, it should be noted that the College Lab School in which I work was included in this study, and that volunteer work at the York Region Nature Collaborative afforded me contacts through social media. This in turn did yield an impressive response to the recruitment call, exceeding my original goal of 10-15 sites. Interested participants were emailed an information and consent letter (see Appendix: B) with contact information for the faculty supervisor and myself.

A brief but detailed outline of the research in letterform was shared with centre supervisors and head educators (gatekeepers) in the recruitment process. The letter and consent form involved information regarding the study, a note on potential risks, as well as an explanation of the voluntary nature and right to withdrawal at any time. Participants had ample time to review the information letter and ask questions as needed. Site gatekeepers granted 
formal permission, and times for data collection were pre-arranged to ensure that limited or no persons were on-site or in jeopardy of being photographed within the area. Photo shoots were scheduled when the outdoor environments were free of children and adults, usually taking place in the early morning or during lunch and sleep time schedules. Site supervisors ensured the outdoor environments were clear of children and adults.

\section{Inclusion/ Exclusion Criteria}

The inclusion criteria allowed only for early learning outdoor sites that identified as being Reggio-inspired, or settings that subscribed or associated to some degree to the pedagogical beliefs of Reggio-inspired practice. Additional criteria included sites that considered some element of natural and/or nature-based planning in the outdoor learning environments. Exclusion criteria were limited to early learning settings that did not identify as Reggio-inspired.

\section{Ethical considerations}

Although a REB application was submitted to Ryerson Research and ethical board, it was deemed unnecessary to receive approval, as there are no human participants in this study. However, ethical considerations were embedded throughout the entire research process to ensure ethical practice and warrant participant comfort. These are inherent in any ethical research study, and were an important consideration.

\section{Confidentiality and anonymity}

Participants in this study (early learning centres and outdoor learning sites) had the choice of anonymity and confidentiality. All sites indicated permission to use site names if needed; however this was deemed unnecessary in the research report. Sites were organized through numeric codes for data analysis.

\section{Tools}

The data was collected using a Cannon Rebel T1i DSLR camera with lens technology. The camera allowed for the use of macro (large scale) and micro (small scale) imaging and provided fairly good quality and ease of use. In addition, a photo shoot script (see Appendix: C) was used to guide the photo shoots at each site. Field notes were taken to supplement the images taken and provide context and understanding of the setting. The field notes were not coded as themes in the data analysis. 


\section{Data Collection}

The data collection was pre-arranged with site supervisors to ensure the outdoor environments were free of human subjects. In most cases, the site visits occurred during midday when the children were indoors. On occasion, the photo shoots were arranged in the early morning or late afternoon at a convenient time for the settings. The photo shoot consisted of an extensive period of time spent on-site, between one to three hours with an average time of two hours per site. This was in part due to the size and number of environments at each location, as some had more than one outdoor learning environment. Of the 20 sites, several had additional outdoor learning environments, namely a toddler, preschool and/or other natural outdoor space used by the children. In this case, some settings opted to include their local natural community grounds or green space as a noteworthy space for the children's explorations. These were included in the data collection as the participants referred to them as additional learning environments frequently accessed by the children. In total of the 20 sites, 42 outdoor early learning environments were sampled. On occasion, some sites invited me to observe the program in the outdoor environments. Although not used as a method of data collection or analysis, it did provide some context for the photos taken. These two sites were Forest Schools, in which the environment is a non-traditional playground set-up, and the observations offered context on the use of space.

In addition, some educators accompanied me during photo shoots, pointing out specific areas of interest and meaning. Educators opted to walk me through and tour the sites along with the photo shoots. Many shared extensive stories of the children's interest and explorations within the area. It may be worth noting the enthusiasm displayed by the educators in telling the story of the children's experiences in these environments. These stories could not be included, as the initial research plan did not plan for interviews. This could be considered a limitation, and will be further discussed in subsequent chapters. These conversations were not used as a source of data, but in some cases used to supplement and provide context to images taken. Assisted tours were the choice of participant sites, and neither requested nor denied. The participants often initiated the tour, which possibly aided their level of comfort in participating in the research.

Touring each site, I approached the collection of visual images in two ways. First, intuitively, by capturing elements in the environment that resonated with me. Second, by collecting images using the photo shoot script. The photo shoot script helped to guide my 
collection of data by providing a loosely structured framework. This method doesn't discount the more intuitive photos, but rather supports the use of theory in guiding the process. With this in mind, some of my photography choices were driven by the principles of Reggio. Photos were taken of the whole environments, trying to capture the physical attributes and areas of the space and materials offered. Photos were intended to give a sense and feel of the space and of the prospect of being there. Adding to this, I focused on smaller details or elements that may of otherwise have been missed. This allowed me to approach the collection of data as a whole, as well as focus on the elements and characteristics that I encountered in the field.

In addition, I aimed to capture the sensorial and textural elements that words could not capture. Photo quality, aesthetics, and technique were further utilized to produce quality images and capture the essence and elements of the outdoor environments. Throughout, I was cognizant of taking both micro (small scale) and macro (large scale) images to capture the whole space and characteristics of the environments. Data collection was deemed complete when a saturation of data appeared, as no new data was emerging through the process. This resulted in nearly 5000 images collected, offering a comprehensive and diverse representation of the sites for analysis.

\section{Data Management}

Visual data was downloaded, sorted and stored based by site in a secure passwordprotected computer file to be analyzed only by the researcher. Digital images were destroyed from the digital camera once downloaded, and photos of poor quality and of a repetitive nature were deleted. Visual images were shared with participants if requested, to check for validity. Subsequently, each site received a copy of all images taken in a CD format. This, I believe, built trust between the participants and myself, and ensured that an accurate representation was produced. Participants were assured that they could omit photos or withdraw from the study at any time without penalty. Many participants opted to have a copy of the final research report to be sent upon completion. 


\section{Data Analysis}

Table 1.

Number of Environments Found in Sites.

\begin{tabular}{|c|c|c|c|c|c|c|}
\hline & \multicolumn{6}{|c|}{ Number of Environments Found in Sites } \\
\hline & & $\mathbf{1}$ & 2 & 3 & 4 & $\begin{array}{l}\text { Off Site/ } \\
\text { Nature }\end{array}$ \\
\hline \multirow{20}{*}{ Reggio Sites } & 1 & $\sqrt{ }$ & & & & $\checkmark$ \\
\hline & 2 & & $\checkmark$ & & & $\checkmark$ \\
\hline & 3 & & & & $\checkmark$ & $\sqrt{ }$ \\
\hline & 4 & & & & $\sqrt{ }$ & $\sqrt{ }$ \\
\hline & 5 & & $\checkmark$ & & & $\checkmark$ \\
\hline & 6 & $\sqrt{ }$ & & & & \\
\hline & 7 & $\sqrt{ }$ & & & & $\checkmark$ \\
\hline & 8 & & $\checkmark$ & & & $\sqrt{ }$ \\
\hline & 9 & $\checkmark$ & & & & \\
\hline & 10 & $\sqrt{ }$ & & & & \\
\hline & 11 & & $\checkmark$ & & & \\
\hline & 12 & $\checkmark$ & & & & \\
\hline & 13 & & $\checkmark$ & & & $\sqrt{ }$ \\
\hline & 14 & & $\sqrt{ }$ & & & \\
\hline & 15 & & $\sqrt{ }$ & & & \\
\hline & 16 & $\checkmark$ & & & & \\
\hline & 17 & $\sqrt{ }$ & & & & \\
\hline & 18 & $\sqrt{ }$ & & & & $\sqrt{ }$ \\
\hline & 19 & & & & & $\checkmark$ \\
\hline & 20 & & $\checkmark$ & & & \\
\hline
\end{tabular}

Note: Illustrates the number of environments per site and off site access to nature.

Table 1. Number of Environments Found in Sites

My initial process of analysis began by examining photos site-by-site on the computer. The large screen allowed to me to look at the data altogether, noticing physical qualities of the space, materials offered, and outdoor equipment. For organization purposes, sites were given a numeric label, and the number of environments at each site was noted (see Table 1). I began noticing smaller details or elements that resonated with me, such as multiple natural elements, the use of tree stumps and textures captured within the images. To begin the process of coding, visual images were printed and organized by site. Examining each site individually I worked inductively pulling out and coding particulars at each site. Creswell (2013) recommends working inductively, from particulars to more general themes and perspectives. These particulars consisted of small details in the environments such as aesthetics, a placement of art or reflective pieces, garden beds, children's seating arrangements, larger structures, and spaces or equipment 
that suggested gross motor play. Each photo was coded with notes and recorded for the purpose of identifying elements and characteristics. These included post-it notes with simple descriptors indicating, for example, the presence of bird feeders, flower garden, real tools, tree stumps, etc. (see Figure 1). All photos were coded site-by-site using post-it notes and hand written notes on the photo margins. As I examined the photos, I began to list repeating elements and characteristics to begin to see commonalities throughout the sites.

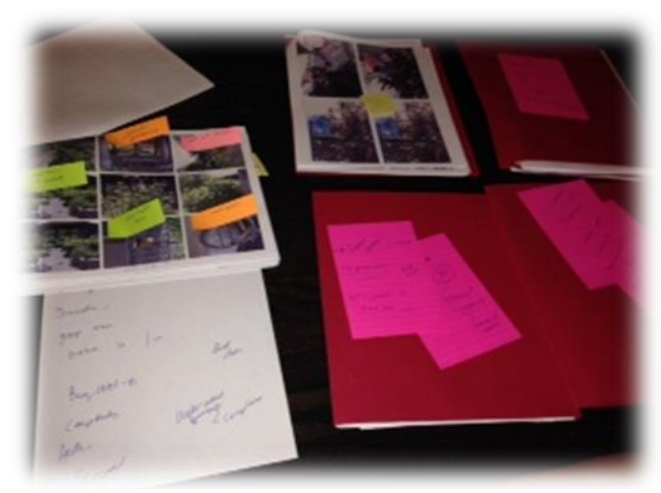

Figure 1. Data Analysis: This image shows some of the data analysis process.

Through this process, photos categories began to emerge, such as art experiences, motor challenges, private spaces, group dwellings, etc. The analysis continued by sorting these elements into larger units, slowly seeing how the photos and the elements fit into another category. Some of this categorization included natural aspects, such as the use of loose parts, art, music, and other notable categories; demonstrating the process of abstraction. Sears \& Cairns (2010) propose that abstraction of data allows the analysis to move from microscopic to macroscopic, providing a grand concept in the end. Creswell (2013) describes this form of coding as deductive, by gathering evidence to support the themes generated. Using deductive thinking, I begun to build categories by constantly checking them against the data and the list of other emerging categories. This employed complex reasoning skills, especially in the process of deciding whether or not certain images fall into a particular theme (Creswell, 2013). This process was repeated several times, as each photo was analyzed for its fit with prospective emerging themes.

I had begun to see emerging connections between sites, such as the use of loose parts or natural materials and provocations. Upon seeing these connections, I had begun to tally their frequency at each site and then the consistency across sites (see Tables 2, 3, 4 and 5). Through 
this process, discrete categories begun to fit into broader themes. For example, I begun to see challenging equipment, multiple learning areas, and the use of nature emerge with some consistency among sites. I also noted other elements that were not as predominant, such as books in the environments, or small creations created by children and used for play. As I examined the elements, characteristics, as well as the physical and sensorial aspects of the images in combination with emerging categories, I noted there were some commonalties. This was observed across sites, and included elements such as outdoor aesthetics, learning areas, and natural playscapes. As these became more explicit I had begun to draw connections with the theory that guided my photo shoot.

The following tables provide the criteria for how the images were analyzed and measured against the theories and principles of Reggio. These criteria were based on the defining characteristics of the Reggio principles outlined in the literature review. These began to provide a means to identify the translation of Reggio principles into each site. Prosser \& Swartz (1998) propose that the interpretation of any photo requires a theoretical framework, and provides logic for sorting and organizing data. 
Table 2.

Evidence for the Environment as the Third Teacher

\begin{tabular}{|c|c|c|c|c|c|}
\hline \multirow{21}{*}{$\begin{array}{c}\text { Reggio } \\
\text { Sites }\end{array}$} & & Aesthetics & $\begin{array}{l}\text { Spaces- } \\
\text { social/private }\end{array}$ & $\begin{array}{l}\text { Presentations } \\
\text { of Materials }\end{array}$ & $\begin{array}{l}\text { Connections } \\
\text { to Nature }\end{array}$ \\
\hline & 1 & $\checkmark$ & & $\checkmark$ & $\checkmark$ \\
\hline & 2 & $\checkmark$ & $\checkmark$ & & $\checkmark$ \\
\hline & 3 & $\checkmark$ & $\checkmark$ & $\checkmark$ & $\checkmark$ \\
\hline & 4 & & $\checkmark$ & $\checkmark$ & $\checkmark$ \\
\hline & 5 & $\checkmark$ & $\checkmark$ & $\checkmark$ & $\checkmark$ \\
\hline & 6 & $\checkmark$ & $\checkmark$ & $\checkmark$ & $\checkmark$ \\
\hline & 7 & $\checkmark$ & $\checkmark$ & & $\checkmark$ \\
\hline & 8 & $\checkmark$ & $\checkmark$ & $\checkmark$ & $\checkmark$ \\
\hline & 9 & & $\checkmark$ & $\checkmark$ & $\checkmark$ \\
\hline & 10 & & $\checkmark$ & $\checkmark$ & $\checkmark$ \\
\hline & 11 & $\checkmark$ & $\checkmark$ & $\checkmark$ & $\checkmark$ \\
\hline & 12 & $\checkmark$ & $\checkmark$ & & $\checkmark$ \\
\hline & 13 & $\checkmark$ & $\checkmark$ & $\checkmark$ & $\checkmark$ \\
\hline & 14 & $\checkmark$ & $\checkmark$ & $\checkmark$ & $\checkmark$ \\
\hline & 15 & $\checkmark$ & $\checkmark$ & $\checkmark$ & $\checkmark$ \\
\hline & 16 & $\checkmark$ & $\checkmark$ & $\checkmark$ & $\checkmark$ \\
\hline & 17 & $\checkmark$ & $\checkmark$ & $\checkmark$ & $\checkmark$ \\
\hline & 18 & $\checkmark$ & $\checkmark$ & $\checkmark$ & $\checkmark$ \\
\hline & 19 & & $\checkmark$ & & $\checkmark$ \\
\hline & 20 & $\checkmark$ & $\checkmark$ & & $\checkmark$ \\
\hline
\end{tabular}

Note: Illustrates the frequency of the characteristics that provide evidence of the

Reggio principle of the environment as the third teacher.

Table 2. Evidence for the Environment as the Third Teacher 
Table 3.

Evidence of the Hundred Languages of Children

Characteristics Providing Evidence of the Hundred Languages of Children

\begin{tabular}{|c|c|c|c|c|c|c|c|c|c|}
\hline & & Art & Sensory & Dramatic & Motor & Music & Building & $\begin{array}{l}\text { Loose } \\
\text { Parts }\end{array}$ & Literacy \\
\hline \multirow{20}{*}{$\begin{array}{c}\text { Reggio } \\
\text { Sites }\end{array}$} & 1 & $\checkmark$ & $\sqrt{ }$ & & $\sqrt{ }$ & & $\checkmark$ & $\checkmark$ & \\
\hline & 2 & $\sqrt{ }$ & $\sqrt{ }$ & $\checkmark$ & $\checkmark$ & & & $\checkmark$ & \\
\hline & 3 & $\checkmark$ & $\checkmark$ & $\sqrt{ }$ & $\checkmark$ & $\checkmark$ & & $\checkmark$ & \\
\hline & 4 & $\checkmark$ & $\checkmark$ & $\checkmark$ & $\checkmark$ & $\checkmark$ & $\sqrt{ }$ & $\checkmark$ & \\
\hline & 5 & $\sqrt{ }$ & $\sqrt{ }$ & $\sqrt{ }$ & $\sqrt{ }$ & $\sqrt{ }$ & $\sqrt{ }$ & $\sqrt{ }$ & $\checkmark$ \\
\hline & 6 & $\checkmark$ & $\sqrt{ }$ & $\sqrt{ }$ & $\checkmark$ & & $\checkmark$ & $\checkmark$ & \\
\hline & 7 & & $\checkmark$ & $\checkmark$ & $\checkmark$ & & & $\checkmark$ & $\checkmark$ \\
\hline & 8 & $\checkmark$ & $\checkmark$ & $\checkmark$ & $\checkmark$ & $\checkmark$ & & $\checkmark$ & \\
\hline & 9 & $\sqrt{ }$ & $\sqrt{ }$ & $\sqrt{ }$ & $\checkmark$ & $\sqrt{ }$ & $\checkmark$ & $\sqrt{ }$ & $\checkmark$ \\
\hline & 10 & $\checkmark$ & $\checkmark$ & $\checkmark$ & $\checkmark$ & & $\checkmark$ & $\checkmark$ & $\checkmark$ \\
\hline & 11 & $\checkmark$ & $\checkmark$ & $\checkmark$ & $\checkmark$ & $\checkmark$ & $\checkmark$ & $\checkmark$ & \\
\hline & 12 & $\checkmark$ & $\checkmark$ & $\checkmark$ & $\checkmark$ & $\checkmark$ & & $\checkmark$ & \\
\hline & 13 & $\checkmark$ & $\checkmark$ & $\checkmark$ & $\checkmark$ & $\sqrt{ }$ & & $\checkmark$ & $\checkmark$ \\
\hline & 14 & $\checkmark$ & $\checkmark$ & $\checkmark$ & $\checkmark$ & $\checkmark$ & $\checkmark$ & $\checkmark$ & \\
\hline & 15 & $\checkmark$ & $\sqrt{ }$ & $\sqrt{ }$ & $\checkmark$ & & & $\sqrt{ }$ & \\
\hline & 16 & $\checkmark$ & & $\sqrt{ }$ & $\checkmark$ & $\checkmark$ & $\checkmark$ & $\sqrt{ }$ & \\
\hline & 17 & $\sqrt{ }$ & $\checkmark$ & $\checkmark$ & $\checkmark$ & & & $\sqrt{ }$ & \\
\hline & 18 & $\checkmark$ & $\checkmark$ & $\sqrt{ }$ & $\checkmark$ & $\checkmark$ & & $\checkmark$ & \\
\hline & 19 & & $\checkmark$ & & $\checkmark$ & & & $\checkmark$ & \\
\hline & 20 & $\checkmark$ & $\checkmark$ & $\checkmark$ & $\checkmark$ & $\checkmark$ & & & \\
\hline
\end{tabular}

Note: Illustrates the frequency of the characteristics that provide evidence of the Reggio principle of the hundred languages of children.

Table 3. Evidence of the Hundred Languages of Children 
Table 4.

Evidence of the Image of the Child

Characteristics Providing Evidence of the Image of the Child

\begin{tabular}{|c|c|c|c|c|c|}
\hline \multirow{21}{*}{$\begin{array}{l}\text { Reggio } \\
\text { Sites }\end{array}$} & & $\begin{array}{l}\text { Challenging } \\
\text { Environments } \\
\text { Risk }\end{array}$ & $\begin{array}{l}\text { Choices } \\
\text { Autonomy }\end{array}$ & $\begin{array}{l}\text { Real } \\
\text { materials } \\
\text { Competency }\end{array}$ & $\begin{array}{l}\text { Contributing } \\
\text { Member of } \\
\text { Class }\end{array}$ \\
\hline & 1 & $\checkmark$ & $\checkmark$ & $\sqrt{ }$ & \\
\hline & 2 & & $\checkmark$ & & $\checkmark$ \\
\hline & 3 & $\checkmark$ & $\checkmark$ & & $\checkmark$ \\
\hline & 4 & $\checkmark$ & $\checkmark$ & $\checkmark$ & $\checkmark$ \\
\hline & 5 & $\checkmark$ & $\checkmark$ & $\checkmark$ & $\checkmark$ \\
\hline & 6 & $\checkmark$ & $\checkmark$ & $\checkmark$ & $\checkmark$ \\
\hline & 7 & $\checkmark$ & & $\checkmark$ & $\checkmark$ \\
\hline & 8 & $\checkmark$ & $\checkmark$ & $\checkmark$ & $\checkmark$ \\
\hline & 9 & $\checkmark$ & $\checkmark$ & $\checkmark$ & $\checkmark$ \\
\hline & 10 & $\checkmark$ & $\checkmark$ & $\checkmark$ & $\checkmark$ \\
\hline & 11 & $\checkmark$ & $\checkmark$ & $\checkmark$ & $\checkmark$ \\
\hline & 12 & & $\checkmark$ & $\checkmark$ & $\checkmark$ \\
\hline & 13 & $\checkmark$ & $\checkmark$ & $\checkmark$ & $\checkmark$ \\
\hline & 14 & $\checkmark$ & $\checkmark$ & $\checkmark$ & $\checkmark$ \\
\hline & 15 & $\checkmark$ & $\checkmark$ & $\checkmark$ & \\
\hline & 16 & & $\checkmark$ & $\checkmark$ & \\
\hline & 17 & $\checkmark$ & $\checkmark$ & & $\checkmark$ \\
\hline & 18 & & $\checkmark$ & $\checkmark$ & $\checkmark$ \\
\hline & 19 & $\checkmark$ & & & \\
\hline & 20 & $\checkmark$ & $\checkmark$ & & $\checkmark$ \\
\hline
\end{tabular}

Note: Illustrates the frequency of the characteristics that provide evidence of the Reggio principle of the image of the child.

Table 4. Evidence of the Image of the Child 
Table 5.

Evidence of Nature as the Third and Infinite Teacher

\begin{tabular}{|c|c|c|c|}
\hline \multirow{21}{*}{$\begin{array}{c}\text { Reggio } \\
\text { Sites }\end{array}$} & $\begin{array}{l}\text { Nature in } \\
\text { Environment }\end{array}$ & $\begin{array}{l}\text { Nature to } \\
\text { enhance } \\
\text { curriculum }\end{array}$ & $\begin{array}{l}\text { Access to nature } \\
\text { through green } \\
\text { spaces }\end{array}$ \\
\hline & $\sqrt{ }$ & $\checkmark$ & $\checkmark$ \\
\hline & $\checkmark$ & $\checkmark$ & $\checkmark$ \\
\hline & $\checkmark$ & $\checkmark$ & $\checkmark$ \\
\hline & $\checkmark$ & $\checkmark$ & $\checkmark$ \\
\hline & $\checkmark$ & $\checkmark$ & $\checkmark$ \\
\hline & $\checkmark$ & $\checkmark$ & \\
\hline & $\sqrt{ }$ & $\checkmark$ & $\checkmark$ \\
\hline & $\sqrt{ }$ & $\checkmark$ & $\checkmark$ \\
\hline & $\sqrt{ }$ & $\checkmark$ & \\
\hline & $\checkmark$ & $\checkmark$ & \\
\hline & $\sqrt{ }$ & $\checkmark$ & \\
\hline & $\checkmark$ & $\checkmark$ & \\
\hline & $\checkmark$ & $\checkmark$ & $\checkmark$ \\
\hline & $\checkmark$ & $\checkmark$ & \\
\hline & $\sqrt{ }$ & $\checkmark$ & \\
\hline & $\checkmark$ & $\checkmark$ & \\
\hline & $\checkmark$ & $\checkmark$ & \\
\hline & $\sqrt{ }$ & $\checkmark$ & $\checkmark$ \\
\hline & $\sqrt{ }$ & $\checkmark$ & $\sqrt{ }$ \\
\hline & $\checkmark$ & $\checkmark$ & \\
\hline
\end{tabular}

Note: Illustrates the frequency of the characteristics that provide evidence

of the found principle of nature as the third and infinite teacher.

\section{Table 5. Evidence of Nature as the Third and Infinite Teacher}

Essentially, I begun to focus on and interpret what the images implied, represented, and illustrated to the viewer through the particulars, space, and environment created at the sites. Here, I began to assess how the categories and developing themes appeared to connect to the theories of Reggio. Reggio principles of the environment as a third teacher, the hundred languages of children and image of the child were particularly represented in the visual data collected. Images were then analyzed on how they illustrated the given Reggio principle. This was repeated for all significant categories generated at each site, assessing whether the images potentially fit into any Reggio principles.

In order to answer my research question of how the principles of Reggio translate into natural outdoor environments, further analysis was needed. This involved constructing an understanding of the intention behind the materials and spaces provided in the environments. As the photographs were examined, connections to the principles and theoretical underpinning of 
Reggio were employed. Data was analyzed considering the following questions: what does the environment communicate about the image of the child? Does the outdoor learning environment communicate a respect for the learner and the process of learning? How is the outdoor environment portrayed as a significant component of the classroom and learning? This analysis was a thoughtful, strategic, and methodical process, sorting and analyzing data into themes. The use of multiple levels of data analysis, ranging from narrow to broader themes, allowed for the validity and accuracy of results, while measuring data against emerging themes augments complex data analysis (Creswell, 2013).

Finally, an additional category was noted outside the principles of Reggio, and could not be ignored. All of the sites incorporated nature and natural materials into the environment and curriculum. These were initially coded as children's gardens, flowers, herbs, bug provocations, etc. and formed a vast category. Images of nature in the physical environment and their significant presence were further noted and coded. Furthermore, half the sites reported the use of additional outdoor learning environments frequently utilized by the children. These included green spaces, local forests, fields, and water access areas such as creeks, lakes and beaches. This formed an additional category that was observed at most sites, the significant presence of nature and nature-based education practices.

\section{Validity}

The validity, reliability, and trustworthiness of data analysis was upheld through the process of analysis. The process of coding was lengthy and thorough, as each site photos was examined, interpreted, and analyzed against the principles of Reggio. This added to the validity of the themes chosen. This process was repeated, checking for accuracy and evidence found in the photos. This process sought to validate and strengthen the data and was a form of triangulation. Employing multiple levels of data analysis, from narrow to broader categories, allowed for validity and accuracy. In addition, the tallying of specific codes and their frequency across sites further strengthened the reliability of data. Validity was strengthened by what Creswell (2013) defines as member checking. In the end, the following themes were generated, based upon Reggio principles: the image of the child, the environment as the third teacher, the ateliers- hundred languages of children, and nature as the third and infinite teacher.

The next stage in the process of data analysis involved sorting the images for photo documentation. Categorized images were carefully examined to choose images that best depicted 
the aforementioned principles and that could provide evidence of the translation of Reggioinspired practice in the outdoor early learning environments. It was deliberately decided to include the images within the summary of results rather in the appendices, as they are relevant and add depth to the results. Further, this addresses the strength of visual research methods and how they were well suited for my research question. Lastly, photo documentation appeared to parallel the process of pedagogical documentation in Reggio, and therefore illustrates the compatibility of these methods with the topic of the study. The use of photo documentation also answered my second research question of whether photos can depict the principles of Reggio in natural outdoor Ontario early learning setting.

In order to minimize the number of photos shared within the report, a careful selection of photos that best captured the translation of the principles were undertaken. Particulars in photos, such as beauty and aesthetic considerations, were chosen to illustrate the translation of the themes generated, and to provide the reader with visuals that may not be accurately expressed in text. This was purposeful and in alignment with the principle of Reggio pedagogy of how beauty, design, and aesthetics add to the representation of ideas and materials. These considerations are built into the process of pedagogical documentation.

The following chapter discusses the results yielded from the in-depth analysis and interpretation of the data, consisting of images taken in natural Reggio inspired outdoor learning environments in Ontario. As this study employs the use of visual research methods, photo data and analysis was shared in photo documentation. This, I believed, will add to the translation of the principles of Reggio and provide the reader with visual aspects of the environments to fully capture the elements and characteristics of the outdoor environments. Additionally, photo documentation aligns with the Reggio principle of pedagogical documentation and was well suited for this research study.

Images capture what words may not express, allowing readers to fully appreciate all the aesthetic and sensorial elements within. As a result, the use of photo representation provided strength as the chosen methodology. These were used to support the documentation and provide evidence of the translation of principles of Reggio in outdoor natural early learning environments. Although the themes here are represented individually, it is important to note that they can merge, complement, and build upon one another, as do the principles and pedagogy of Reggio. For the purpose of sharing the data, it is categorized within the following three themes: 
the image of the child, the environment as the third teacher, and the hundred languages of children. Further, an additional theme emerged as a result of the analysis: evidence of naturebased approaches and practices within the Reggio inspired outdoor environments. As the themes listed relate to the principles of Reggio, they will be discussed as principles going forward. 


\section{Chapter 4: Findings}

The findings of this study demonstrated that the principles of Reggio can be translated into outdoor natural playgrounds. These principles, as outlined in the literature review include: image of the child as competent, environment as a third teacher, and the hundred languages of children. Photo documentation effectively captured various elements and characteristics of the Reggio-inspired natural outdoor environments, and therefore answered my second research question.

Of the 20 outdoor nature based environment sites used in the collection of data, all sites presented evidence of translation of the principles listed in Table 6. However, some sites demonstrated stronger or multiple elements and characteristics of principles compared to other sites. Visual research methods showed stronger translation of two principles: the environment as the third teacher and the hundred languages of children. Photographs were able to effectively capture elements and physical characteristics of the principles through thoughtful, intentional choices in these environments. The principle of image of the child as competent, although prevalent in the environment, required further interpretation as this principle is less tangible that the preceding ones. Table 6 indicates the codes used in the interpretation and analysis of photographs. These codes supported the indication of a Reggio principle. 
Table 6.

Connecting Reggio Principles to Codes.

\begin{tabular}{|l|l|}
\hline \multicolumn{1}{|c|}{ Reggio Principle } & Evidence Included and Demonstrated \\
\hline $\begin{array}{l}\text { The environment as the third teacher: use of } \\
\text { engaging spaces and materials. }\end{array}$ & $\begin{array}{l}\text { Child -initiated choices, provocations, space's } \\
\text { beauty, aesthetics, connections to nature }\end{array}$ \\
\hline $\begin{array}{l}\text { The hundred languages of children through the use } \\
\text { of ateliers and learning areas. }\end{array}$ & $\begin{array}{l}\text { Meeting children's individual modes of expression, } \\
\text { multi-modes of learning through learning labs and } \\
\text { mini ateliers. }\end{array}$ \\
\hline $\begin{array}{l}\text { The image of the child: as strong, capable and } \\
\text { inquisitive. A creator of knowledge and contributing } \\
\text { member of class }\end{array}$ & $\begin{array}{l}\text { Risk, challenging environments, choice, } \\
\text { development of autonomy and contributing member } \\
\text { of class, items/materials to demonstrate proficiency }\end{array}$ \\
\hline Nature-based approaches & $\begin{array}{l}\text { Emerged through analysis: nature in environments } \\
\text { as well as access to natural spaces. }\end{array}$ \\
\hline
\end{tabular}

Table 6. Connecting Reggio Principles to Codes

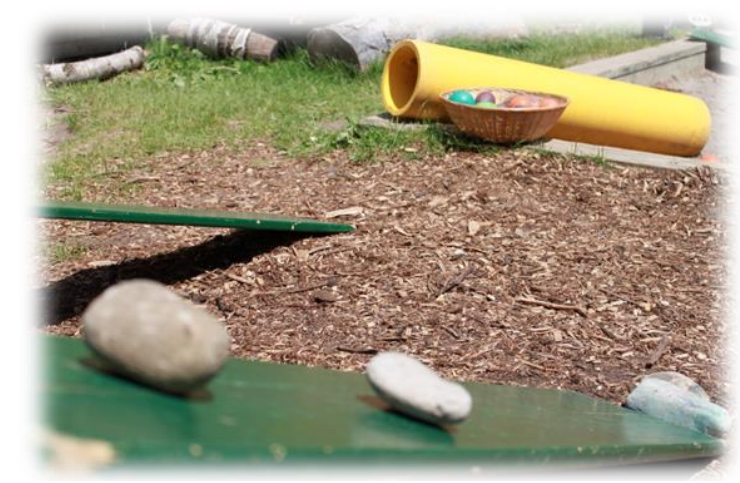

Figure 2. Provocations: To illicit the

testing of inclines.

In the design of the Reggio environment, educators create opportunities for exploration through provocations and various set-ups throughout the learning environment. This can be an indication and reflection of beliefs in children's natural inborn curiosity and value placed in the process of learning. "The main task is to create situations within, which creative processes can be experimented with, grow and evolve" (Gandini, 2012, p. 311.). Figure 2 demonstrates the use of provocations set out in the environment to illicit the testing of inclines using various materials. Materials set out in the Reggio environment are placed with purpose and intention. Each material, learning lab, and provocation is an invitation to learning, facilitating a process the child 
discovers and creates. This view helped inform and shape the interpretation of the data and to assess transferability of principles in the outdoor environment.

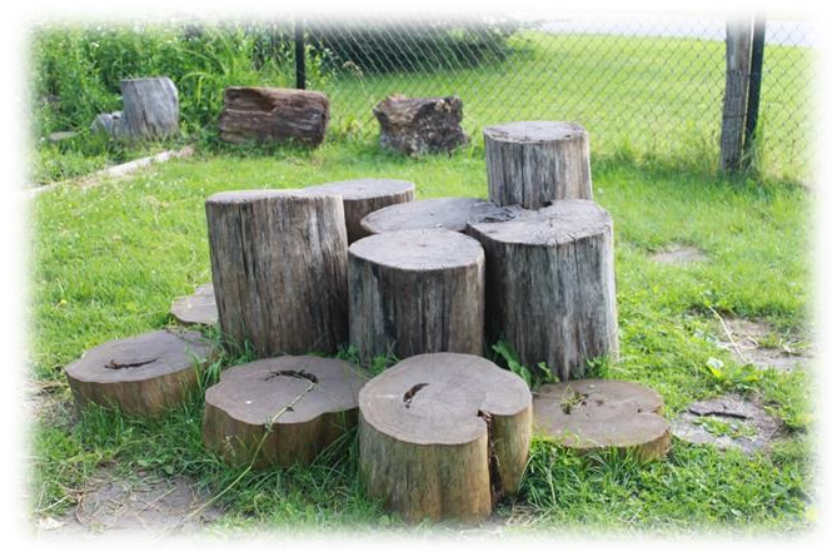

Figure 3. Climbing Logs: Cluster of logs constructed to represent the image of the child as capable and competent.

Additionally, in Reggio pedagogy, materials and space are considered an expression and communication of views. The image of the child from a Reggio perspective, for example, holds the construction of a belief that children are capable, strong and full of potential. Materials placed in the Reggio environment should communicate this. For example, in analyzing the data from a developmental perspective, the placement of the tree stumps (see Figure 3) may be viewed as an opportunity to develop motor skills. However, a Reggio educator may place the tree stumps for what they can potentially communicate. It could be suggested that the tree stumps communicate that the educator holds the belief that children are strong, capable and competent. As this principle reflects a belief, it is less tangible and requires analysis and interpretation. Through this premise, I analyzed the data to consider how the space, materials, and opportunities offered can potentially communicate educator's beliefs and values. At the same time, some principles such as the environment as a third teacher or the hundred languages of children could be interpreted due to the physical elements in design and space. For example, the uses of aesthetics in the environment or multi-sensorial gardens all communicate the aesthetic presence and consideration in the space as offered by the educator. 


\section{Environment as the Third Teacher}

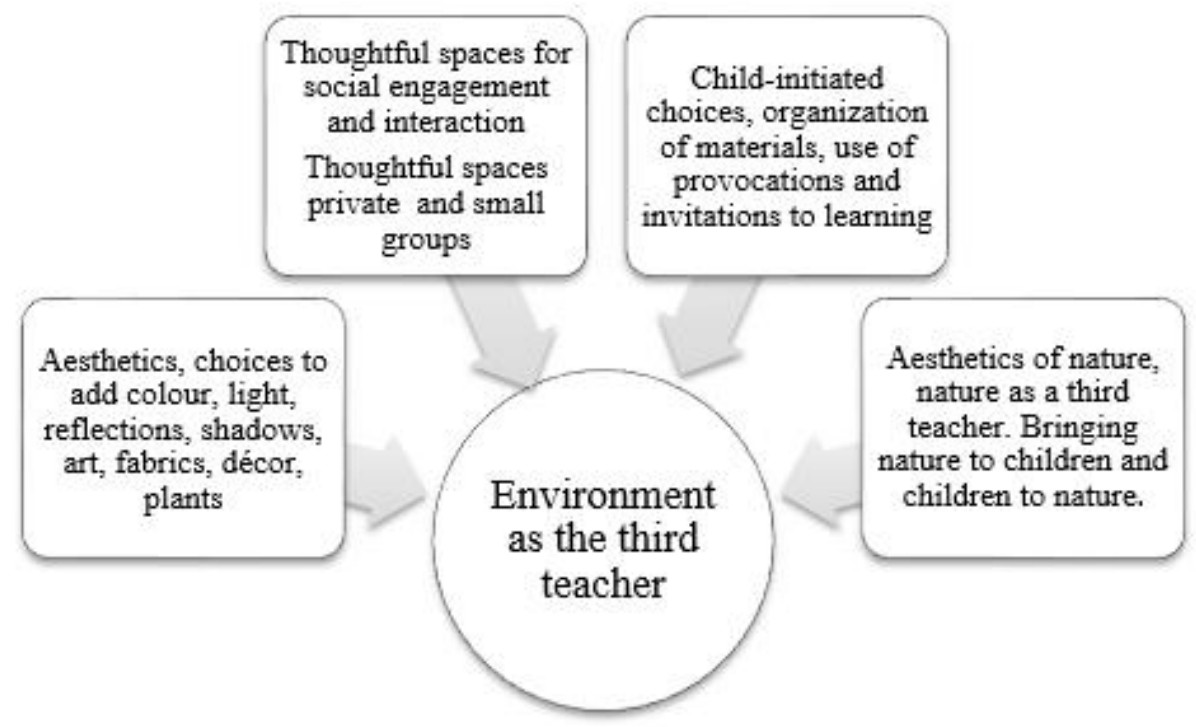

Figure 4. Evidence of the environment as the third teacher: Observed

elements that were considered into the theme.

In Reggio pedagogy, the educator, the child, and the environment are all considered to be teachers. Therefore, in Reggio the environment is often referred to as the third teacher. The principle of the environment as the third teacher was a significant theme derived from the data. Across all sites, there was an increased importance placed on this principle, one that visual research methods easily captured. All sites appeared to treat the environment as an essential element to learning. The same considerations applied to the indoor environment were equally visible outdoors. Care, consideration, and thoughtful planning emerged from the images collected. Each site drew unique and individual attention to design elements, considering the use of spaces, materials, child-initiated choices, provocations, beauty, and aesthetic elements. To expand, the above considerations were purposeful and made explicit by the educators' choices with both naturally occurring elements and ones chosen to add aesthetic value.

The Reggio indoor environment is a significant place of inquiry, learning, and social interactions. These environments embody design elements to emphasize interaction; childinitiated choices to lead to investigations, as well as invitations to learning provided by educators. These elements and characteristics were evident in the outdoor learning environments that appeared to entail the same thoughtful consideration to design. Spaces in the environment communicated purposeful areas to provide social and intimate engagement for the children. 
Areas in the outdoor environment were clearly defined to encourage a variety of play, both provided by the educator, and for children to exercise choice and autonomy. This was demonstrated through the use of learning labs, child choice in materials, and a purposefully planned curriculum offered as invitations to learning and provocations. The environments in many ways communicated equal respect to the learner and to the process of learning, and offered significant choice beyond the typical gross motor experiences found outdoors.

In addition, the data revealed a significant importance in adding aesthetic value to the environments through the use of light, colour, shadows, textures, sound, and scent. These appeared to be very deliberate, and made explicit through the aesthetic value of space and as contributing elements to children's sensorial development. In Reggio environments, children's natural inclination to learn through and with their aesthetic sense is honored and incorporated in many aspects of the program and environment. Children's attention to the beauty of the space and aesthetic considerations is of great importance to the indoor Reggio environment, and this attribute was demonstrated throughout all outdoor early learning settings in some capacity. There was an increased presence of softness, art, artifacts, fabrics, and garden décor that created aesthetic value to the environment not typical of most outdoor early learning environments. The images captured provided evidence of the translation of the principle of the third teacher and are shared through the following photo documentation.

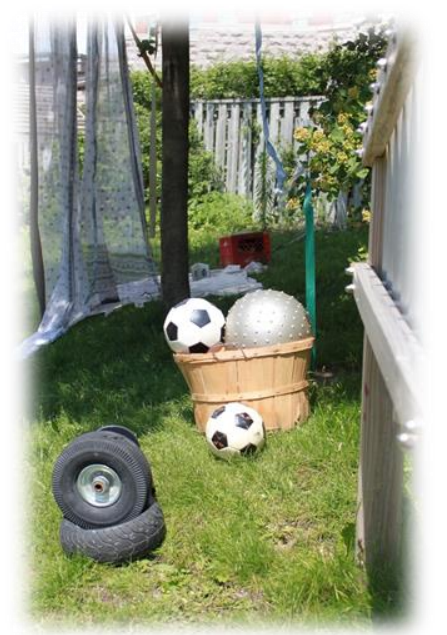

Figure 5. Evidence of choice: A variety of options for children to use.

Figure 5 depicts child-initiated choices seen with the variety of experiences offered. This addresses the Reggio principle of the environment as a third teacher, as the environment is 
designed to support children in exercising choice of materials and investigations. This was observed in most sites as additional experiences other than typical gross motor options were offered. Further, children were provided choices within the environments through open shelves, displays of materials in baskets and crates, and in carefully designed provocations that promoted choice.

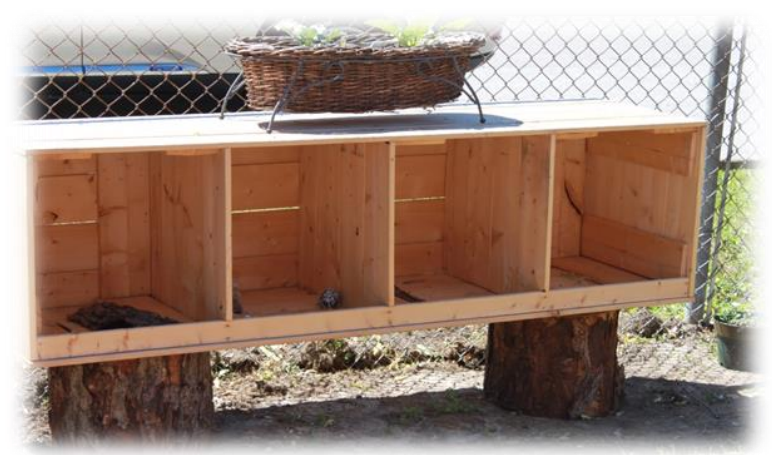

Figure 6. Aesthetic considerations: Materials are displayed with aesthetics in mind.

Careful consideration and the display of materials in aesthetically pleasing and inviting ways embody this principle of Reggio. Here, the environment as the third teacher communicates respect to the learner through the organization and presentation of materials. Most centres participating provided attention to the storage of materials in aesthetically pleasing ways (see Figure 6).

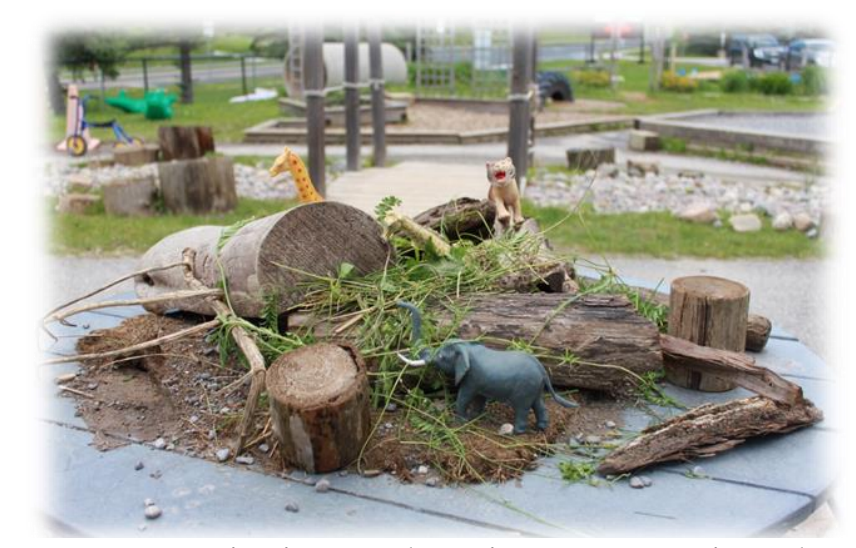

Figure 7. Invitations to learning: Provocation placed

to invite children to learn through play.

Several of the participating sites provided invitations to learning through thoughtful setup of materials (see Figure 7). A carefully planned table invites children to explore imaginative play 
through the combination of natural items and toy animals. This display represents the principle of the environment as a third teacher, as significance is placed on creating attractive invitations to play not typically seen in outdoor learning environments.

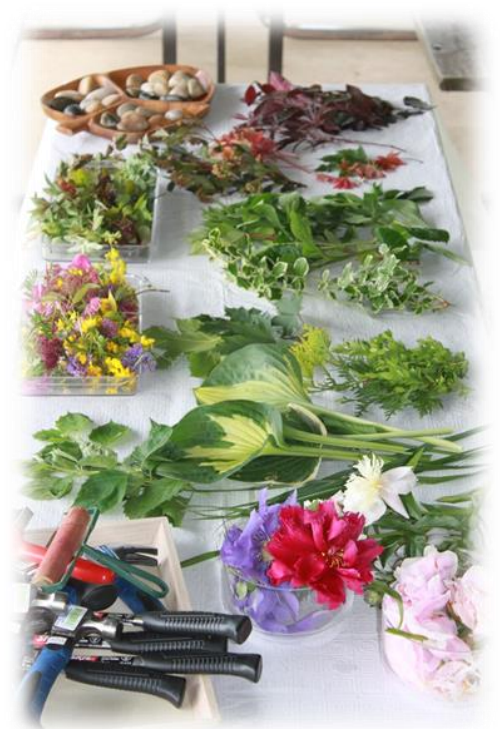

Figure 8. Real tools and natural materials: The children are offered real tools to create impressions with hammers and natural items.

Figure 8 demonstrates a provocation encompassing the use of real tools with natural materials to be explored by the children. Half of the Reggio sites observed provided a variety of provocations in the outdoor environments to invite investigations and test scientific properties. These materials included cause and effect learning labs often containing loose parts, water, and sand, and the use of tools to provoke investigations. These materials and areas are not typically included in outdoor learning environments, but were observed in the outdoor Reggio settings. 


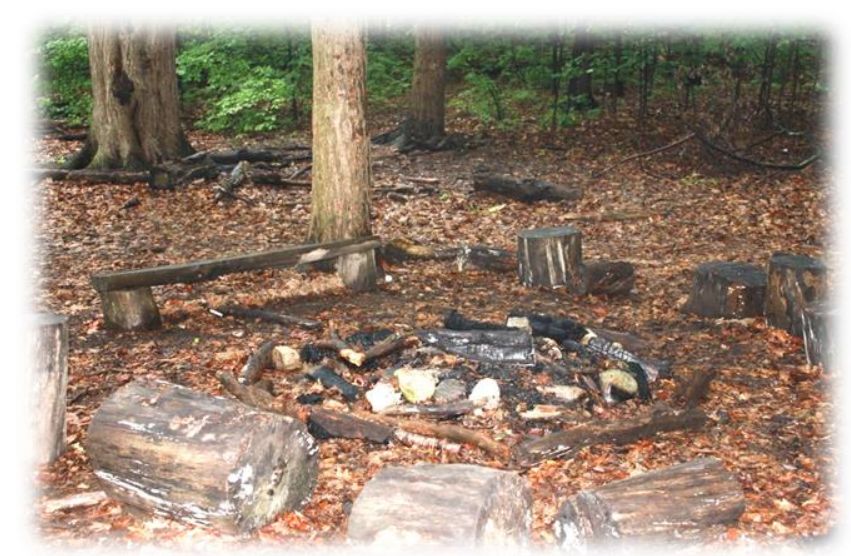

Figure 9. Spaces to gather: This photo shows a space

for a large group to gather and engage.

Part of the principle of the environment as a third teacher is the creation of spaces to elicit social interactions and opportunities to build knowledge socially (See Figure 9). Careful design to this element of space outdoors provides opportunities for children and educators to greet and have class meetings and provides a social gathering space. All sites used natural materials such as boulders, fallen logs, tree stumps, and tree benches to create these spaces. The use of space designed for large groups was captured across all of the sites, showing the significance of social interactions in Reggio outdoor environments.

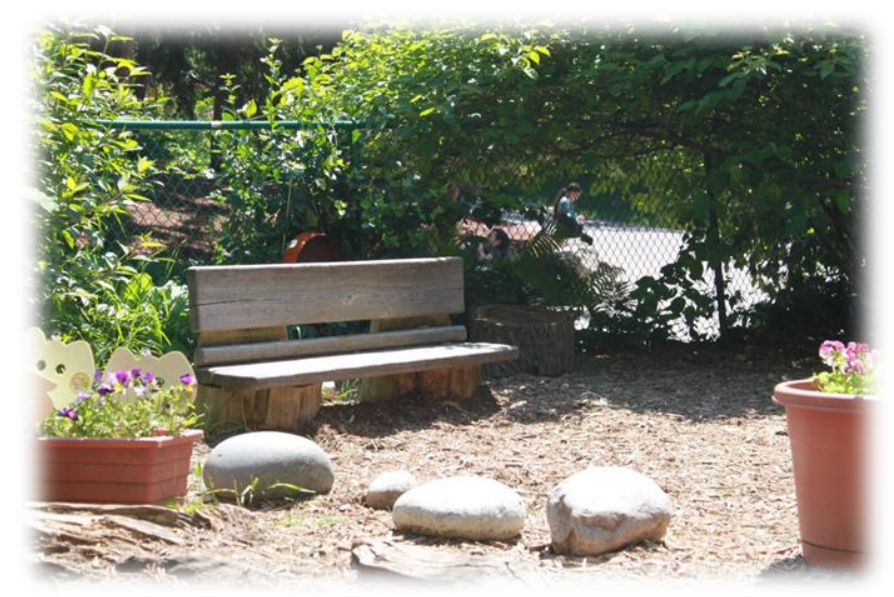

Figure 10. Small cozy spaces: An example of a small cozy areas for children to explore in.

In addition, all sites incorporated small, quiet, and cozy places for children to be alone or to use in small groups (see Figure 10). This is a key element of design to support relationships in the learning environment. Particular to the Reggio sites observed was an aesthetic element added 
to the creation of these spaces. All sites incorporated natural elements such as flowers, bushes, tree stumps, and logs as chairs to define and embellish these spaces.

\section{Aesthetics}

Aesthetics awareness is part of the indoor Reggio environment, as careful consideration to beauty, wonder and delight are always present. The quality of aesthetics was a significant characteristic of the outdoor Reggio environments. In some settings the aesthetic value was stronger than others. However, it was clear that all sites had placed substantial effort in the use of décor, art, light, shadow, reflection, and nature to add to the environment. This element was captured in photos throughout the settings and supported the translation of the principle of the third teacher.

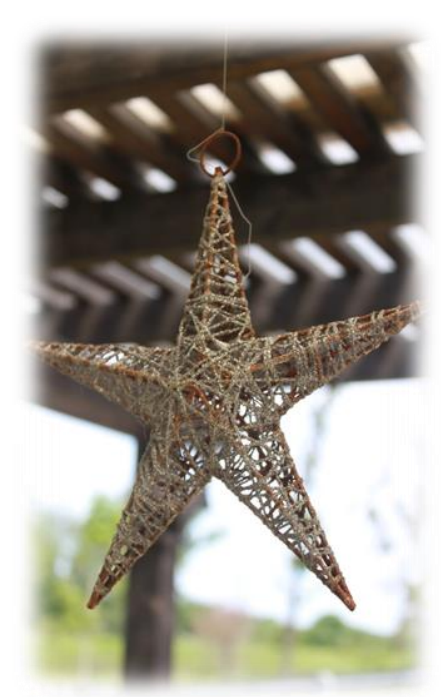

Figure 11. Décor: An example of items used to decorate and add beauty to the space.

The majority of the sites used a variety of interesting décor to add to the beauty of the environments. Rather than teacher-made displays, often used in traditional early years settings, aesthetics call for the purposeful selection of beautiful and interesting material adding to the quality of the environment (see Figure 11). Many sites used decorative, enticing garden décor and hung chandeliers added to and enrich the space. 


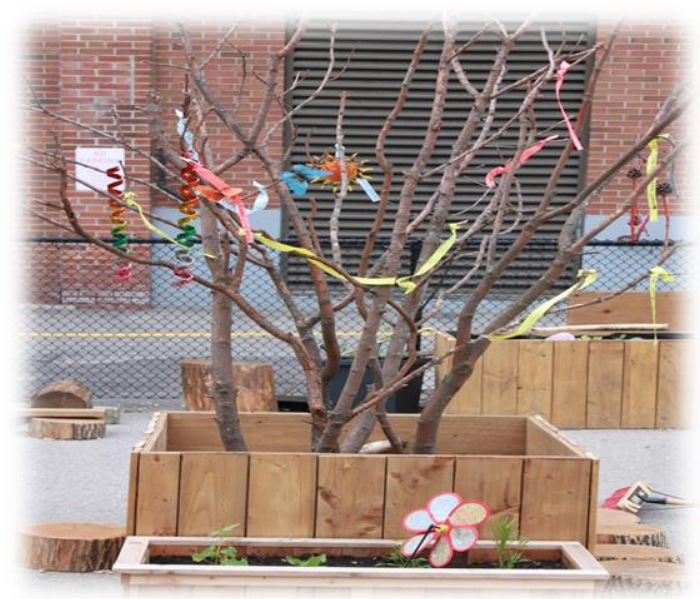

Figure 12. Art: Artwork used to add aesthetic value and honor the children's work.

A significant number of the sites used art to embellish the outdoors (see Figure 12). Adding to the principle of the environment as a third teacher was the use of children's art to add to the aesthetic value of the environment. Further, this element makes the children's work visible to others, reflects children's contribution to the space, and honors their work. This can be construed as communicating respect for the learner and the process of learning. Children's work therefore becomes part of the design elements in the environment. Examples of this were seen in most of the sites as painted trees, sticks, rocks, weaving, and webs created by the children were displayed throughout the space.

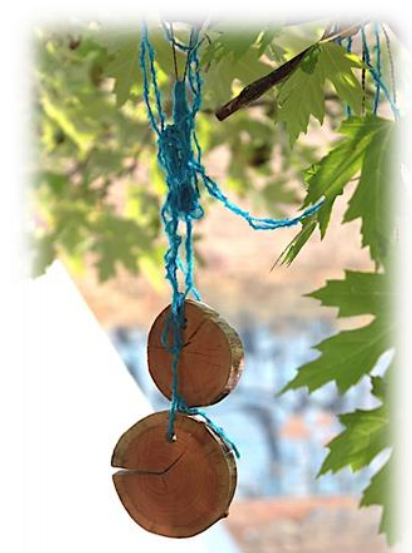

Figure 13. Natural Art: Natural objects displayed as art to acknowledge the beauty of nature.

Many of the settings used nature as an artistic form of expression in the environments (see Figure 13). Pinecones, rocks, and tree-cookies displayed as art in the outdoor environment 
played tribute the beauty of nature and addressed the aesthetics in the principle of the environment as a third teacher.

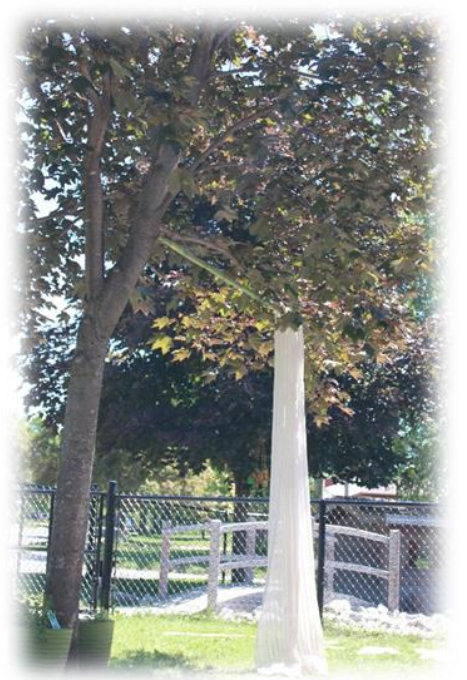

Figure 14. Movement: Fabric hung on a tree adds movement to the space.

The aesthetic use of fabric hung on trees, fences, and posts was used to add to the décor and define space in many of the participating sites (see Figure 14). One subtle element noted was the way in which fabric communicated movement in the wind and could potentially be played with by children. This can add to the soft inviting aesthetic value outdoors and create a sense of wonder.

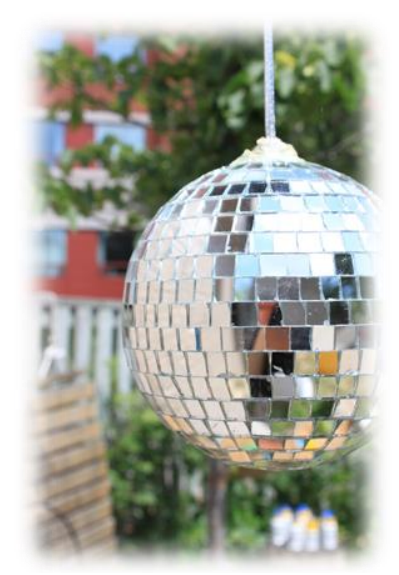

Figure 15. Reflections: Reflective surfaces used through spaces to add interesting reflections of light.

The element of wonder is always present in the Reggio environment. Figure 15 shows a disco ball, which when caught by the sun created hundreds of reflective lights and provided a 
sense of wonder. Other sites placed hanging objects around the environment, and provocations in trees to embrace the sense of wonder and the joy of learning. This aesthetic quality of Reggio environments was observed across the participating sites and added to the overall ambiance of the outdoor environments.

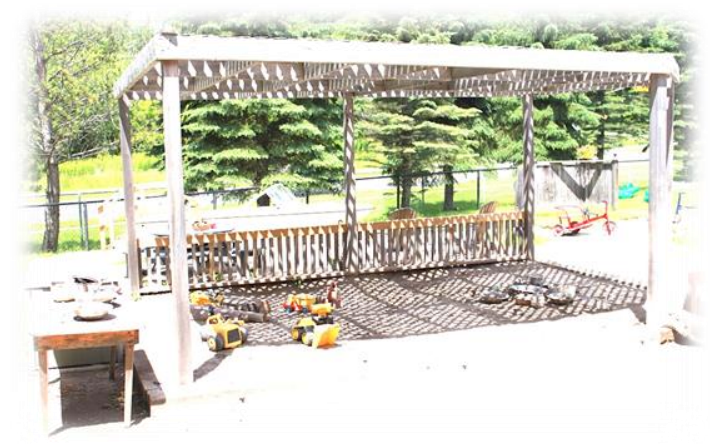

Figure 16. Shadows: Structures designed to cast

interesting shadows are added to the space.

Several of the centres provided spaces with shade covered by a trellis and/or decorative valance. These areas brought opportunities for shadows to cast in children's play spaces. Shadow and light play is considered one of the hundred languages of children in Reggio. It is used as one mode for children to express, learn, and construct knowledge. Several centres incorporated a lattice similar to the one in Figure 16 to provide an aesthetic quality to the environments that cast various shades over children's play areas. This offers another element to the environment and children's play.

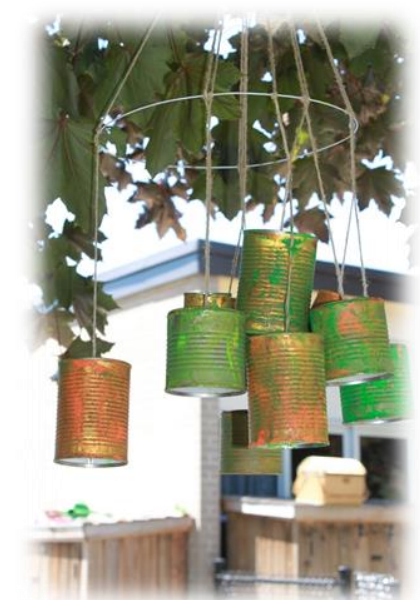

Figure 17. Sound. An example of items

hung to create sounds in the wind.

The element of sound was found throughout all the sites, producing a sense of mystery, delight, and surprise. Furthermore, sound created an ambiance in the environments and enriched 
the children's experiences. These items communicated a thoughtful consideration and addition to the aesthetic qualities. Various wind chimes, bells, and sound makers left in unexpected places invited the possibility of sound with the movement of wind (see Figure 17). It is another sensorial element added to the rich Reggio outdoor environment.

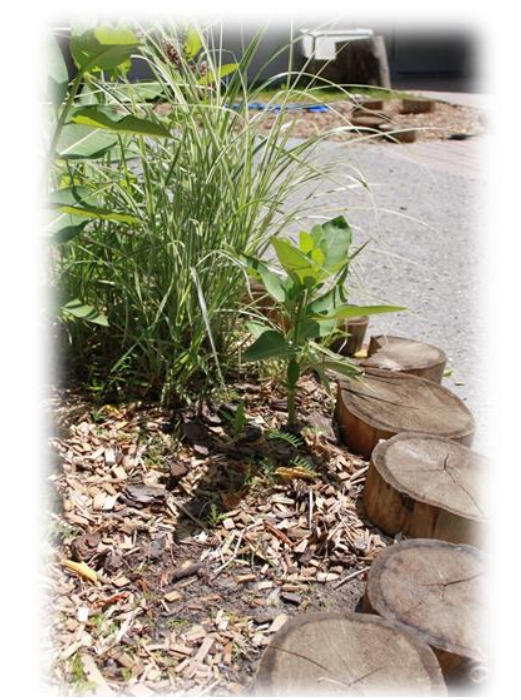

Figure 18. Textures: Natural materials used to create a variety of textured surfaces in the environment.

Adding to the principle of the environment as a third teacher was the use of textures to create aesthetic value in the spaces (see Figure 18). This was consistent across all the settings, as observations of hard, soft, smooth, and rough surfaces were seen throughout the sites. More so, these items were placed in purposefully organized and aesthetically pleasing a ways that enriched the environments. Many sites incorporated sand, grass, rocks, trees, bushes, gardens, mulch, soil, wood, and tree-cookies to add a level of textural and sensorial quality to the to the design of the environments. 


\section{The Atelier as an Expression of the Hundred Languages of Children}

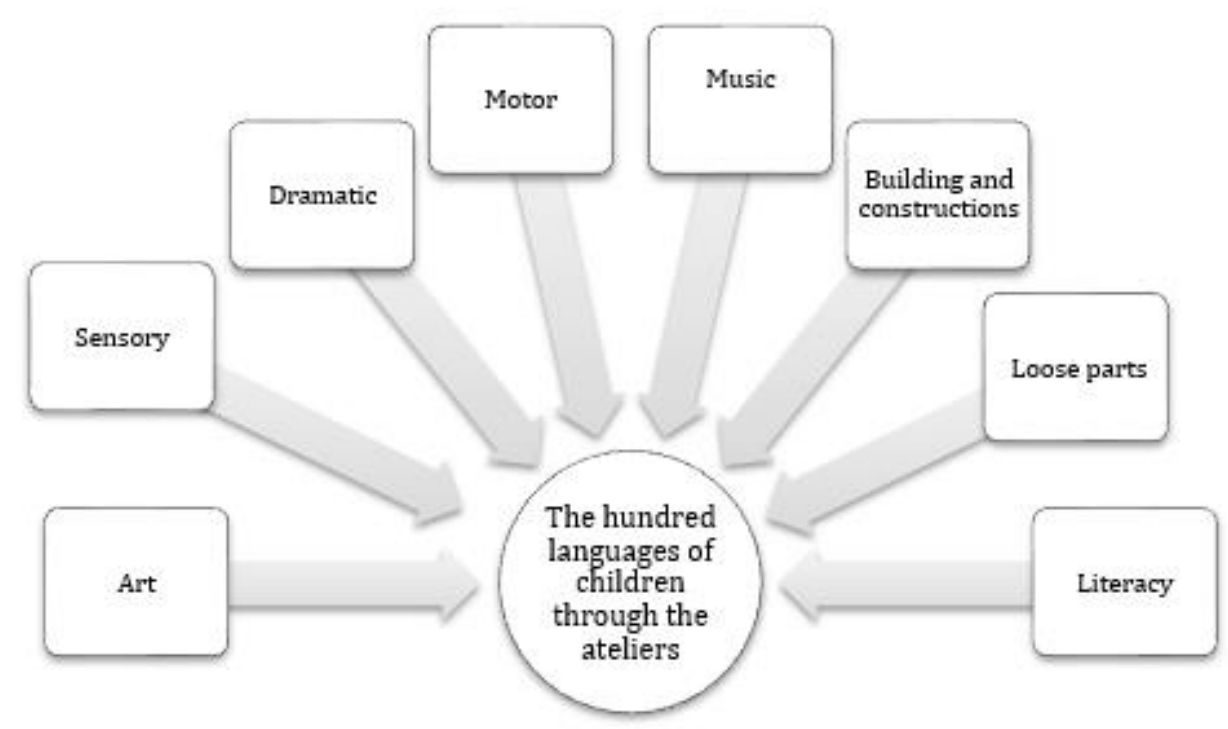

Figure 19. Evidence of the Atelier: The hundred languages of children.

The Reggio principle of the hundred languages of children translated well and the use of the ateliers (mini labs or learning areas) was evident throughout each of the learning environments. The data revealed strong connections to this principle as the spaces were designed to honor the hundred languages of children. The outdoor natural learning environments incorporated many modes of learning, or learning labs as Malaguzzi defined them (Gandini, 2012). They translated as evidence of rich learning areas for children, and this principle was identified consistently through the many mini ateliers located throughout the Reggio natural outdoor environments.

The translation of the ateliers was used in connection to the principle of the hundred languages of children. This Reggio principle contends that children have a natural receptivity towards materials. As children engage in the environment, they construct knowledge and develop a personal language from direct interaction with materials, the environment, and one another. In Reggio, the hundred languages of children refer to children's endless potential to communicate. This principle proposes that children have multiple languages and that they need opportunities to develop, express and construct them (Fiore, 2013). The principle conceptualizes that there are infinite possibilities within the hundred, which may include but are not limited to movement, art, 
dance, light and shadow play, sensory, design, construction, and drama. The role of the school, environment, and educators is to honor and provide opportunities for this expression of the hundred. This can be expressed through the design of ateliers that are rich in space with materials and possibilities. These areas become places of research and meaning making in the Reggio environment, and are used to express the hundred languages of children. The design of such places is evident in the indoor Reggio environments, and therefore this criterion was set to assess the transferability of this principle outdoors. Essentially, was there evidence of the translation of this principle through children's ability to construct, express, and represent the hundred languages outdoors as well?

This principle was inherent throughout the data collection across each of the sites, as photos captured the multiple ateliers though the Reggio outdoor environments. The most predominant ateliers revealed through the data collection were the use of dramatic, sensory, art, and music as well as loose parts. These areas are not typically found in an outdoor early learning environment. Block construction and literacy ateliers were the least present, as they were only visible in one third of the Reggio sites. This could be due to the time of the collection of data as it varied depending on site availability. In some cases the collection of data commenced in the early morning or late afternoon when the environments were not in use. Therefore, the areas could possibly have been either not yet set-up for the day, or already tidied-up in the evening. Regardless, all sites encompassed the use of mini ateliers and expressed strong connections to the principle of a hundred languages of children. The following photo documentation supports the translation of the principle of the hundred languages of children through the use of ateliers. 


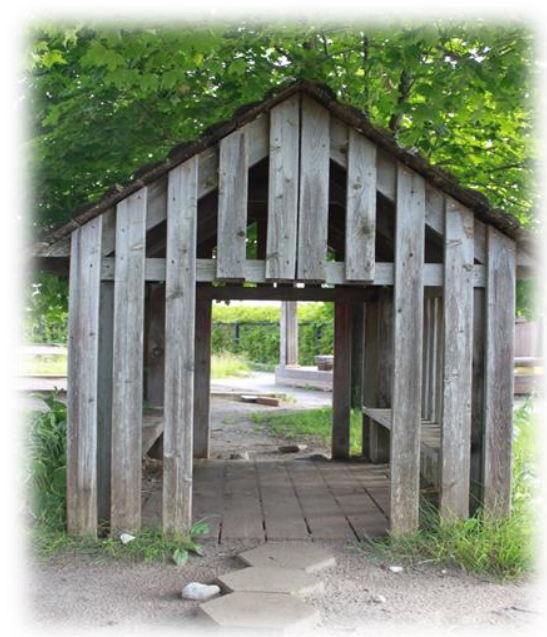

Figure 20. Dramatic Dwellings: An example of a structure that allows for dramatic play opportunities.

All sites had at least one home or house structure as depicted (see Figure 20) in the outdoor environments. This addressed the imaginative and creative play potential that can be expressed through dramatic play. Consistently across the sites the structures were open-ended and allowed for a variety of play scenarios. Some showed evidence of materials and loose parts added to extend and enhance play. This represents the translation of the principle of the hundred languages, through the opportunities for dramatic play.

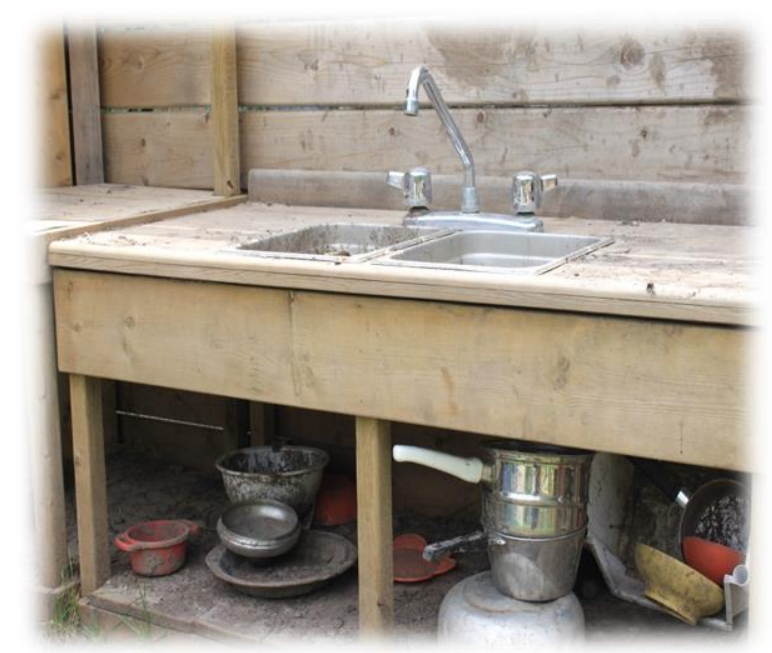

Figure 21. Mud Kitchens: A kitchen setup for children to engage in dramatic play.

More than two thirds of the sites had some form of a mud kitchen within the outdoor learning environment (see Figure 21). The location of the mud kitchens was often near the dramatic area or in close proximity to sand, water, or mud. This could be interpreted as an 
opportunity presented within the environment for another form of expression through the hundred languages of children. These ateliers supported the children's investigations of combining materials and honored the sensorial language of learning and expressing.

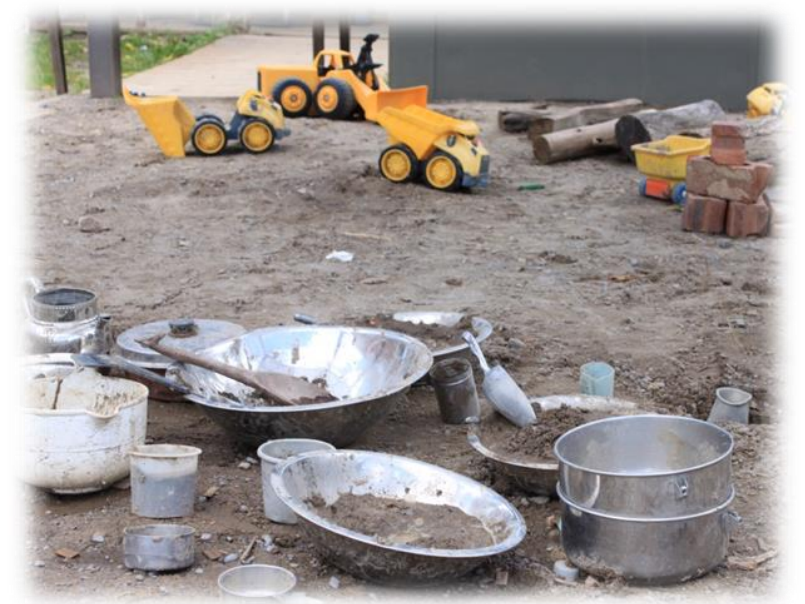

Figure 22. Sensory exploration: Multiple provocations set up for the use of sand and sensory play.

A predominant number of observed sites incorporated sand and water play in the environments. Among the sites observed was the use of interesting materials such as real cookware or bricks added to the sand and water areas, in addition to regular sand toys. Offering materials in interesting ways speaks to the creative and imaginative potential of the child and extends and enriches the play. This sensory atelier could be interpreted as recognizing children's sensorial language and providing opportunities to explore, construct, and combine materials. Figure 22 demonstrates the use of dramatic items, loose parts, and real materials, speaking to the many languages of children. In addition, children were offered more complex and challenging opportunities to engage though the use of real gardening tools, trees logs, as well as large and small loose parts. This was observed across many sites. 


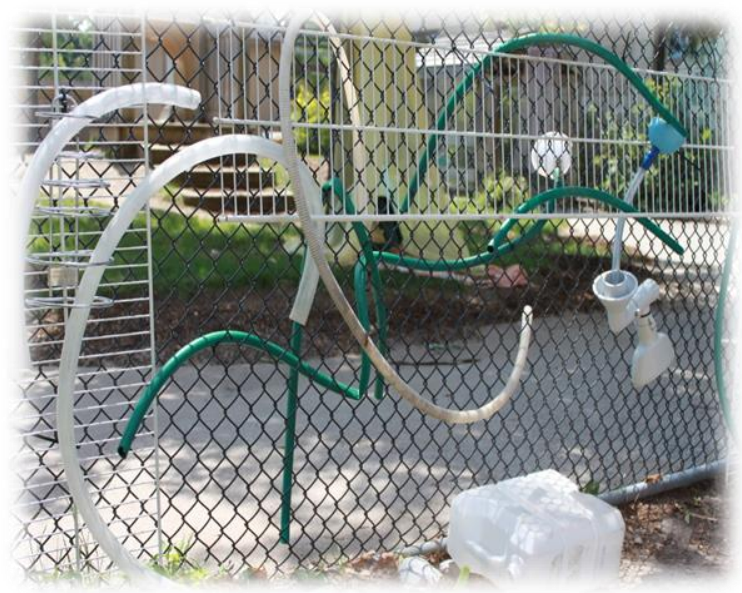

Figure 23. Water Wall: Tubes and funnels set

up to allow for testing theories with water.

Most sites indicated the use of a water lab as another mode of expression of children's thought processes of developing and testing theories. Through water play and explorations, children's natural curiosity is honored as they are presented with opportunities to test, explore, and develop the language of science. Many outdoor sites offered elaborate water labs for children to explore, manipulate, and test ideas. The outdoor water lab can be viewed as an opportunity addressing the hundred languages of children (see Figure 23).

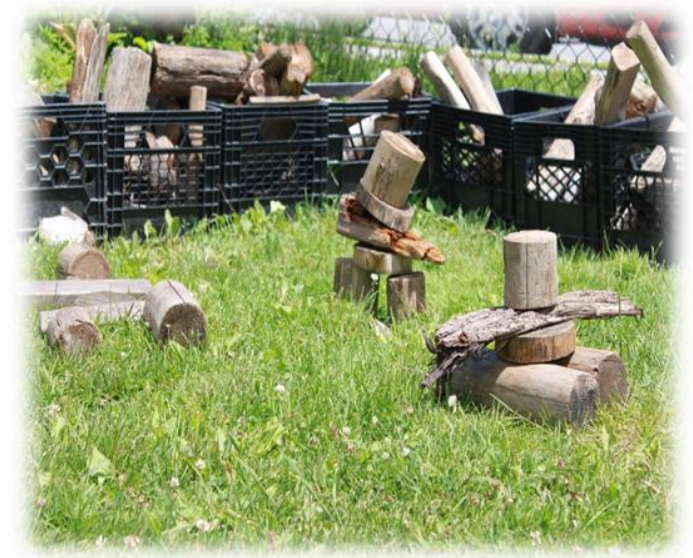

Figure 24. Loose parts: This image shows free

standing structures created with loose parts.

Building with loose parts and open-ended materials offers children endless possibilities to create, represent, and extend learning and play. The Reggio indoor environment has many areas for children to mess about with loose-parts and materials, to construct and build ideas and thinking. There was evidence of these materials being transferred to the outdoor learning environment (Figure 24), as two-thirds of the sites offered loose parts as distinctive areas or 
ateliers and as additions to other learning areas. There were variations to the types of loose parts observed, but they consisted of mostly natural materials such as branches, trees-cookies, tree stumps, sticks, rocks, and pinecones. Others included recycled materials such as tubing, piping, spools, and many more. Loose parts honor the creative potential of children, as they are openended materials that have varied potentials to add and enhance children's play. These speak to children's languages of science, creativity and imagination.

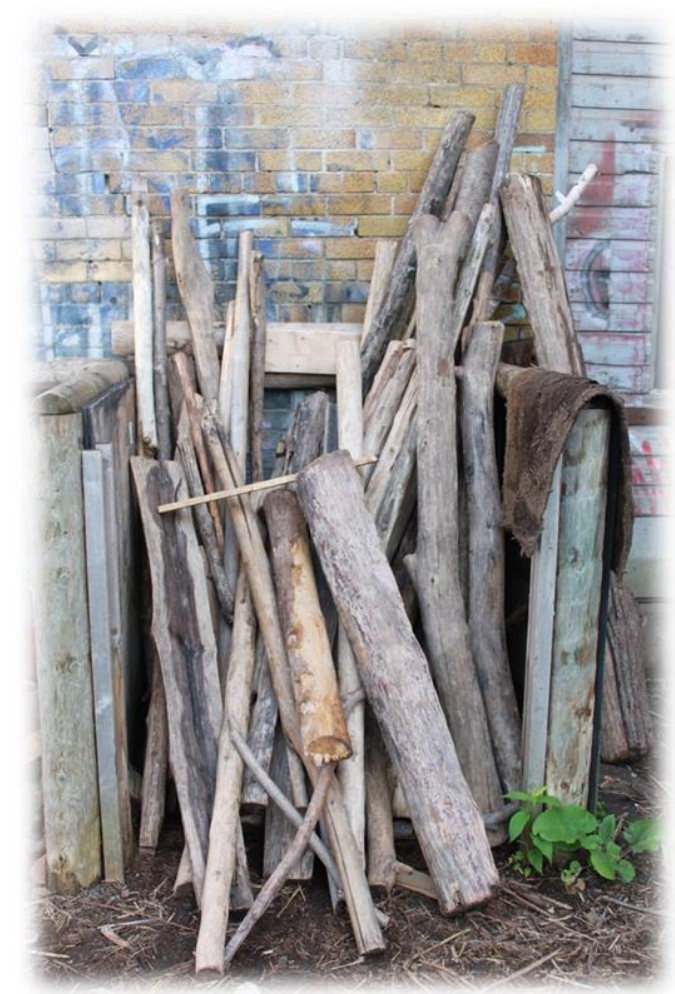

Figure 25. Large loose parts: Large logs and branches

offered to children for the use in creative construction.

Although not a part of all sites, half of the sites offered large loose parts for building and construction. These materials allow children to explore, construct and represent their thinking. Further, they support the development of building and designing, which be construed as evidence of the representation the hundred languages of children. These types of large loose parts materials are not typical of other outdoor early learning environments (see Figure 25). 


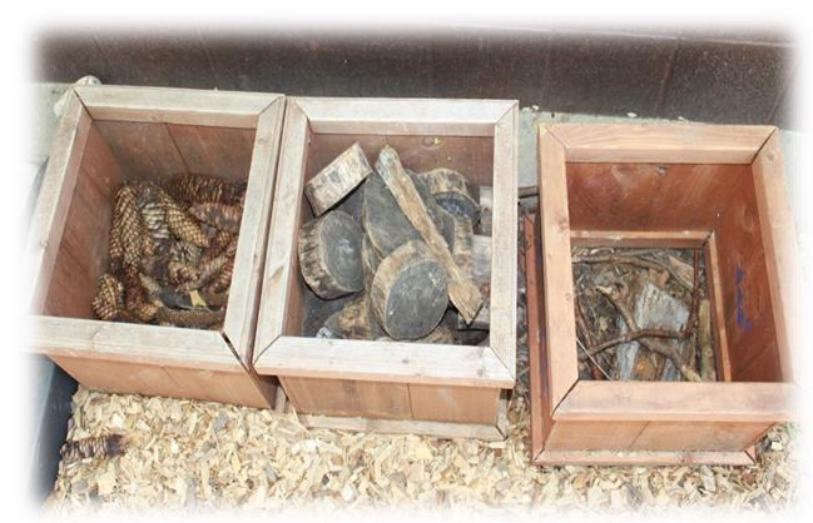

Figure 26. Small loose parts: A collection of small loose parts to enhance children's play.

The majority of the Reggio sites used smaller loose parts to enhance play. They were left in a variety of areas such as in the sand, dramatic, and building areas. They also added to the aesthetic details of the environments and children's play (see Figure 26).

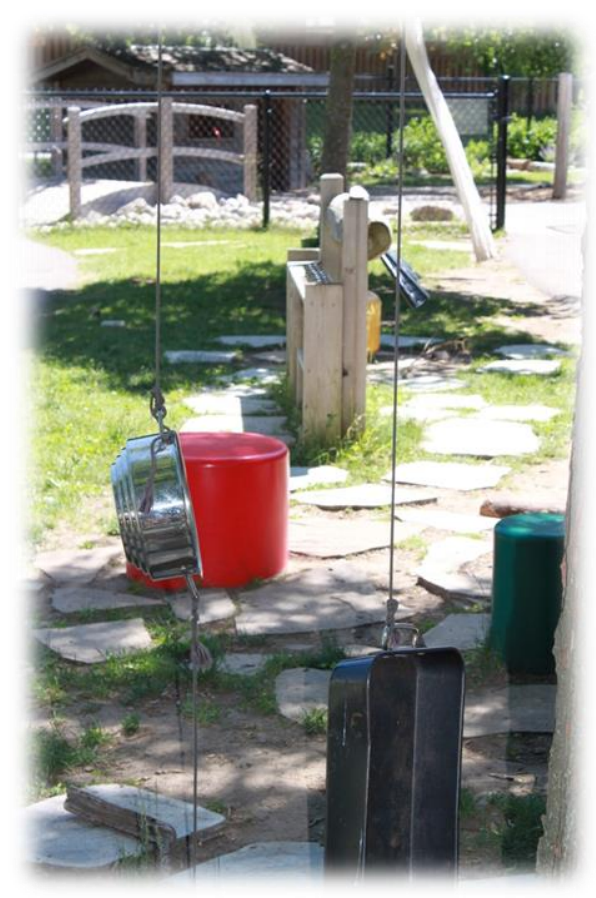

Figure 27. Music: An example of a homemade music atelier using household materials to create unique sounds.

Consistently across the majority of sites was the atelier of music (see Figure 27). Various forms of musical explorations were offered to the children outdoors. This provided evidence of the principle of the hundred languages, through the music ateliers being translated to the outdoor environment. Music ateliers consisted of teacher-constructed or handmade musical walls and 
instruments using recycled or found materials. In some cases pots, pans, hubcaps, and tubing were used for music explorations. In addition, some settings incorporated commercial outdoor musical instruments as permanent fixtures.

\section{The Image of the Child as Competent}

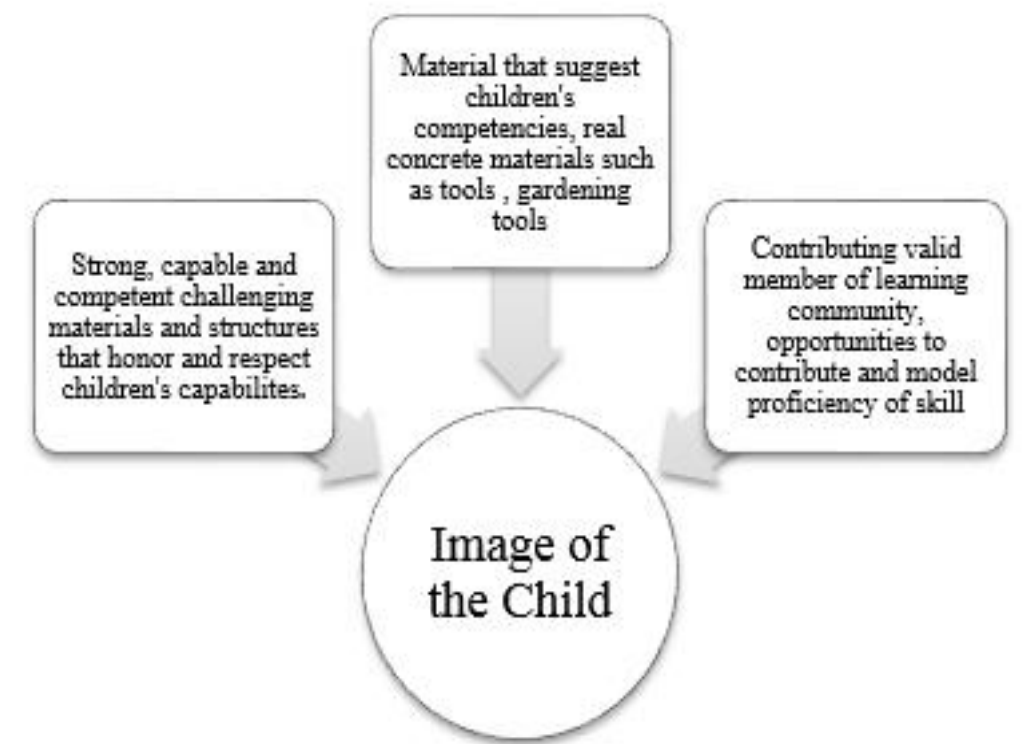

Figure 28. Evidence of the image of the child: Elements considered for the theme.

Unlike the other principles, the Reggio principle of the image of the child was not directly apparent in the photo data collected. It was through interpretation from a Reggio perspective, however, that it became clear that the principle of the image of the child used in the indoor environments was translated into the outdoor environment as well. This principle regards the image of the child as full in potential with strong, capable, and competent qualities. It also views children as active, contributing members of the environment. In order to assess these characteristics, the data selected as evidence incorporated elements to indicate child choices, risk, challenge, and the potential for competency. In turn, these qualities can be interpreted to demonstrate the principle of the image of the child. Photos that depicted the above characteristics presented some indication of risk play, challenge, and choice in the environment. Specifically, the indicator of child competency was demonstrated though the accessibility of self-help materials that promoted the concept of children as contributors to the learning environment. As a result, self-help materials such as life-size gardening tools for use in the garden could be interpreted as a communication of children's competency, and represent the image of a capable 
child. Nearly all sites showed evidence of this principle, captured through photos depicting the capability and competency of children to contribute to their classroom (environment) in some regard. In addition, competencies were demonstrated through opportunities to exhibit proficiency and gain illicit responsibilities. In this case, children were portrayed as contributing members to the environment, through the use of real-life materials such the use of a watering can to tend and care to gardens.

In addition, all sites incorporated challenging climbing structures, made from both natural and often recycled materials, which are not often seen in traditional childcare playgrounds. The majority of sites had removed their traditional play structures and replaced them with natural environments and playscapes. One-third of the sites had traditional climbing structures, yet indicated they were in the process of removing them and were moving toward more natural environments. Further, natural non-traditional play equipment was used and evident in all the sites, and placed in purposeful and thoughtful ways. These incorporated challenging terrains including but not limited to ramps, inclines, steep hills, tree stumps, fallen trees for balancing or climbing, and access to waterfronts. The following photo documentation provides evidence and supports the translation of the principle of the image of the child as strong, capable, and competent as it is applied in Reggio natural outdoor learning environments.

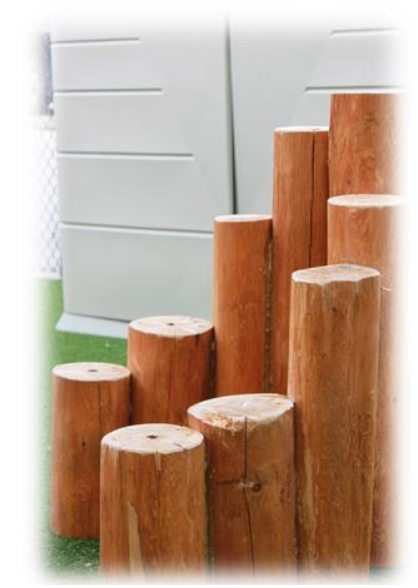

Figure 29. Tree stumps: Tree stumps of varied heights for climbing and balancing on.

The use of tree stumps was a predominant theme through all of the Reggio sites (see Figure 29). Not typically used in childcares for the use of climbing and balancing, these tree stumps offer a challenge as well as a risk to the young child while building on emerging motor skills. Therefore, presented to children in the environment, they convey and can be construed to 
indicate the principle of the image of the child as strong and capable of handling the risks involved.

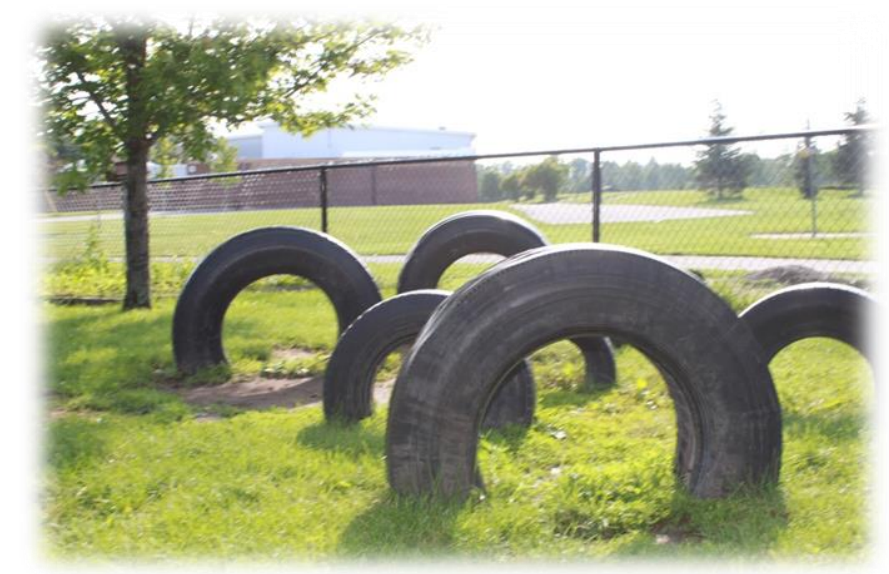

Figure 30. Tires: A number of tires set up to present a physical challenge for the children.

Half of the Reggio sites had removed the traditional climbing structures, and offered a variety of non-traditional opportunities to climb for children (see in Figure 30). These structures offer children unique and varied challenges. This can be interpreted to portray the principle of the image of the child as strong and competent, as these non-traditional structures offer a wider range of challenges, risk, and possibilities.

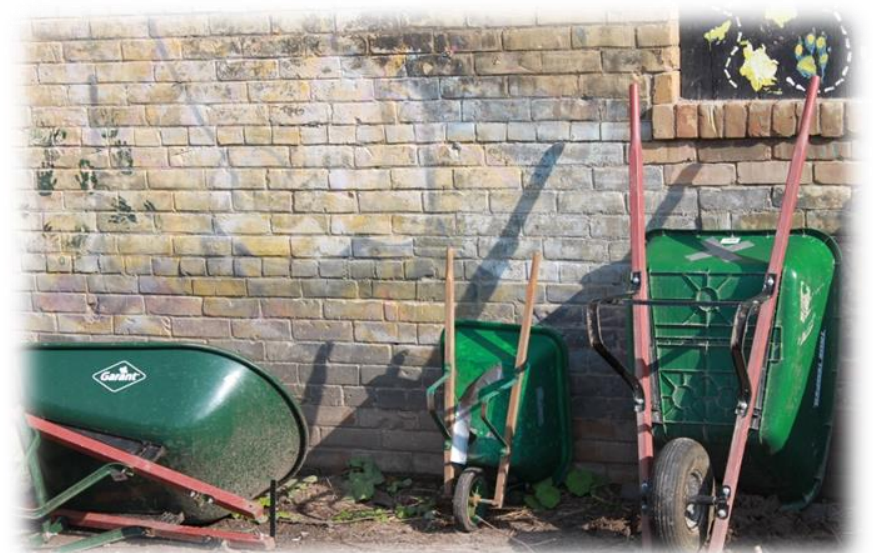

Figure 31. Real tools: An example of real tools provided for the children's use.

Figure 31 illustrates, through the use of real tools and materials such as these wheelbarrows depicted, the image of the child as competent with the ability to select, load and transport materials using real equipment for use in their play. This speaks to children's ability and the belief that they may determine what is required for their play and learning. In essence, 
children are provided with authentic materials to exercise and respect their capabilities and autonomy.

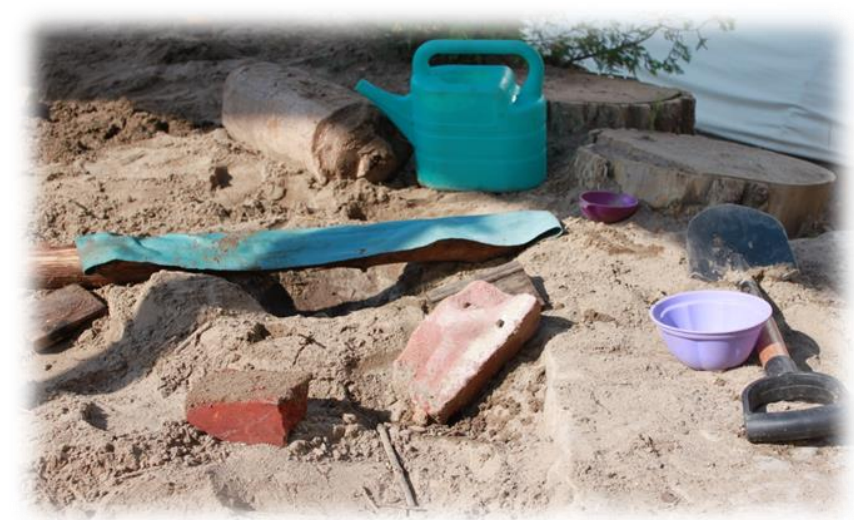

Figure 32. Competency: A variety of materials provided

which demonstrate children's competency to use them.

Figure 32 illustrates the Reggio principle of the image of the child as rich in potential. The materials suggest the use of real tools. A watering can demonstrate proficiency in the child's ability to locate the water supply on his or her own. The use of bricks implies a trust in children's capability to use real materials that others may deem unsafe for children. Further, the photo suggests that children can create and add to their play independently, without the need for an educator, as the materials allow for child-initiated choices.

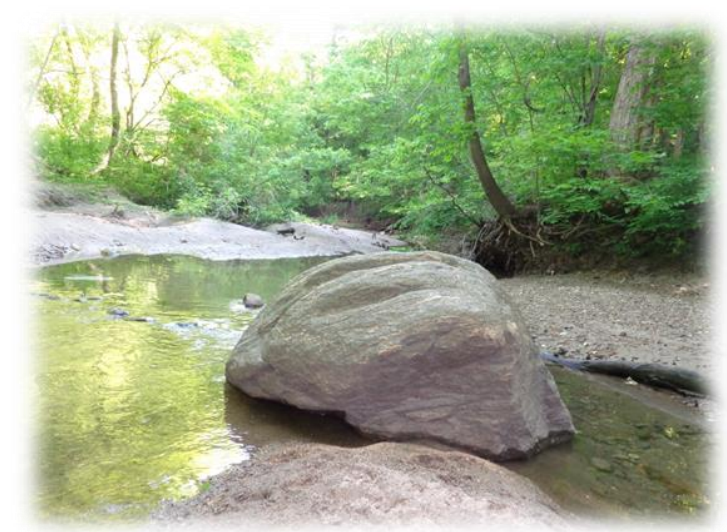

Figure 33. Boulders: Large boulders in the environment to challenge children.

Several Reggio sites offered children opportunities to climb large rocks and boulders (see Figure 33). All forest school sites used boulders as climbing structures. This is not typical in most childcare centres, as the rocks could be deemed dangerous. Their inclusion in Reggio sites 
indicates a belief in children's abilities to assess risks and accept challenges. This can be interpreted to represent the image of the child as capable and strong.

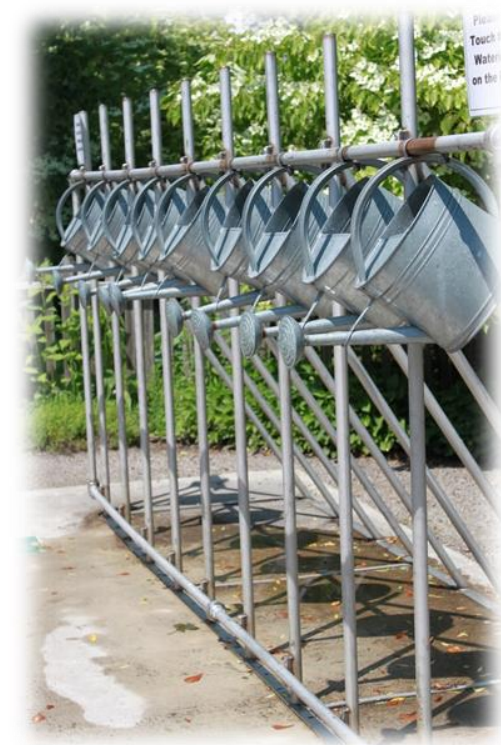

Figure 34. Watering cans: A large selection of watering cans accessible for children's use.

Figure 34 depicts the principle of the image of the child as a valuable contributing member of the learning community. Children are capable of accomplishing real tasks such as watering gardens. This demonstrates the image of the child actively contributing to the environment.

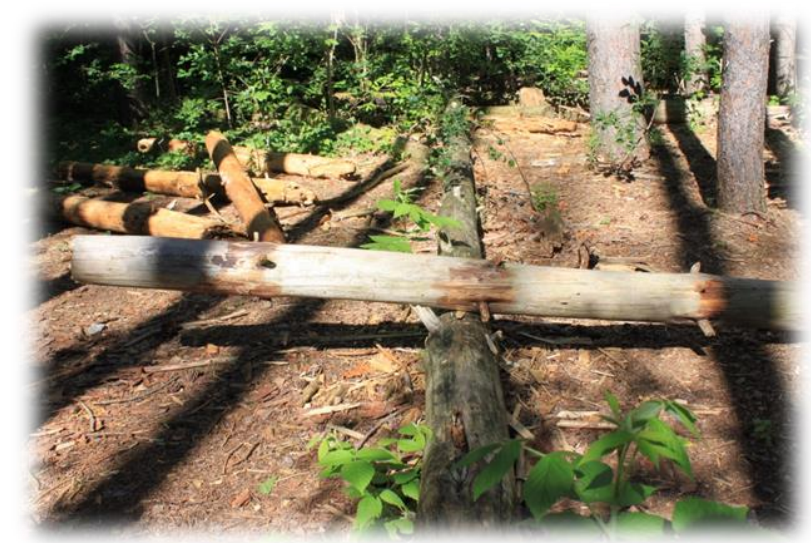

Figure 35. Balancing: Long logs presented as an opportunity to explore balance.

A predominant number of sites used fallen trees to support and challenge children's capabilities. Figure 35 illustrates the principle of the image of the child. Here the materials suggest an image of the strong child who is capable of exploring balance on these fallen trees. 
The use of these materials may not be utilized in most programs, yet many of the Reggio sites used fallen trees as tools to explore balance, stability and coordination.

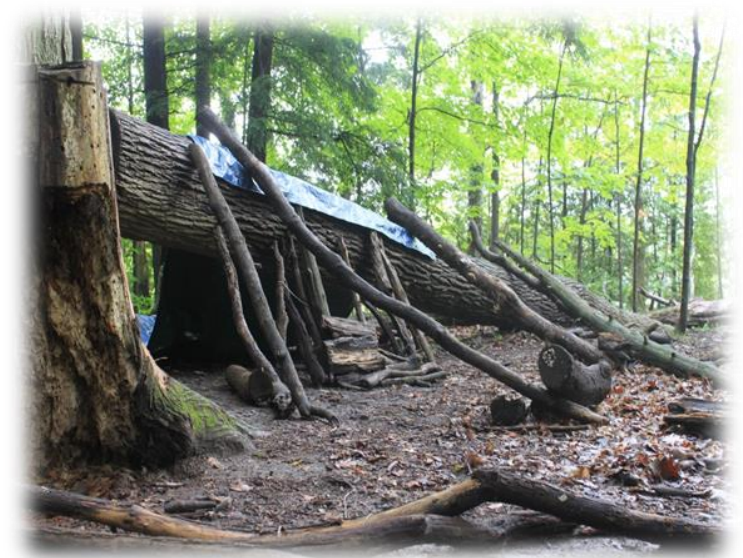

Figure 36. Large building: A structure

created with large loose parts.

Several of the Reggio sites, such as the one pictured in Figure 36, provide large materials for use in construction. These materials may not be found in traditional playgrounds but were visible in half of the Reggio settings and in all three-forest school settings. These large items for building challenge children, while addressing the image of the child as capable and strong, as well as providing elements of risks.

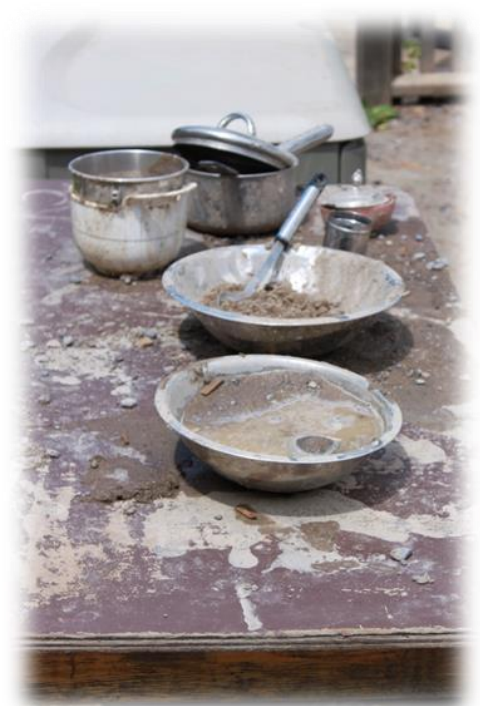

Figure 37. Concrete materials: Metal kitchenware provided for the children to engage with.

Illustrating the image of the child as capable and competent is the use of real materials that demonstrated respect for the learner and a belief in the child's ability to use them. Rather 
than the use of plastic commercial toy materials, such as plastic dishware or tools, Reggio settings recognize the worth of real concrete materials (see Figure 37). These materials communicate respect for the child and the learning process. The use of real items was a theme demonstrated through the majority of Reggio settings. This included the use of real tools and gardening equipment.

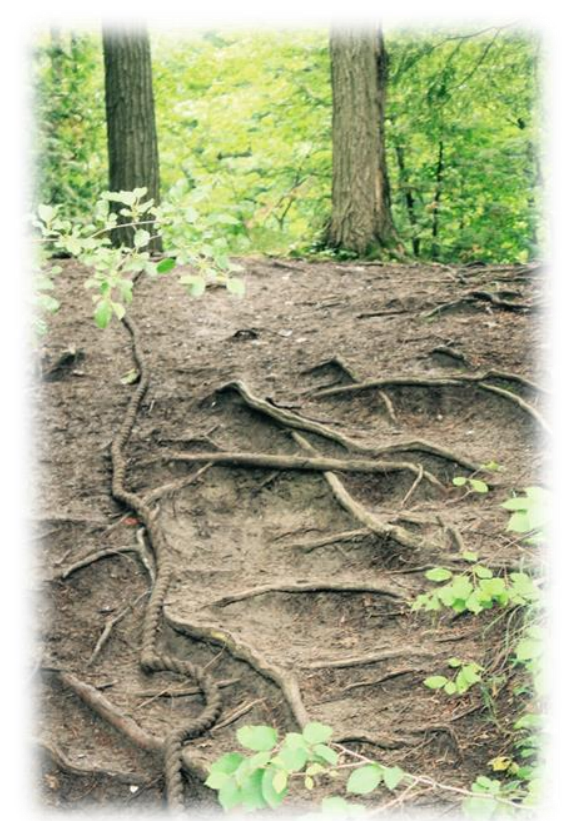

Figure 38. Climbing structures: Nature based climbing challenge in place of a commercial climbing structure.

Figure 38 depicts the Reggio principle of the image of the child in providing children with challenging grounds and terrain to climb. This can be indication of a belief in children's abilities and strengths. All three-forest school settings incorporated a variation of challenging structures at their sites. This was illustrated in many of the sites with uneven terrain, steep hills, and challenging materials to climb. This figure demonstrates a climbing experience that is not typical in traditional Ontario playgrounds. 


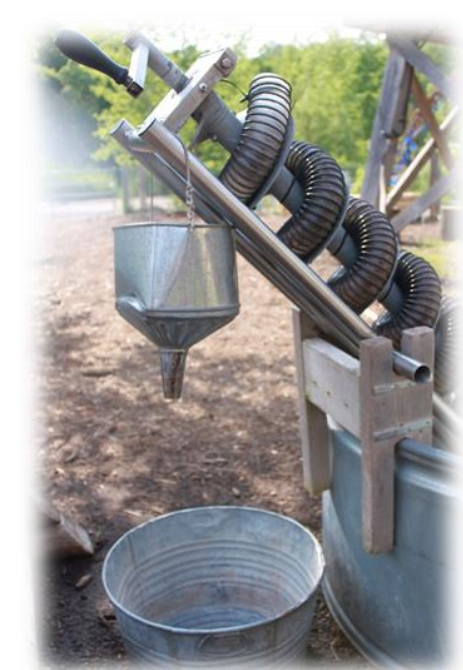

Figure 39. Self-help tasks: A manual water pump for children to get their own water supply for use in play.

In Figure 39 children are provided an opportunity to demonstrate they are capable of getting their own water supply from this manual water pump. Filling their own buckets, children are encouraged to water and care for the gardens, or incorporate the use of water play in other areas of the environment. This demonstrates respect for children in exercising choice, autonomy, and in directing and planning their own play and inquiry. 


\section{Nature as the Third and Infinite Teacher}

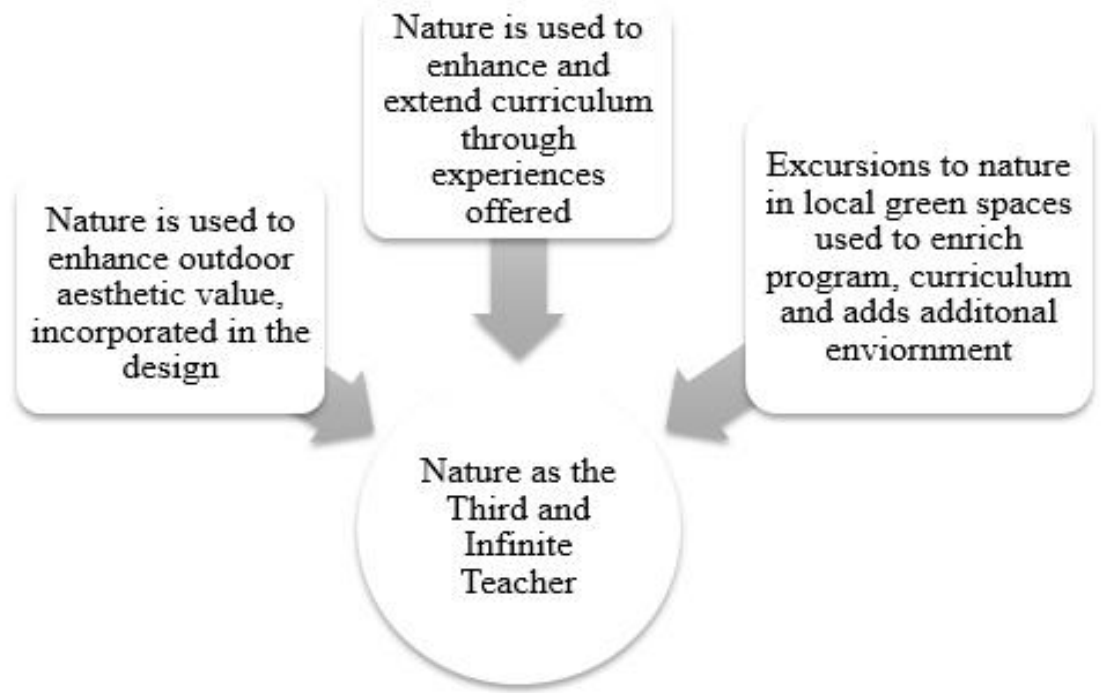

Figure 40. Evidence of nature as the third and infinite teacher

An additional theme from the data revealed that not only were the principles of Reggio translated in the outdoor environment, but that there was a significant presence of nature-based pedagogy in the environments themselves. Analysis of data resulted in evidence to suggest that nature-based approaches were incorporated into the Reggio natural outdoor environments in two ways. One, nature was a large component of the outdoor environment and a significant part of the outdoor curriculum. Two, photo data further revealed that half of the Reggio sites sought to include regular excursions to local green spaces, and therefore not only brought nature to children, but also brought children to nature and natural spaces. These spaces were therefore alterative outdoor learning environments and additional extensions to the curriculum.

Within these natural outdoor learning environments, there were multiple ways in which nature was incorporated consistently across all sites and rendered a predominant element. Multiple photographs captured nature being embedded into the designed space and purposefully added to the physical environment. Further, nature was seen in all settings through the incorporation of natural and nature-found materials, garden beds, flowers pots, native plants and herbs, and strategically placed birdfeeders for observations. Multiple gardens and flowerbeds added to the aesthetic value of the space and were also a part of the children's curriculum in the form of planting and science learning experiences. 
Natural loose parts were added to a variety of learning areas and ateliers to enhance children's play and experiences. Natural items such as tree logs, branches, and tree-cookies were used as loose parts for construction and imaginative play. Data captured nature throughout the environments as a predominant element that enriched and added to the curriculum. Nature within the outdoor learning environment offered children infinite possibilities and opportunities for play and learning. Nature has endless potential and many variants in how it encompassed the spaces and how it was used to provide materials for children in play.

Second, indicating a possible trend, bringing children out into nature was identified in the curriculum of half of the sites. This was evident through the educators' choices of utilizing local green spaces as a different way to connect children to nature. These sites had scheduled, frequent visits to explore the local green areas in close proximity to their settings. These sites included local walks, natural parks, fields, forests, woodlands and water access such as in creeks, lakes, and beaches. These excursions connect children to nature and offer additional learning environments and curriculum potential. Nature was in many ways a third teacher, both in the environment and in the local natural setting, offered infinite possibilities for connecting the children to the natural world. Thus, in the spirit of Reggio, I offer this principle as another language to the hundred and a hundred more languages of children. 


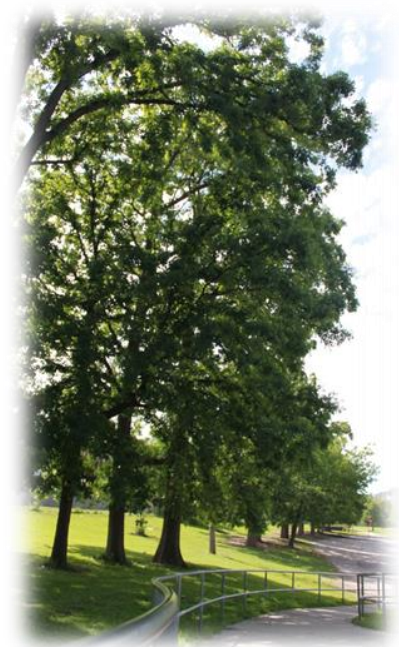

Figure 41. Trees on a walk: Large trees

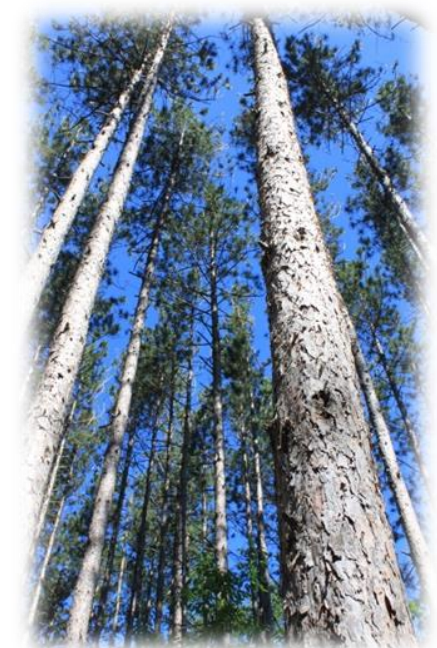

Figure 42. Forest Trees: Trees in a forest children visit off site.

Half of the sites revealed the use of local grounds and natural areas for the children to play. There was a particular focus on woodland, parks, and areas where children could play amongst the trees, connecting children to the natural elements. Figures 41 and 42 depict the use of green spaces adjacent to the school grounds for children's excursions and observations during the change of the seasons. The forest added to the sense of wonder and offered an array of possibilities and discoveries. In the forest children, have opportunities to explore the many wonders that nature offered.

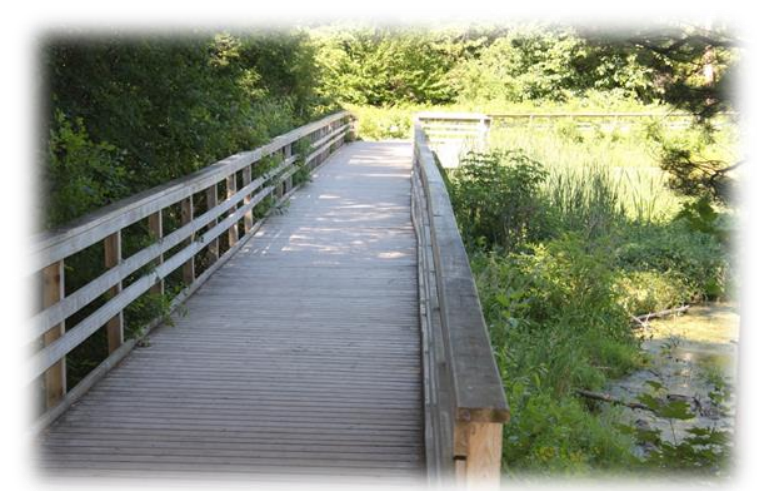

Figure 43. Water access: Offsite water source visited by children on walks.

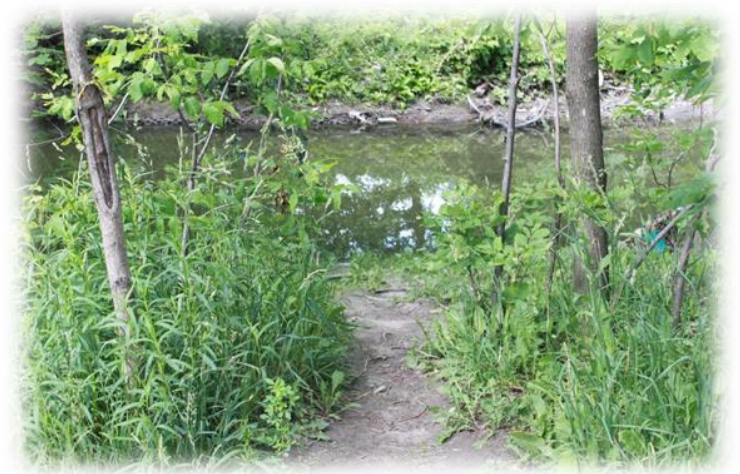

Figure 44. Local creek: A natural water source the children are taken to for explore.

Another common element was the use of local water access areas (see Figures 43 and 44). Many of the sites that utilize these areas planned excursions to waterfronts for children's investigations. This illustrates the image of the child as capable and competent, trusting in 
children's abilities to be safe and assess risk. Reggio sites accessed creeks, ponds, lakes, and beaches to add to children's outdoor experiences.

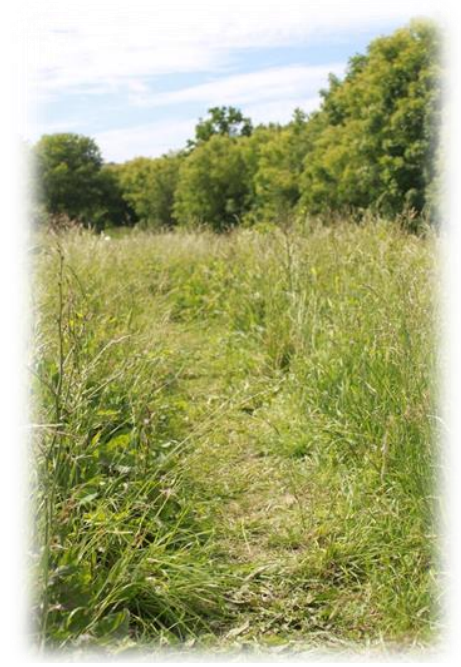

Figure 45. No-mow zone: An area adjacent to a

site with natural growth for children's explorations.

This photo provided evidence of the use of natural areas. Figure 45 depicts the use of a no-mow zone kept natural for children's explorations adjacent to the schoolyard. This area was used to explore the natural local landscape. It encompasses a no-mow area, where the children explore in the tall grasses and have planted various trees and shrubs.

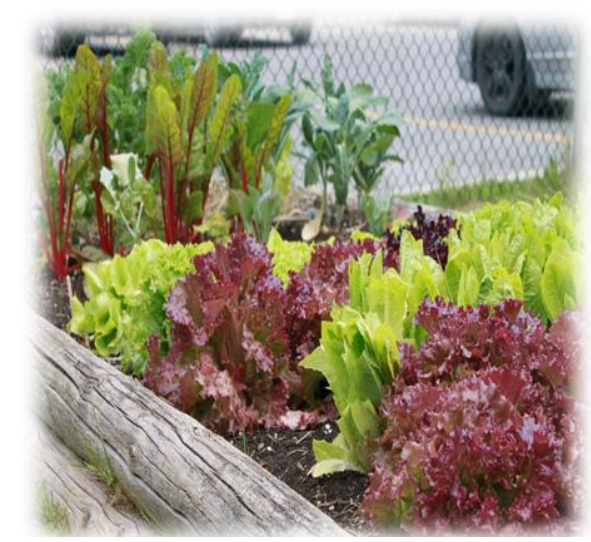

Figure 46. Gardens: One example of a garden

bed within the outdoor learning environment.

In all sites there was a significant presence of nature, and bringing nature into the outdoor environments. This photo (Figure 46) illuminates the use of various gardens added to the outdoor environments. There were several types of gardens captured such as flowerbeds, pots, hanging baskets, herbs, vegetable gardens, as well as native plants throughout. Nature was noted in all 
sites for connecting children to the rich sensorial aspects of the environments. Nature in the environment provides children with rich, beautiful spaces as the third teacher in which to learn and discover.

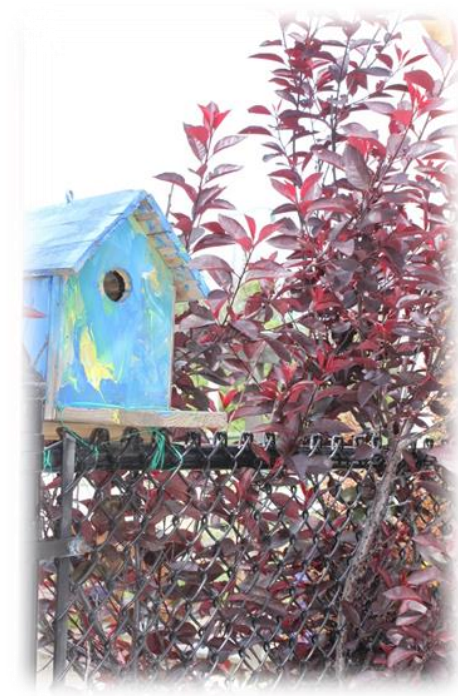

Figure 47. Bird feeders: A bird feeder placed

within the environment to invite more nature in.

All sites incorporated bird feeders (see Figure 47) in and around the outdoor

environment to bring nature to children. Many of the bird feeders were made or decorated by the children, placing the value of children's work in the environment. The birdfeeders were placed around in interesting, provocative, and aesthetic ways for effective use of observation of wild life.

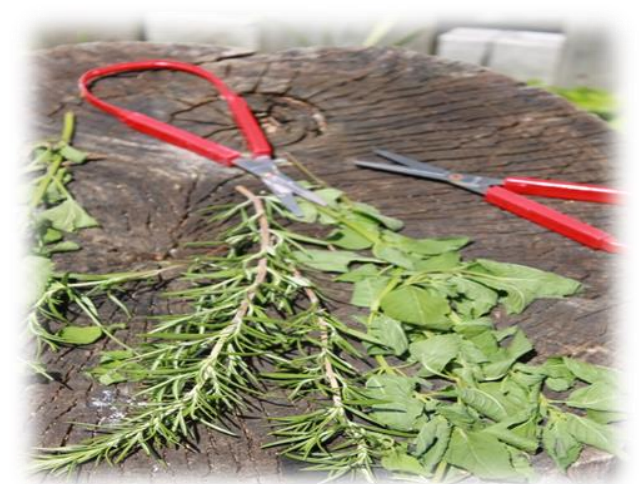

Figure 48. Cutting herbs: A provocation using nature provided to children to encourage the use of scissors.

The photo documentation as seen in Figure 48 provided evidence of nature-based curriculum. Throughout many sites, the use of nature as part of the curriculum was 
demonstrated. This could include the cutting of herbs from the garden, art, and nature-based projects, as well as gardening and tending to garden beds.

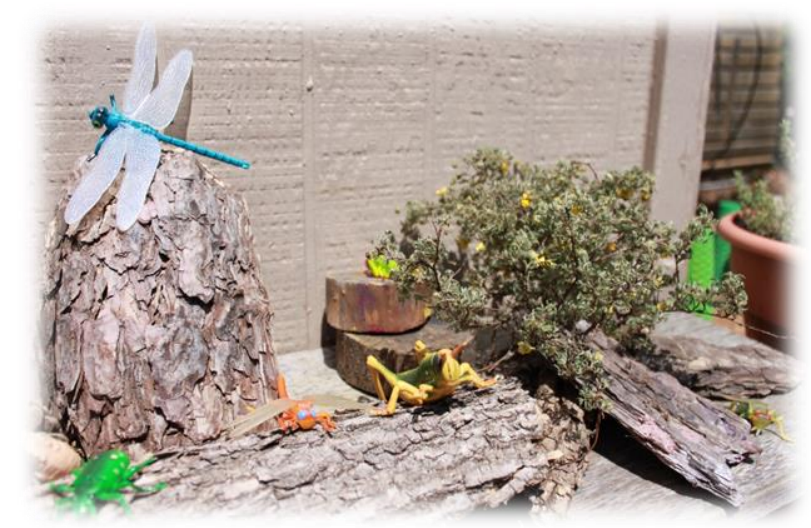

Figure 49. Bringing nature to Children: An

exploration of insects

Figure 49 illustrates the use of connecting children to nature in the invitations set out. This photo depicts the use of nature as part of the curriculum. Further, it depicts the use of natural items to enhance play.

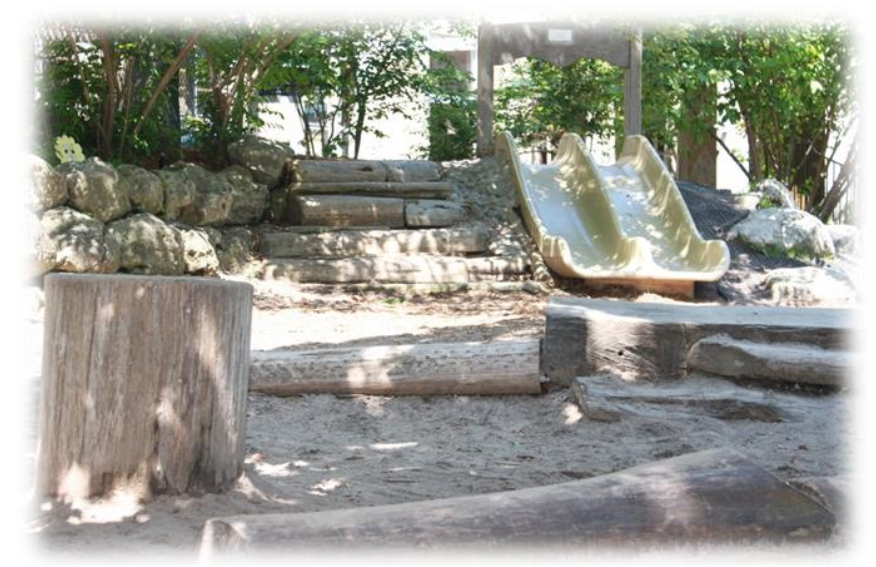

Figure 50. Natural playscapes: A playscape

replaces a traditional outdoor structure.

The majority of sites had removed their traditional commercial play structures and replaced them with a more nature-based alternative. The natural playscape depicted in Figure 50 provides evidence of the recent trend emerging from the data. The remaining one-third of sites that had traditional climbing structures indicated they were in the process of removing them and replacing them with a nature based climbing structure and playscapes.

This chapter discussed the findings as a result of this study that provided evidence of the translation of Reggio principles in natural outdoor learning environments. The following three 
Reggio principles were discussed and found translated in the environments, the environment as a third teacher, the hundred languages of children and the image of the child. Additional results indicated nature as a predominant presence both in the environment and curriculum as well as an extended learning area used in local green spaces. The following chapter will provide a discussion around the findings and implications for practice. 


\section{Chapter Five: Discussion}

This chapter will provide a discussion of this study's findings, focusing on the evidence provided in the translation of the principles of Reggio in Ontario natural outdoor environments. Photo documentation through visual research methods provided a valid and effective method to answer the research question. Reggio principles that emerged in the findings included the image of the child, the environment as a third teacher, and the hundred languages of children. Additional results revealed a significant presence of nature-based educational practices in Reggio-inspired settings. This resulted in the emergence of an additional theme: that of nature as a third teacher. Further discussion will include the parallels between and complementary nature of the principles of Reggio and nature-based education, and how combined together they can address the HDLH guide in effectively meeting the diverse and changing needs of children in Ontario. Limitations and future considerations to this research will also be addressed at the end of this chapter.

\section{Reggio Principles Observed Outdoors}

This research provides evidence of the translation of Reggio principles into outdoor learning environments. The use of photo documentation served to support the analysis and interpretation of these principles' transferability. This translation was consistently evident across all the Reggio-inspired settings examined in this study, providing implications for practice.

Each of the Reggio-inspired setting demonstrated evidence of the principle of the environment as the third teacher. This principle places significance on the richness of materials and spaces created. Gandini (2012) proposes "the structures, choices of materials and the attractive ways educators set them up for the children become an open invitation to explore. Everything is thoughtfully chosen and placed with the intention to create communication" (p.319). The outdoor environments in this study provided additional programming opportunities outside, as they were places of discovery and learning, and mirrored spaces typically created and found indoors. This was reflected as photos captured invitations and provocations for learning outdoors, as multiple experiences were set up throughout the outdoor learning spaces. The outdoor learning areas captured provided rich opportunities for play as part of an extended curriculum. 
Photographs taken in the Reggio-inspired outdoor environments provided further translation of this principle through the purposeful design of learning spaces, created as places for social engagement and small and large group gatherings. The schools of Reggio place special significance on the design of space and its ability to facilitate social interaction, as Reggio principles posit that children learn and construct new ideas both alone as well as in relation to others (Gandini, 2012). This was evident across the Reggio outdoor environments, as spaces were created to promote both small and large group play, as well as opportunities to be alone. The use of tree stumps carefully and strategically placed to be used as tables and chairs conveyed an invitation for small social encounters. Additionally, these spaces focused on aesthetics, as spaces were defined and augmented with the use of natural materials such as rocks, fallen trees, mulch, tree stumps, garden beds, and flowerpots. Large group areas were often defined through the use of fallen trees or boulders as an outline for gathering spaces. The thoughtful organization of materials and the use of aesthetics were demonstrated consistently throughout the outdoor environments.

Aesthetics are a significant component of the indoor Reggio environment. Part of the role of educators is to offer aesthetically rich environments that respond to children's aesthetic sensibility, and communicate value for children and their process of learning (Vecchi, 2010 as cited in Keyte-Hartland, 2010). Educators consider the use of light, colour, softness, sensory and rich materials as a way to support children's cognitive processes and ways of learning (Gandini, 2012). This was seen through the use of beautifully arranged rich materials offered to children, creating surprising and stimulating invitations in the environment. Photo documentation illustrated the translation of aesthetics, as it was communicated through thoughtful consideration of the design of the environments across sites.

The use of these materials enhanced the outdoor environments and children's learning. The strategic placement of hanging wind chimes, fabrics, reflective pieces, and art served to demonstrate the teachers' understanding of this principle. These materials offered an abundance of sensorial aspects, which is an inherent element of the indoor Reggio space and was translated into the design of the natural outdoor Reggio-inspired environments. Indeed, the aesthetic value was abundant in the use colour, light, shadows, sound, and fragrances in the gardens and outdoor environments. This use of rich materials and planned experiences help educators to meet children's diverse needs. 
The translation of the principle of the hundred languages of children was also demonstrated, again in the carefully planned outdoor environments. Although similar indoor spaces are predominant in most early learning environments, outdoor environments rarely reflect this principle. The creation of inviting spaces, providing opportunities to explore dramatic play, sensory, construction, loose parts, art, and music were seen throughout the Reggio inspired outdoor environments. These areas in Reggio environments are considered ateliers, or places for children's rich and varied research (Gandini, 2012). Through the use of the ateliers, children are encouraged to construct knowledge and communicate their understanding through the various areas and materials provided. This can be viewed an opportunity for children to explore and communicate the multiple languages and expressions of learning within the outdoor environment. This principle was consistent across settings, as all the outdoor spaces reflected this principle in the photo documentation. The use of ateliers in outdoor spaces allowed for children to follow their own interests and direct their own learning. This supports the image of the child as capable and competent. In this regard, children are viewed as having power in decisionmaking and in making choices to direct learning. This addresses the principle of the image of the child as an equal member in the learning community.

In Reggio, children are seen as active contributors to the process of learning, and are constructed as rich in potential, strong, and capable (Rinaldi, 2012). The principle of the image of the child was also translated in the outdoor environments. The outdoor learning environments offered opportunities for children to demonstrate capability, potential, and strength. The outdoor spaces studied communicated this belief in children's competency by the choices of materials and challenges offered within. The Reggio outdoor environments presented several challenges in their physical spaces, not typically observed in most early learning settings. Photographs captured alternative challenging equipment, including the use of fallen trees for balancing, boulders for climbing, and alternative climbing structures seen in the use of recycled tires. These were interpreted to communicate held beliefs of children's capabilities and competencies. "The environment you construct around you and the children also reflects this image you have about the child" (Malaguzzi, 1994. p. 1). The view of the competent and capable child was also seen through the materials provided, such as real tools and gardening materials, as children were encouraged to contribute to the space in meaningful ways. Overall, the environments offered rich materials and choice that speak to the children's sense of autonomy. 
In the words of Malaguzzi, as cited in Gandini (2012), “we value space because of its power to organize and promote pleasant relationships [...] We also think it has been said that the space has to be a sort of aquarium that mirrors the ideas, values, cultures of the people who live within it" (p. 339). I interpreted the photos through this lens, taking the outdoor environments to be a reflection of held beliefs and values. Consistent across all the Reggio-inspired environments was the high value placed on the outdoors environment as a critical component of learning. Children's interest and various modes of expression were supported through these engaging environments, rich with materials and choices. The use of provocations and invitations to learning, encompassing many aesthetic qualities were offered throughout, which supported the children's learning, interests, and showed the potential of the outdoor environment in the curriculum offered.

These findings provided evidence that the principles of Reggio can be translated outdoors, and photo documentation captured thoughtful considerations of space and design incorporating various Reggio principles. Children were offered challenging and engaging environments that were respectful of their choices and the learning process. The Reggio principles of the environment as a third teacher, the image of child, and the hundred languages of children were all visible through photo documentation, showing the value and possibility in creating rich outdoor learning environments for children.

Photo documentation facilitated the analysis of the theories of Reggio and how they may be translated outdoors. Photo documentation mirrored the Reggio principle of pedagogical documentation in many ways, and helped in constructing an understanding of the translations of the principle of Reggio in outdoor environments. Dahlberg (2012) proposed that, through pedagogical documentation, educators can challenge the usual frameworks of beliefs or habits of mind. Prosser (2007) advocates that photographs allow the researcher to see hidden habits of mind within schools, which he calls the "hidden curriculum" (p. 14). With this in mind, I approached the photos as having more opportunity for interpretation than what was physically seen.

As photos were the only source of data, the images were analyzed to see how theory is translated into practice in the outdoor environment. It was my belief that the photographs may assist in providing evidence of the presence of Reggio theories or principles. The analysis of the photos allowed me to step outside my practice, slow down, and explore the photo documentation 
critically. This was considered a strength to this approach as it allowed me to consider what the images communicated through the intentions reflected in the spaces created and the materials offered. Dahlberg (2012) refers to pedagogical documentation "as the process for making pedagogical (or other) work visible and subject to dialogue, interpretation, contestation and transformation" (p. 225). It was in this process that meaning was made and that connections to the principles of Reggio were seen. The photo documentation used in this study was helpful in analyzing the data, but was also complementary to the principle of Reggio that contends pedagogical documentation as a valuable learning and teaching tool. Visual research methods using photographs as data and photo documentation to support the analysis of findings was an effective tool to assist me in answering my research question. Further, this tool was consistent with my conceptual framework, in that it allowed the construction of meaning.

Further exploration of the photo documentation provided evidence of the emergence of a new theme: the consistent and significant presence of nature and nature- based education practice embedded across the outdoor environment and in the outdoor curriculum. The Reggio-inspired outdoor environments placed significance in providing children with a variety of nature-based experiences, as the sites relied heavily on natural elements both in their design and in the materials provided. Moore (2014) contends that natural settings are rich in endless play opportunities. Nature play is fundamentally engaging and open-ended, and allows children to develop a sense of awe and wonder for the natural world (Moore, 2014).

Observed and documented through photos was an abundance of nature and natural materials used to support and design the environments. Spaces were often open-ended and childdirected. Children could explore the gardens offered and had opportunities to water, mend, and tend to the gardens by choice as materials were often left out for child-initiated choice. Ernest (2014) contends there must be efforts to incorporate natural elements into the design of early educational settings, as natural environments and gardens hold endless possibilities. Gardens provoke children's curiosity and act as provocations to investigate through play and inquiry. Contact with nature enriches the sensory imprint in childhood memories, through the sights, smells, tastes, colours, and textures it eludes (Ernest, 2014).

This was seen throughout the Reggio settings, as photos captured nature being at the core of the experiences provided, and as provocations and invitations often accompanied nature and natural materials. In the Reggio-inspired natural outdoor learning environments, the aesthetic and 
sensorial elements included the use of a variety of garden beds throughout, raised and at ground level for various heights and explorations. The gardens often included rich green foliage, native plants, vast colorful flowers, fragrant herbs, and luscious vegetables. There gardens were a significant presence in the environments, and were indications of curriculum choices and environment design.

Nature is part of the curriculum, with bug investigations, sensory exploration of sand, water and mud to be explored or combined with other areas, etc. The use of natural loose parts such as rocks, leaves, twigs, tress-cookies, and bark were additional natural elements found in the environments. These capture and capitalize on the aesthetic value of nature and the multisensorial elements within it. Photographs captured a significant presence of such materials that could not be ignored. The curriculum and the natural environment communicate the importance of nature, embracing the environment as a third teacher and the hundred languages of children naturally and effortlessly. Children have vast opportunities to learn in and with nature. In addition, nature holds many aesthetic qualities, adding to the elements of the environment and contributing to its richness. Here again, the principles of Reggio work and complement one another in offering a rich, lush and engaging environment that focuses on natural aesthetics from the environment and opportunities for learning that hold nature as a core element.

North American trends in ecological education address the need to connect children to nature in a variety of ways (Frumkin, 2014). This was demonstrated throughout the early learning settings. Nature was part of the curriculum in the many experiences offered outdoors, as well as through the rich natural environments created for children. The use of nature and its aesthetic sense appeared to complement the Reggio principles of the environment as a third teacher. This suggests an ease of transferability in these approaches, both due to the thoughtful provocation of nature and the inherent aesthetic value that it offers.

Photo documentation captured further connections to nature and the principles of Reggio in the forest and nature schools. Indeed, the self-identified Reggio-inspired forest schools were welcoming, thoughtfully planned, and engaging. The forest school principles complemented the principles of Reggio, as the child is viewed as competent, capable, and as a contributing member. Photos captured the use of unique challenging terrains, choices of experiences, and real tools. This provided evidence for the image of the child as competent and capable in the forests school setting. The opportunities presented to children were vast and spoke to the hundred languages of 
children. In their experiences in the outdoor learning environments, children used the natural materials offered throughout the forest and nature settings. These included large branches for building, and naturally found loose parts such as twigs and stones, which were added to extend play and explorations within the forest settings.

The principle of the environment as a third teacher was present in the spaces defined by nature, as well as in the varied opportunities for exploration made possible. The aesthetic qualities of the forest lend themselves to a sense of wonder and embrace the principles of Reggio. The movement of the trees glistening in the sunlight and the soft reflection of shadows offer a full sensorial experience in the forest. The forest, the trees, the leaves, stumps, mud, and water edges all offer a natural aesthetic sense. Nature can be seen as another language for children to explore, invent, discover, and construct knowledge, holding endless possibilities. In the forest schools, children have opportunities to develop a connection and bond with space. Frumkin (2014) contends that educators need to provide children with natural outdoor settings and support the development of emotional bonds with nature, in order to instill a fascination, appreciation, and protective relationship with it. Frequent nature experiences and becoming familiar with the natural world creates a positive ethical responsibility. Rich natural outdoor environments heavily situated in nature and nature play can support children in developing an emotional bond with nature.

In addition the research revealed that half of the sites attended local green spaces as an extension to their regular outdoor programs and curriculum. This can viewed as additional connections to the natural world. Sobel (2004) recommends this practice of connecting children to local space in place-based education. He asserts this supports children's connection and bond for the planet, and in turn supports future stewardship. He argues that children need opportunities to develop relationships with the earth through touch, sight and smell. Pelo (2008) agrees that in supporting children in developing an ecological identity and love of the earth, they need repeated experiences in their local areas. She believes our work as educators is to give children a sense of place as an extension to curriculum (Pelo, 2008). Connecting children to their backyards, green space, and forests adjacent to early learning sites can support this idea and support the children's development of love and care for local spaces (Pelo, 2008).

This research study suggests a possible trend emerging in Ontario settings, as all sites had placed significance in connecting children to nature in a variety of ways. The first way was 
increasing the amount of natural elements in the settings, and the second was bringing children to local green spaces, which half of the twenty sites sought to do. Exploring this pedagogical shift further in future research may provide insight into this new pedagogical practice, and deepen understanding in this area. The connections and similarities between the principles of Reggio practice and nature education should be further explored as this research saw important connections and parallels between these two practices.

These approaches appeared complementary to the principles of Reggio as they build and enrich each other. The principles of the environment as a third teacher, the image of the child as competent, and the hundred languages of children were expressed in both the Reggio-inspired settings and through the nature based approaches. Further, nature appeared to act as a third and infinite teacher in all sites.

In connecting the principles of Reggio practice and nature-based education, a holistic approach to outdoor natural environments and curriculum is observed. A holistic approach to education encompasses relationships among various domains and ways of knowing and supports relationships between thinking, the mind, body and relationships to others and the natural world ((Miller, 2007). An approach that respects the child as competent and capable, by providing challenges that recognize the child as rich and full of potential, an outdoor pedagogy that embraces the environment and nature as the third teacher and supports the diverse needs of children through the hundred languages. This becomes a space rich and diverse in possibilities, learning areas, and experiences. This pedagogy can provide a continuum of indoor and outdoor experiences, with provocations to promote inquiry and investigation through a rich and engaging environment.

This pedagogy embraces the principles of Reggio in the outdoor environment and places significance in connecting children to nature in two fundamental ways. First, in bringing nature to children through naturalized playgrounds and curriculum. Secondly, by bringing children to nature in local green parks, forest, and naturalized areas. This pedagogy of outdoor natural play and Reggio principles can work together to create optimal learning experiences for Ontario's children, creating an overall pedagogy that is both context-specific to each setting but also in line with Ontario's vision for the early years.

Reggio is known for its quality in indoor environments, and this research demonstrates the possibility of the translation of the principles of Reggio in the outdoors. Further, these 
principles not only can be translated but also applied and re-invented to be meaningful into each specific context. For this is what Reggio provides, inspiration to make anew. Barrett \& Scott (2012) argue the need to explore the full potential of quality outdoor experiences, rich in opportunities that place nature as a core element. This is possible with the exploration of outdoor natural environments that embrace the image of the child as rich and full of potential. This also offers opportunities for rich sensory natural environments with a focus on providing an emerging curriculum based on children's innate desire to investigate. These outdoors environments can become more than opportunities for gross motor play, while still providing an ideal context in which to construct knowledge with others.

This can be achieved through a curriculum that is authentic, purposeful, and meaningful based on children's emerging interests and their many modes of expression. The same purpose and thoughtful intent that is considered indoors has the potential to be translated outdoors. The environment can offer a multitude of learning areas or mini ateliers to allow children's expression and cultivation of their many interests and languages. The outdoor and indoor curriculum builds upon one another, extending and bridging to provide seamless investigations. Provocations and invitations provide places to begin in the search of children's interests and work to extend the curriculum. These environments are responsive to children's needs and build on the image of the child as capable, competent, and a contributing member of the community.

Merewether (2015) proposes that outdoor environments should be thoughtful educational environments with vast opportunities provided to meet children's diverse needs and the opportunity for the interdependence of themes. In creating meaningful outdoor learning environments, educators must consider various aspects. The environment can viewed as rich and full of potential and offers children a variety of experiences to explore the hundred languages of children.

Herrington \& Lesmeister (2006) contend that learning areas must be flexible, manipulative, and offer children the ability to modify and extend learning through combining areas and materials. Children are offered areas to mess, dig, and explore water, sand, and other manipulatives while addressing children's sensory learning needs. This combining of materials to enrich and extend play offers children the ability to leave impressions of play and take an active part in creating spaces of their own that are meaningful to them in the environment. This 
was demonstrated with the addition of loose parts to play throughout the outdoor environment, seen as opportunities to enrich and extension children's play.

The opportunity to create, combine, and construct was captured in the various outdoor loose parts offered outdoors. Many of the sites represented this concept with the creation of small and large structures for children to create homes. Children become masters of their classroom and the uses of such mini ateliers provoke meaningful engagement. Children become invested in social and emotional ways as they add to the physical environment and are viewed as contributors to the space. Merewether (2015) maintains that opportunities for dramatic play in the outdoors inheritably provide the freedom to move in large unencumbered ways. Large open spaces for dramatic play with the use of natural elements and loose parts enhance the potential for imaginary play opportunities and enrich children's creativity and inspiration (Merewether, 2015). In Reggio-inspired natural playgrounds, the combined use of large and small natural loose parts and malleable materials offered ample opportunities to enrich the play and extend play possibilities, particularly in dramatic play. These natural spaces provide freedom to explore while at the same time offer serenity and peace, with a unique combination of natural and sensory experiences. These sensorial elements shape dramatic and imaginative play and enrich children's experiences (Ernest, 2014).

Merewether (2015) also recommends that outdoor environments should provide spaces for social and intimacy in partially closed areas. Intimate areas not only inherent in design principles but also in pedagogical approaches. A pedagogical perspective such as the one demonstrated in this study offer spaces created for social encounters, and supports the social constructivist approaches to learning. In this, environmental design place value on social interactions to enhance learning. Further, it recognizes and respects children's desire to want to work alone or in small groups.

In many ways, nature as the third teacher provides vast and endless opportunities for discovery and active explorations. The environment as the third teacher can be purposefully applied outdoors. In this, children have opportunities to experience and connect with nature in the outdoor learning environments and in engaging in regular outings with and in nature. This development of nature-based educational practices has occurred outside environmental education, and can be seen developing across the early learning sector, in particular across Ontario as this study illustrated. This study illustrated the connections to natured-based education 
and the principles of Reggio are complimentary and can build and enhance one another. The examples of these two approaches working together illustrate the compatibilities and offer new understanding of the possibilities of outdoor education. Early childhood education has an important role in establishing firm foundations for responsible future stewards; it is through carefully planned curriculum and environments situated in nature that embrace these two approaches that this can be realized. Together, these approaches can address and strengthen Ontario's vision for the early years.

\section{Implications and Possibilities for Practice}

The Ministry of Education's (2014) HDLH guide encourages educators to engage in ongoing critical reflective practice. In this, it offers the foundations of learning: belonging, well- being, engagement, and expression to support children in learning and optimal health and development. The foundations of learning as expressed in the guide can support educators in planning and creating environments and curriculum to better meet children's needs. The guide explores the significance of quality, positive, stimulating, and engaging environments to support the healthy development of children.

The HDLH guide suggests that space speaks and that as educators we must begin an educational discussion around the physical environment, both indoors and outdoors (Ministry of Education, 2014). The guide suggests that educators view themselves as researchers and coconstruct what the environments may convey. It cautions against the idea of superficial decorating of environments but, rather, advises educators to engage in the critical analysis of the environments and what these environments communicate. In this, it invites educators for a commitment to strengthen the quality of practice in the early years (Ministry of Education, 2014).

This research considers the potential to address this opportunity in the outdoor learning environments, by exploring the potentials of outdoor spaces, as rich opportunities for learning. The research found that the principles of Reggio could be translated outdoors and, further, that these opportunities, in combination with nature-based education, offer potential for enriching outdoor programs. Many of the principles outlined within the HDLH guide resemble theoretical foundations similar to those found in the educational philosophy of Reggio Emilia. In light of these connections, this research could be applied and viewed as a complementary resource in the early years. The HDHL guide can encourage discussions about the outdoor environment and the 
significance of connecting children to nature in the early years pedagogy. However, the document fails to offer specific pedagogical approaches that may address this significance.

The HDLH guide probes educators to consider a pedagogy that nurtures inclusive learning environments that support inquiry and consider planning and creating environments as a third teacher. Callaghan (2013), a contributor to the HDLH suggests the environment is a third teacher and that it communicates messages through spaces, materials, and time. "The environment as a third teacher has the power to mirror the values, attitudes, beliefs and cultures of those that use the space" (Ontario Ministry of Education, 2014, p. 20). In addition, the HDLH offers a more complex view of the child, through careful consideration of creative, aesthetic, and spiritual dimensions in addition to the traditional domains as evidence in the following statement "each child's unique spirit, individuality and presence are valued" (Ontario Ministry of Education, 2014 p. 24). The HDLH invites educators to explore more complex views of children, promoting rethinking of theories and views held (Ontario Ministry of Education, 2014).

The HDLH guide recognizes the value of play and nature, and proposes that children need opportunities to interact with the natural world on a daily basis, to enact a sense of joy and relationship with it. This vision for Ontario's early years pedagogy recognizes the need for children to develop a sense of belonging to the natural world. It suggests that daily opportunity to engage in and make connections to the natural world support children's development and connection to the community, natural environment and all living things (Ontario Ministry of Education, 2014). It calls on for growing research to suggest that connections to earth contribute to children's mental, physical, emotion and spiritual health and well-being. It states that children need opportunities to recognize, explore and make connections to the natural world, as children thrive in natural outdoor spaces that present manageable levels of challenge (Ontario Ministry of Education, 2014). The HDLH seeks to create meaningful, safe, and stimulating environments, and has recognized that many outdoor spaces have removed playgrounds in favor of natural ones. It proposes that a carefully designed outdoor environment can be an opportunity for the expression of a child's full body and places of discovery and learning. 


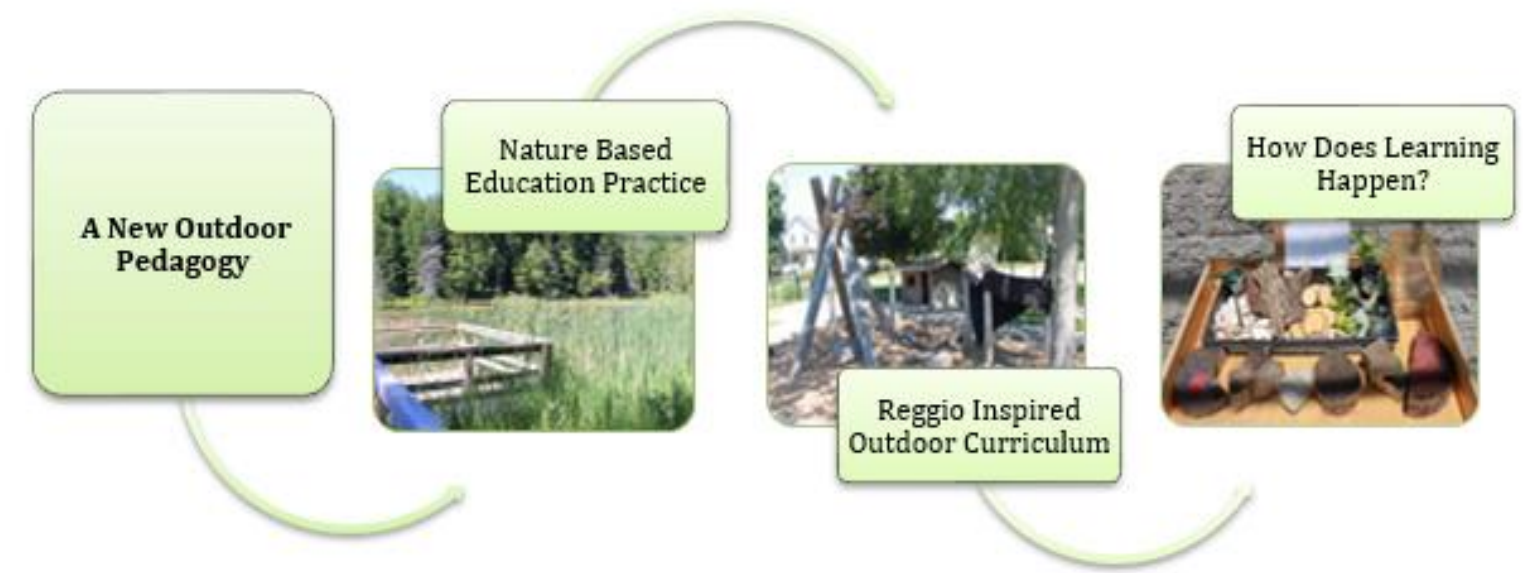

Figure 51. New outdoor pedagogy: The combination of approaches builds on one another to create a new pedagogy

The principles of this document closely resemble those of the principles of Reggio, and address the similarities of these two perspectives while considering the importance of connecting children to nature. Therefore, this research proposes that, through the complementary approaches of Reggio inspired outdoor environments and nature- based education, an outdoor pedagogy supporting the vision of the early years in Ontario can be built (see Figure 51).

Together, these approaches merge to create a meaningful, relevant early learning outdoor pedagogy for Ontario; one that embraces the significance of the environment as a third teacher, promotes the hundred languages of children, and the image of the child as competent. This, combined with North American initiatives and pedagogical practices of connecting children to nature, embody the principles reflected in the HDLH document. This research provides the opportunity to begin critical discussions and reflections on early learning environments. It can begin to support educators in re-conceptualizing the role of outdoor environments as an effective contributor to enhancing children's development. Figure 52 illustrates results from this research, and provides recommendations for practice that can be applied in all outdoor learning environments throughout Ontario. 
- Image of the child as strong capable, competent and rich in potential:

- Provide alternative challenging materials and structures to demonstrate competency: fallen tree logs, tree stumps, loose parts for construction.

- Manipulation of space

- A valuable contributing member of community allows children to demonstrate competency with real tasks, gardening, watering gardens, using real tools

- Allow children's choice, independence

- Provide natural materials, garden spaces and connections to natural world through local natural play space

- Connecting to space-local community/green spaces

\section{Belonging:} Sense of connectednes5 to others, relationships to Indmiduals, group and natural world. Contributing and valued member.

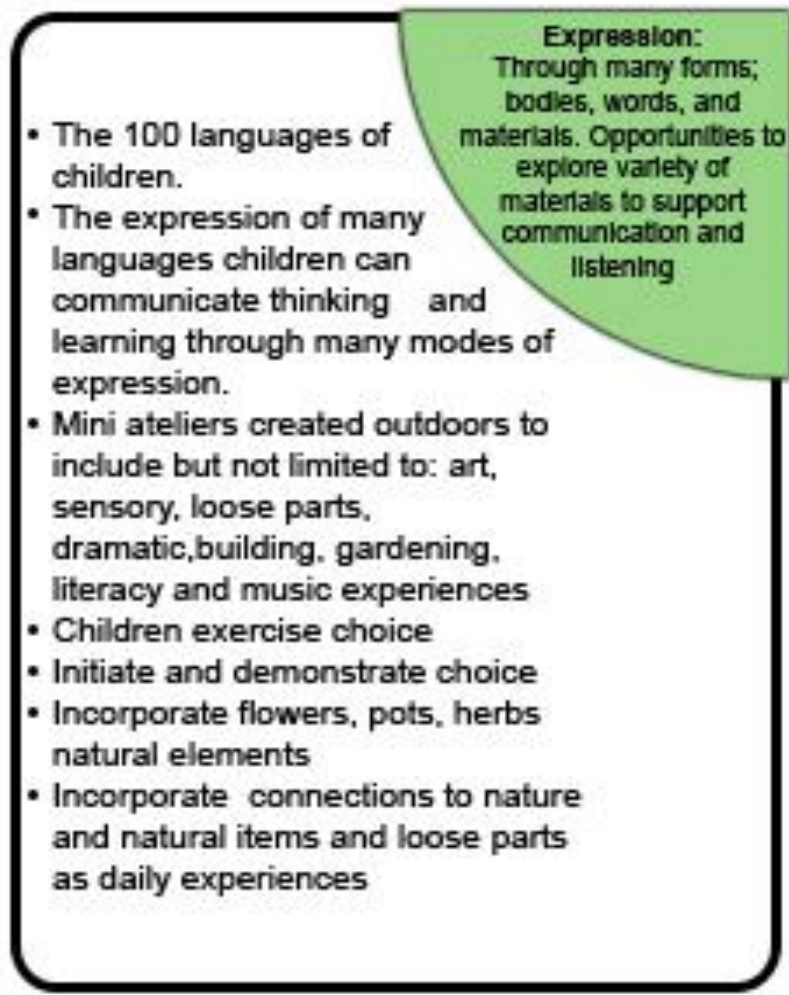

- The image of the child supports the postive development of self

- The Environment as a third teacher supports the development of self through choices and relationships to others and materials provided

- The 100 languages of children supports children's holistic development

- Nature as central component all work together to meet children's diverse developemental needs.

- Connections to nature, care of garden. plants and developing a sense of place contribute to development of self

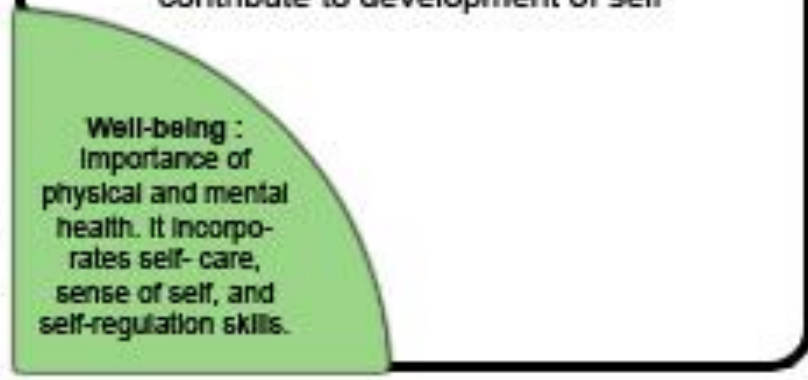

\section{Engagement :} Involved and focused. Explore the world with natural curlosity through play and inquily. In the - The enwircnment as a third teacher, opportunitles to engage in emvironment rich in materlais that support inquiry development of whole Indoors curriculum. Provide child. - interesting materlals as forms of provocations and lnvitations - Consider children's aesthetic sense, olfer and arrange an enviomement of beauty, provoking materlals in pleasent unexpected ways. Use of decor, art, fabrics and sound outdocrs

- Incorporate flowers, pots, herts natural elements

- Incorporate connections to nature and nabural items and loose parts, as dally embedded curriculum and experiences

Figure 52. A proposed Ontario outdoor pedagogy for the early years: A pedagogy embracing

Reggio principles and nature-based education in Ontario. 


\section{Limitations \& Future Considerations}

This research offers some examples of the richness and possibility of practice in natural outdoor learning environments for Ontario. It provides an essence of what can be translated in the outdoor environment. This research addressed the possibilities and potentials inherent in addressing Ontario's vision for the early years, through the proposed Ontario outdoor pedagogy for the early years resulting from this study.

Through visual research methods, photos captured the translations of the principles of Reggio in outdoor learning environments in Ontario. Further, it revealed that, within these environments, nature-based educational practices were found and complementary in values and practice to one another. These together with the HDLH guide, provide a proposed outdoor pedagogy for Ontario.

The strengths in using visual research methods are that they offer a wide range of possibilities. The need to address the topic further can be explored through other approaches to add and enrich these perspectives. Visual research methods can be seen as an effective approach in understanding outdoor learning environments, as visuals offer a perspective of being in the space and are effective representations of those environments. The use of this method offers a rich and sensorial representation through photos. To add to this research, further visual research methods could include participatory visual research methods including the perspectives of educators and children. Through this, interpretations of the images captured could offer additional perspectives about these spaces.

Valuable additions to this research could include teachers' and children's perspectives of the outdoor learning environments. Although the teachers' stories were not part of the research approach; the stories shared as we toured the sites were valuable and enriched my experience and understanding of the spaces, children's inquiries, and the significance of those encounters. Future research could include educators' perspectives on the outdoor environment, through interviews and/or site observations. This would be a valuable component in understanding how teachers' beliefs play a significant role in designing outdoor learning environments.

An additional limitation of this research was the lack of understanding the intention of chosen materials and the set-up of materials provided. My research could not provide an understanding of the choice of materials in relation to children's interest and emergent curriculum. To understand this perspective more, an exploration of the emergent curriculum 
process and child-led investigations is needed. Photos told one story, of the essence of these environments and how the principles of Reggio can influence design and the selection of materials and aesthetics choices. To add to this research, an understanding of how or why materials and spaces were offered and created would strengthen these findings. This could be in the form of educator interviews, and child observation in the spaces. This could contribute to further understanding the intentions behind the creations of space and the materials and choices provided. Observing children in child-initiated and child led experiences could allow for deeper understanding of the intentionality behind the creation of space and the emergent curriculum cycle. Additionally, it could address the child's perspective in the natural outdoor environment and offer multiple viewpoints.

A copy of the photos in a CD format was provided to each participant site. This served to validate the accuracy of photos, but also further to encourage the beginning of discussions about the spaces photographed. The photos can provide a starting point or continue discussions, as site educators can begin their own form of teacher research. Given the current climate of change in Ontario early years context, more exploration of this topic is warranted. This research can be seen as a preliminary exercise in addressing this current gap of literature in Ontario, as more research including outdoor environments is needed from a Canadian perspective.

Lastly, another limitation of visual research methods was the cost of photo documentation, which was high, particularly when printing numerous images. Although helpful and necessary in the analysis of data, the cost could be cumbersome for some researchers. This would be a consideration in publication, as online publication resources may serve best to share this research and others that use visual research methods, particularly those that subscribe to the use of colour photos to enhance the presentation of data.

This research adds to the literature on outdoor environments and pedagogy from the perspectives of Reggio and nature-based education. It proposes the possibilities of this practice in complementing and building upon the new Ontario early learning framework. Future considerations in creating a comprehensive Ontario outdoor pedagogy for the early years would include changes to teacher education and early childhood programs within post secondary institutions. These post secondary institutions can include curriculum on nature-based approaches and designing natural environments such as playscapes. Additionally, a bridging between environmental design programs and early childhood education programs could create 
further knowledge in this area, as these two fields of study could complement one another. In this, both fields will be equipped with the tools and knowledge to better meet today's changing landscape in early childhood environments. Finally, there is a need to develop an outdoor pedagogy in Ontario, as seen in other countries and provinces. Government interest in creating a clear outdoor pedagogy is necessary to establish the significance of both quality outdoor natural environments for children in the early years, and in the movement to connect children to nature. This will serve to better meet children's diverse needs through a holistic and comprehensive outdoor pedagogy now and for future generations to come.

\section{Conclusion}

An outdoor pedagogy inspired by the principles of Reggio and nature-based education can fully met the Ontario provincial vision for the Early Years. It is not a model to follow, but rather a philosophy to inspire. Connecting children to nature and the principles of Reggio is a philosophical perspective to deepen our practice and inspire our teaching in a realization of the full potentials of outdoor pedagogy. Connecting the principles of Reggio and the North American pedagogies of nature-based education is reflective of the vision of the Ontario early years sector. It addresses the changing landscape of education and the importance of connecting children to nature. The nature movement will continue to inspire, influence and create change in the landscape of early childhood education, in similar ways as the philosophical educational practices of Reggio Emilia have across the world. These two influences are supported in the HDLH guide, providing a promise for change across Ontario. This research hopes to inspire and create change in early childhood education in addressing the potentials of practice in outdoor nature-based pedagogy. This is essential to the realization of the very best in educational practices for Ontario's children. It is intended to provoke an investigation into Ontario's educators' views on the potential of enriching outdoor learning spaces. It is dependent upon each early learning context, community, and the culture inherent within. No two could be the same nor should they, but similarities in their core underlying principles are seamlessly embedded throughout. The bridging of the two pedagogies is fundamental and necessary for the future of Ontario children.

Returning back to the poem written by Loris Malaguzzi (as cited in Gandini, 2012. p. 4) (see Figure 53) that so eloquently provided understanding to the theories and principles of Reggio, we see that the photo documentation shares the realization of the potential of Reggio 
natural outdoor learning environments in Ontario. Embracing these approaches can meet children's diverse needs, and address the hundred languages of children in and through natural outdoor environments. Through this merging of new possibilities we can articulate along with the children represented in the poem "No way... the Hundred is there", outdoors, in every environment, in the possibility of an outdoor pedagogy for Ontario.

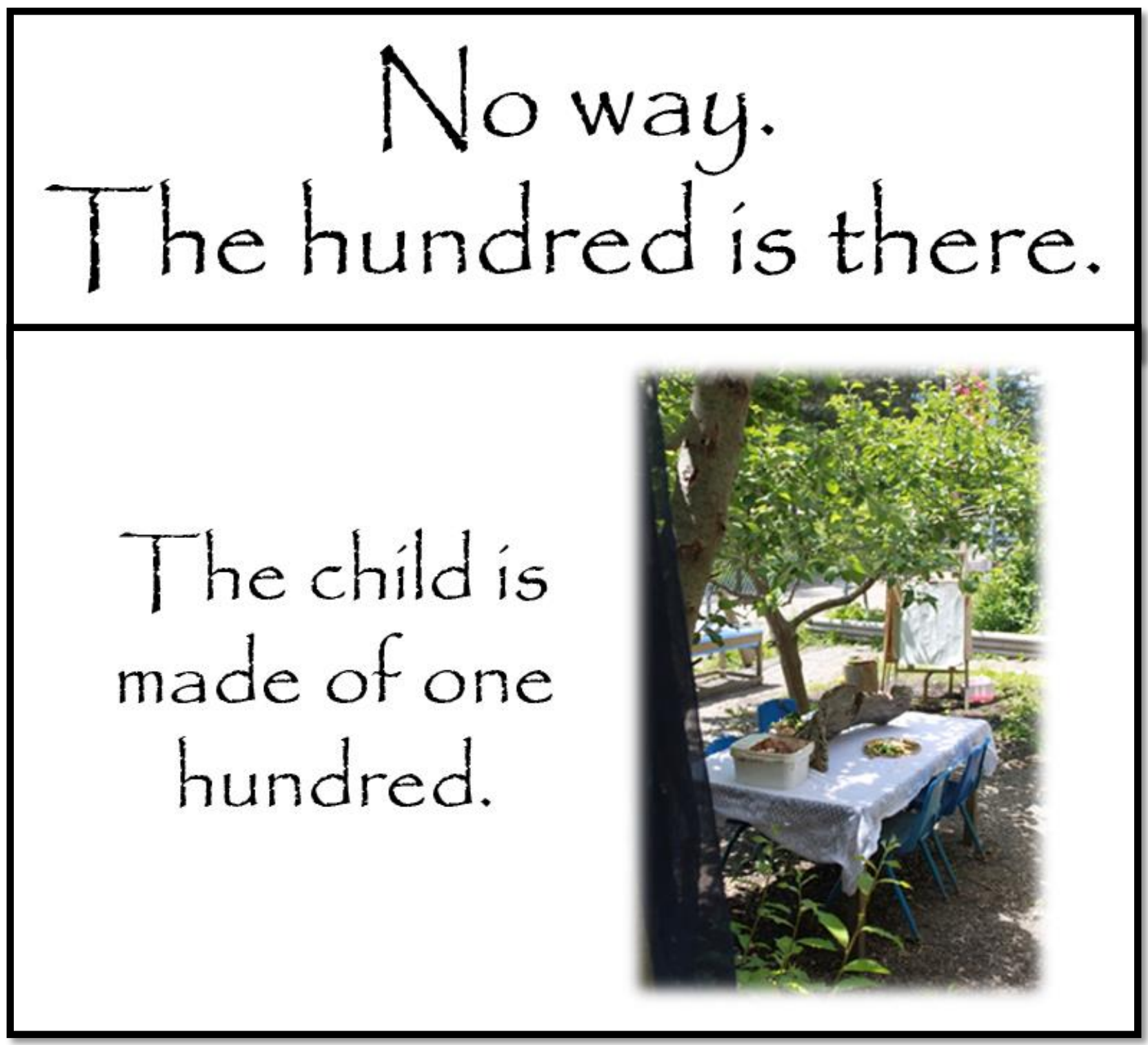




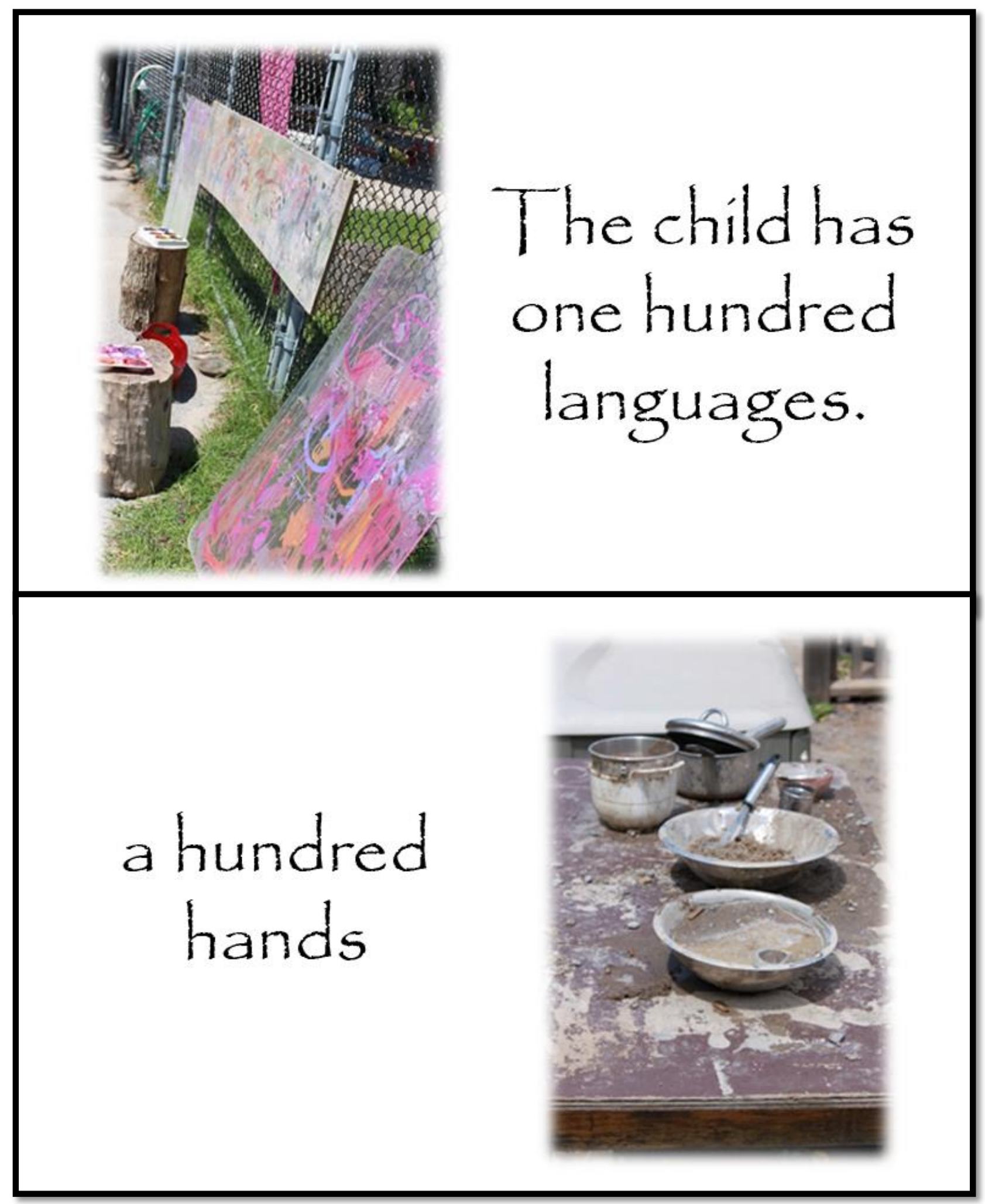




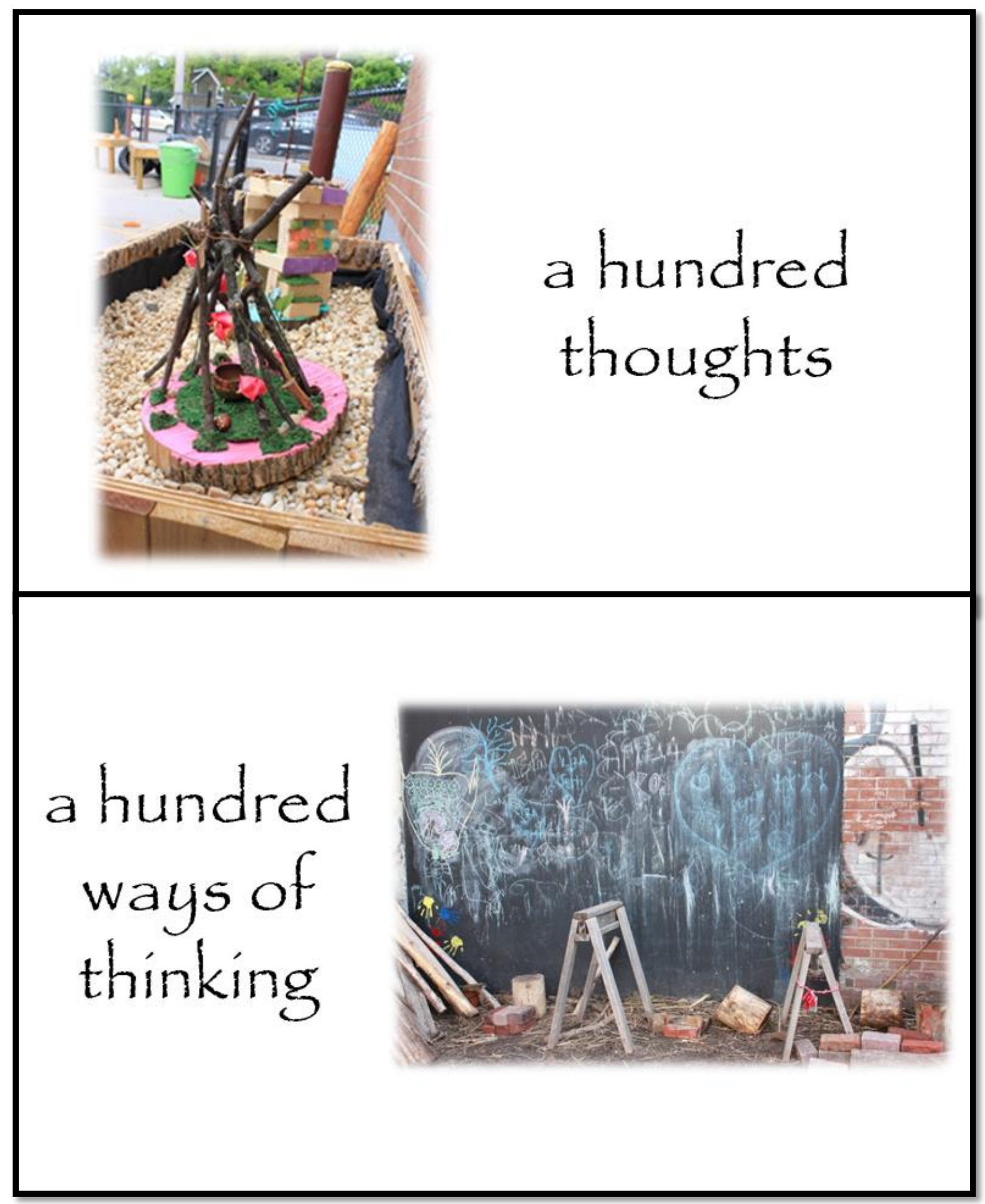




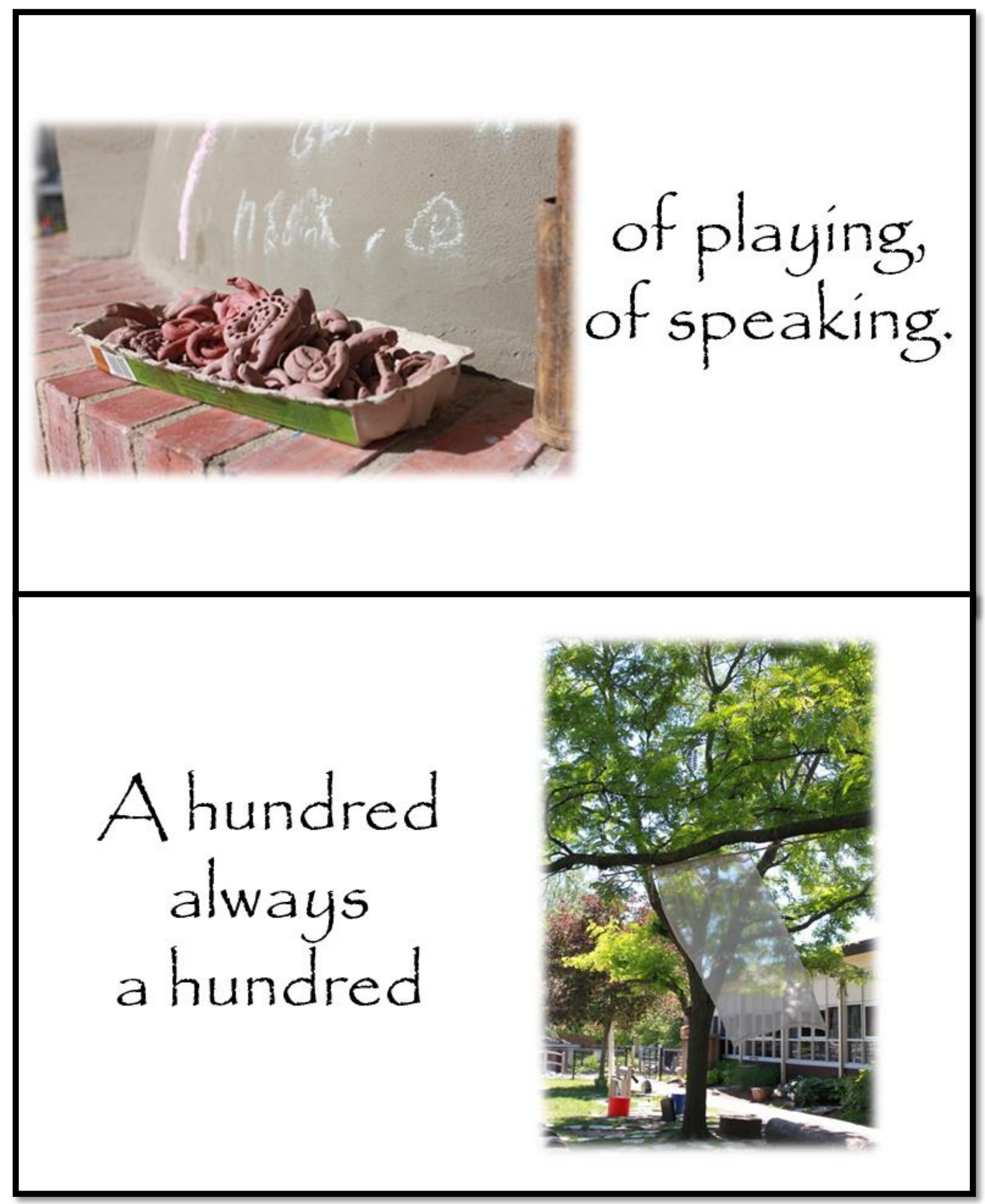




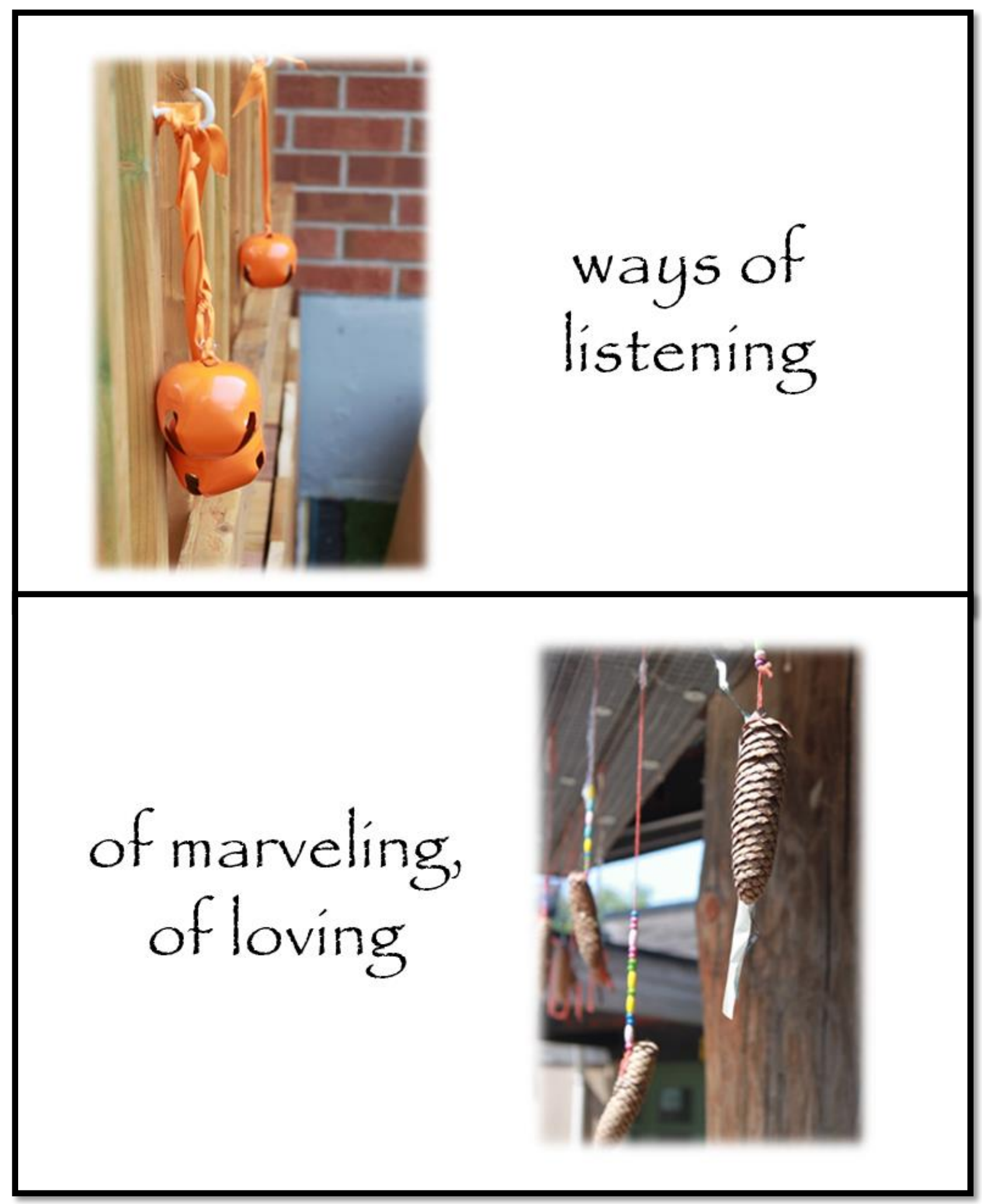




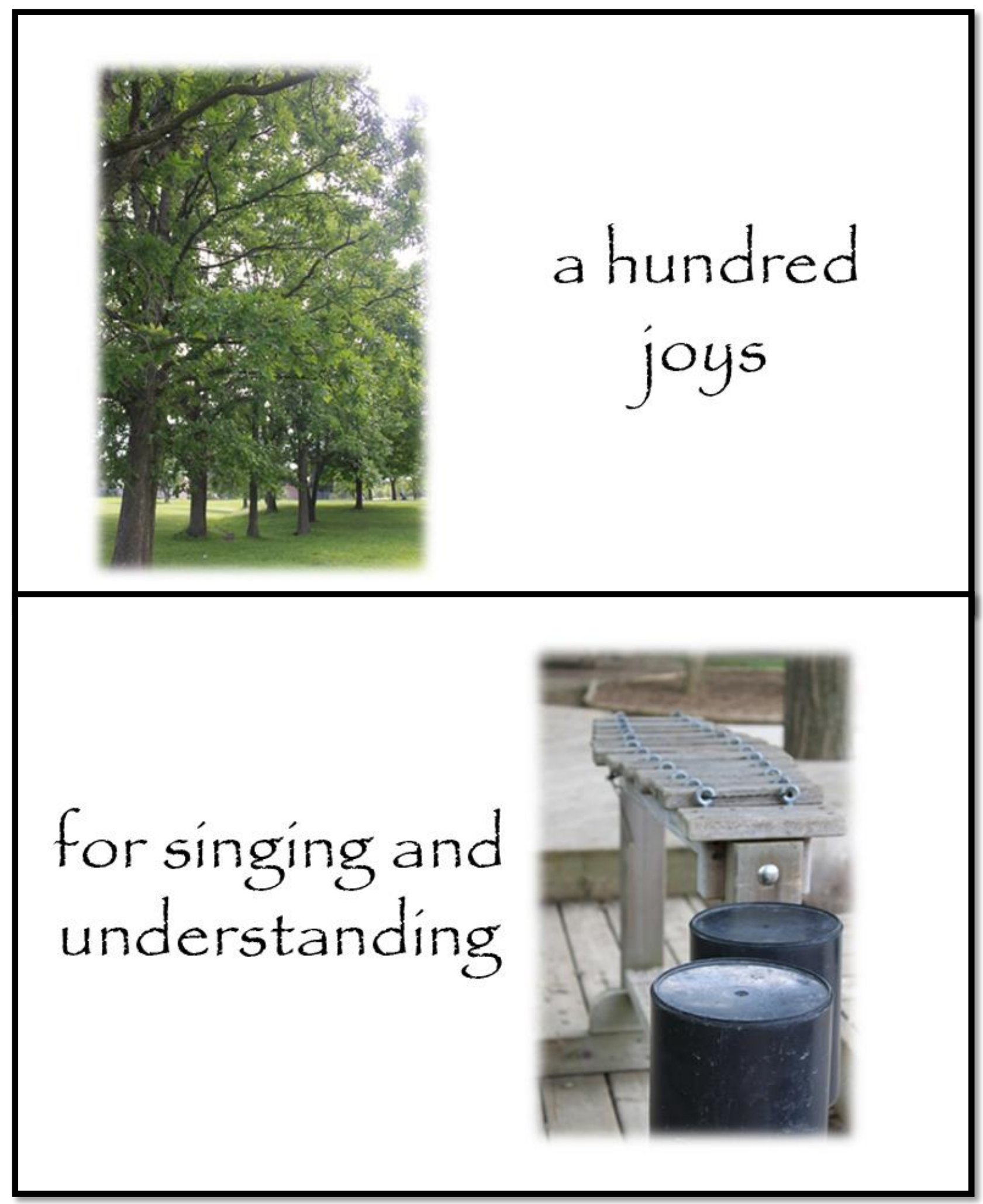




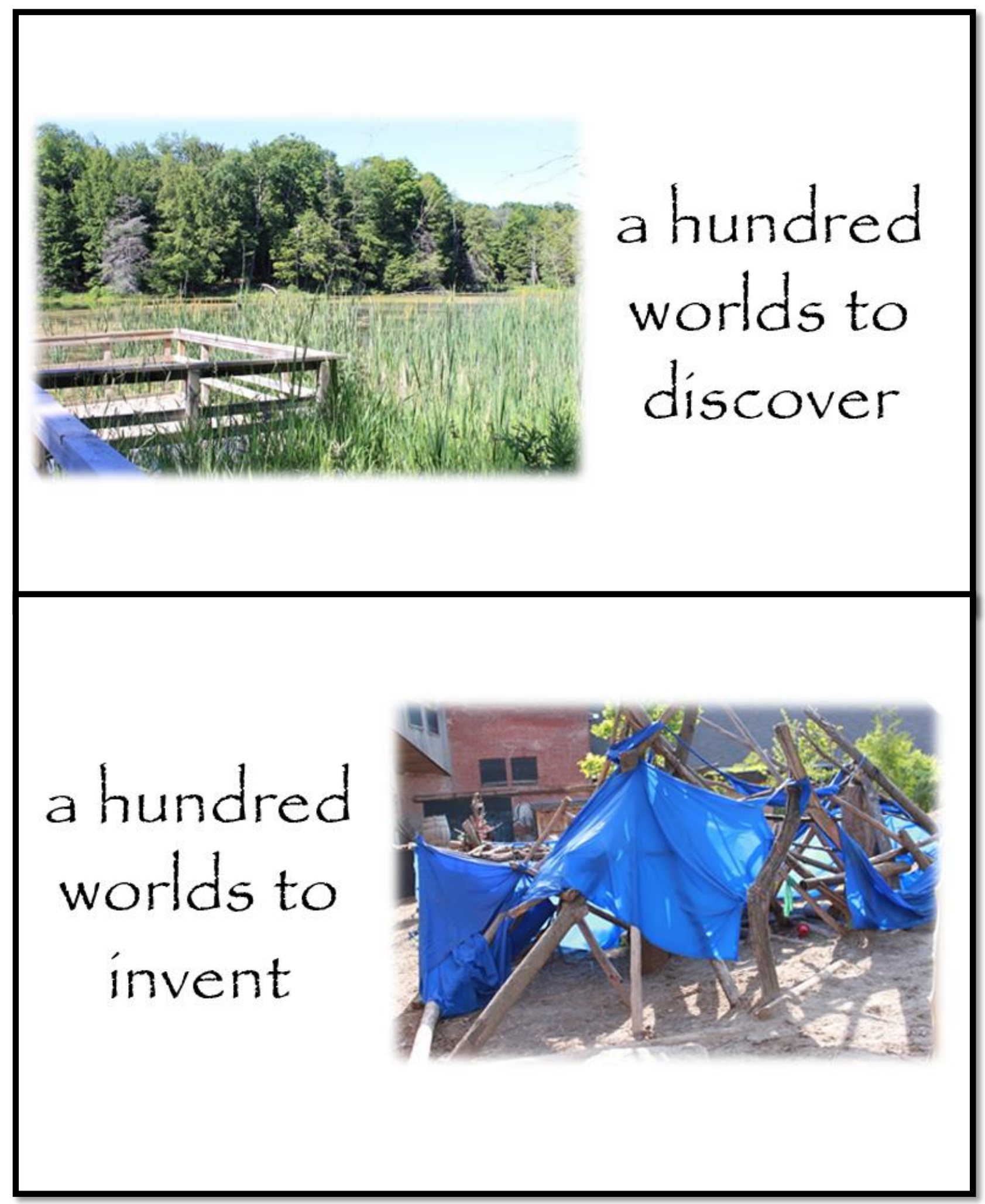




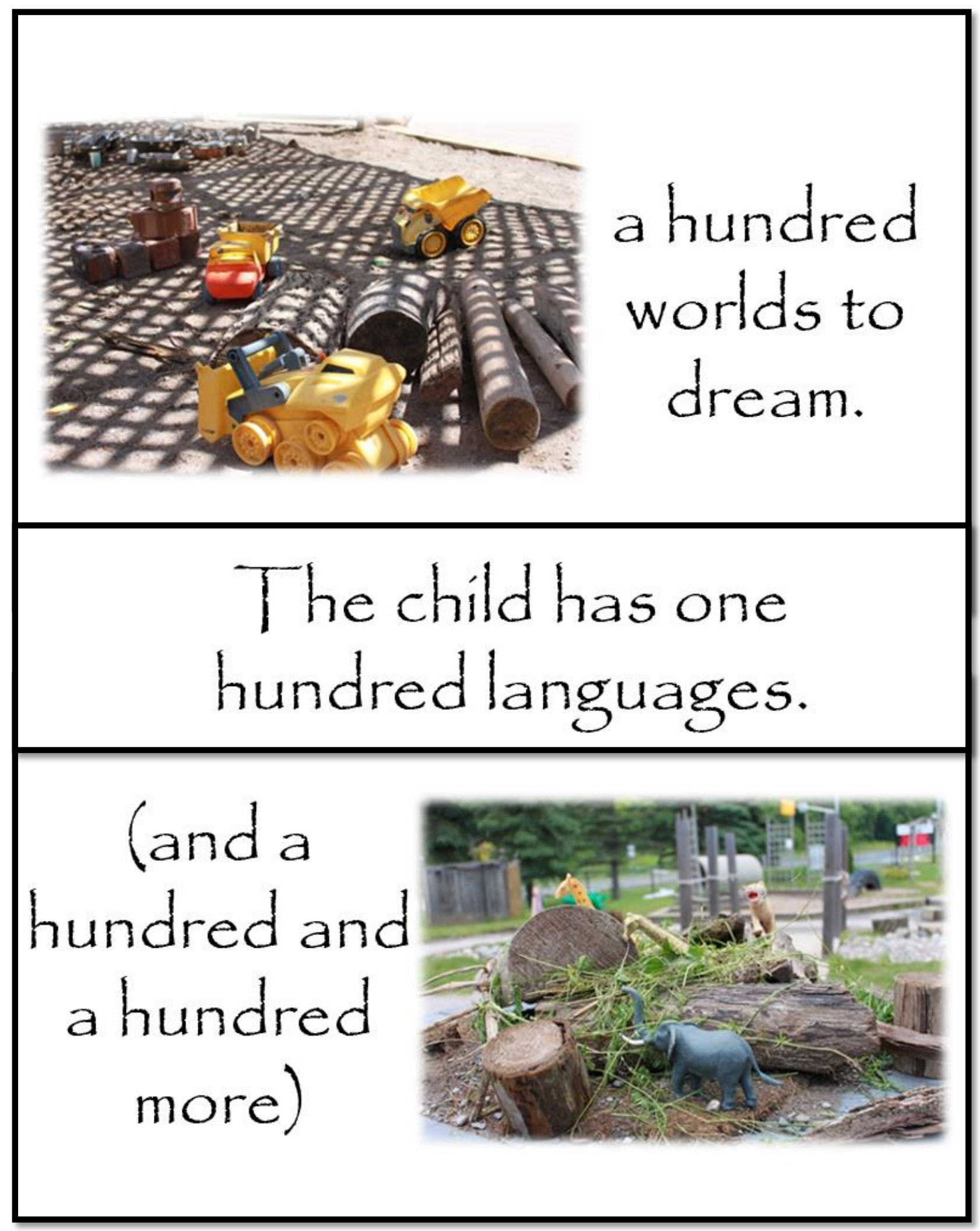




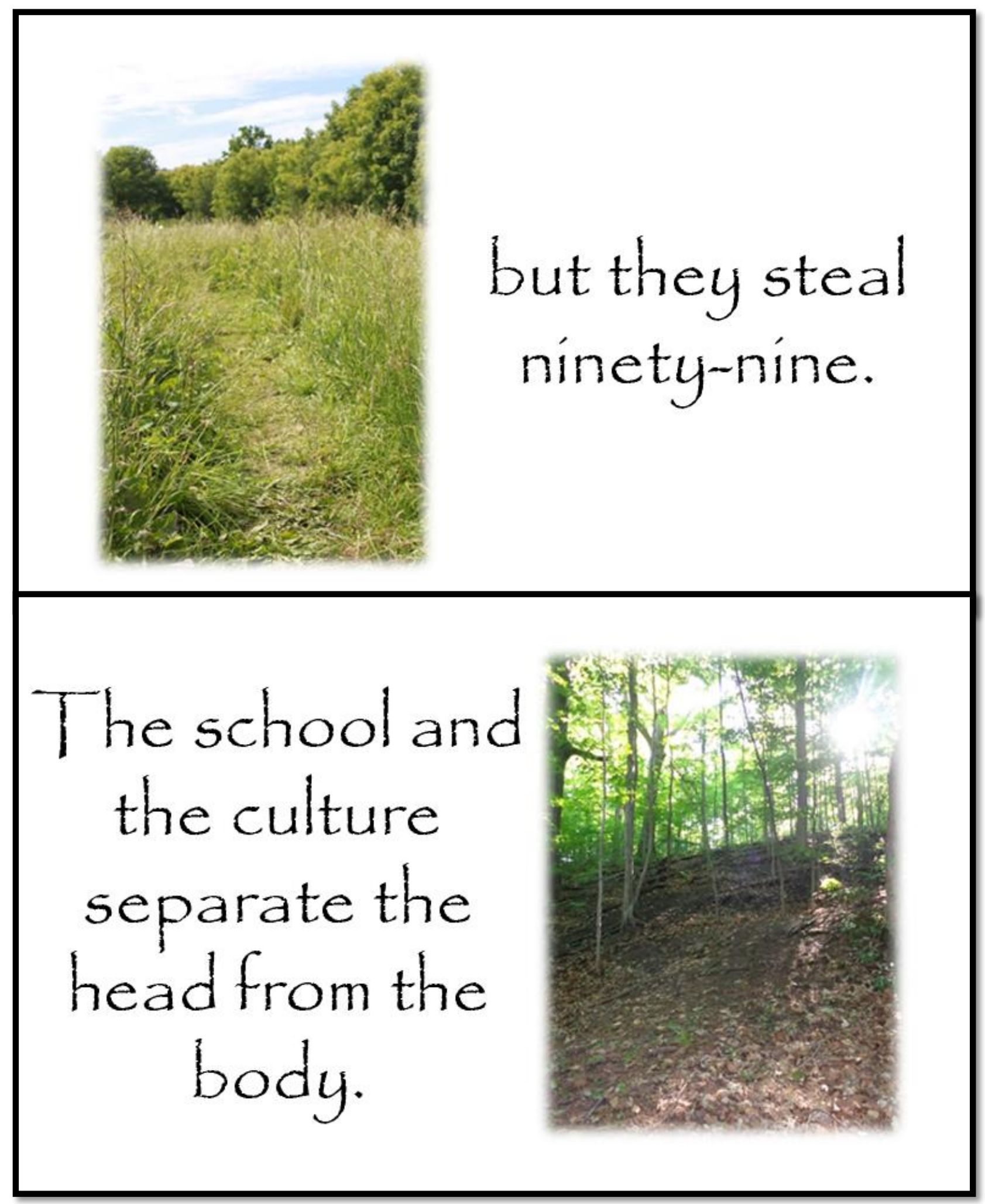




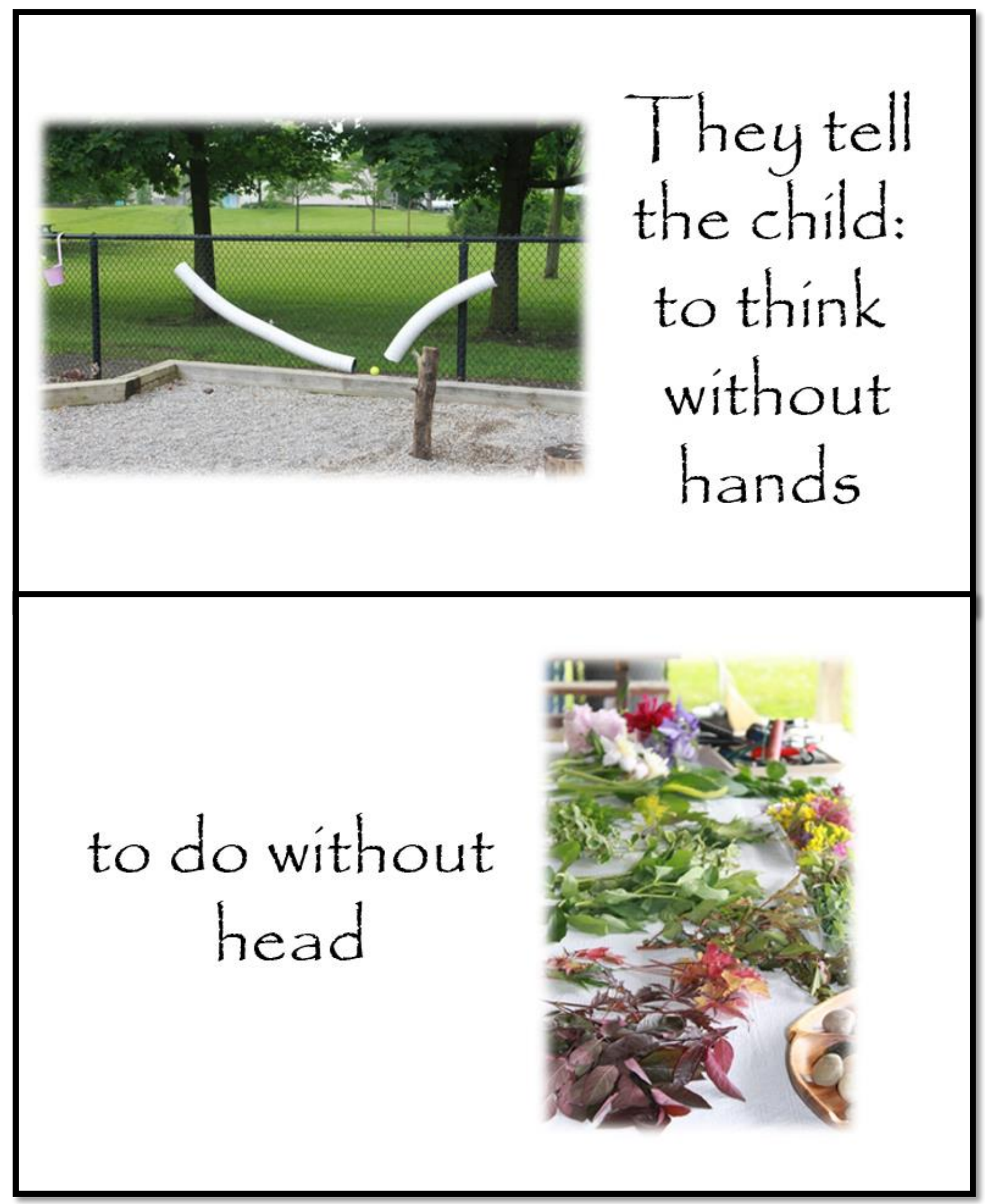




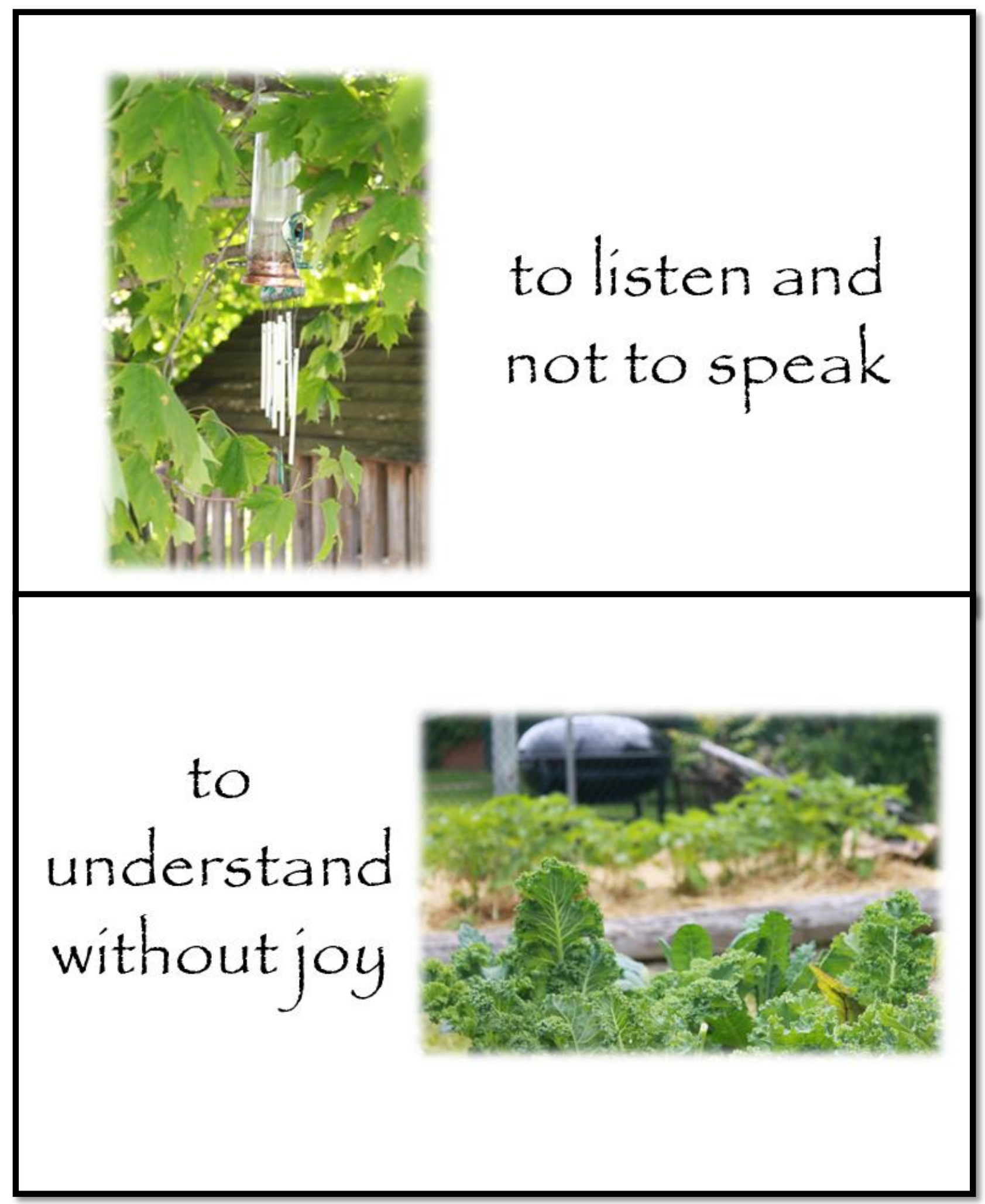




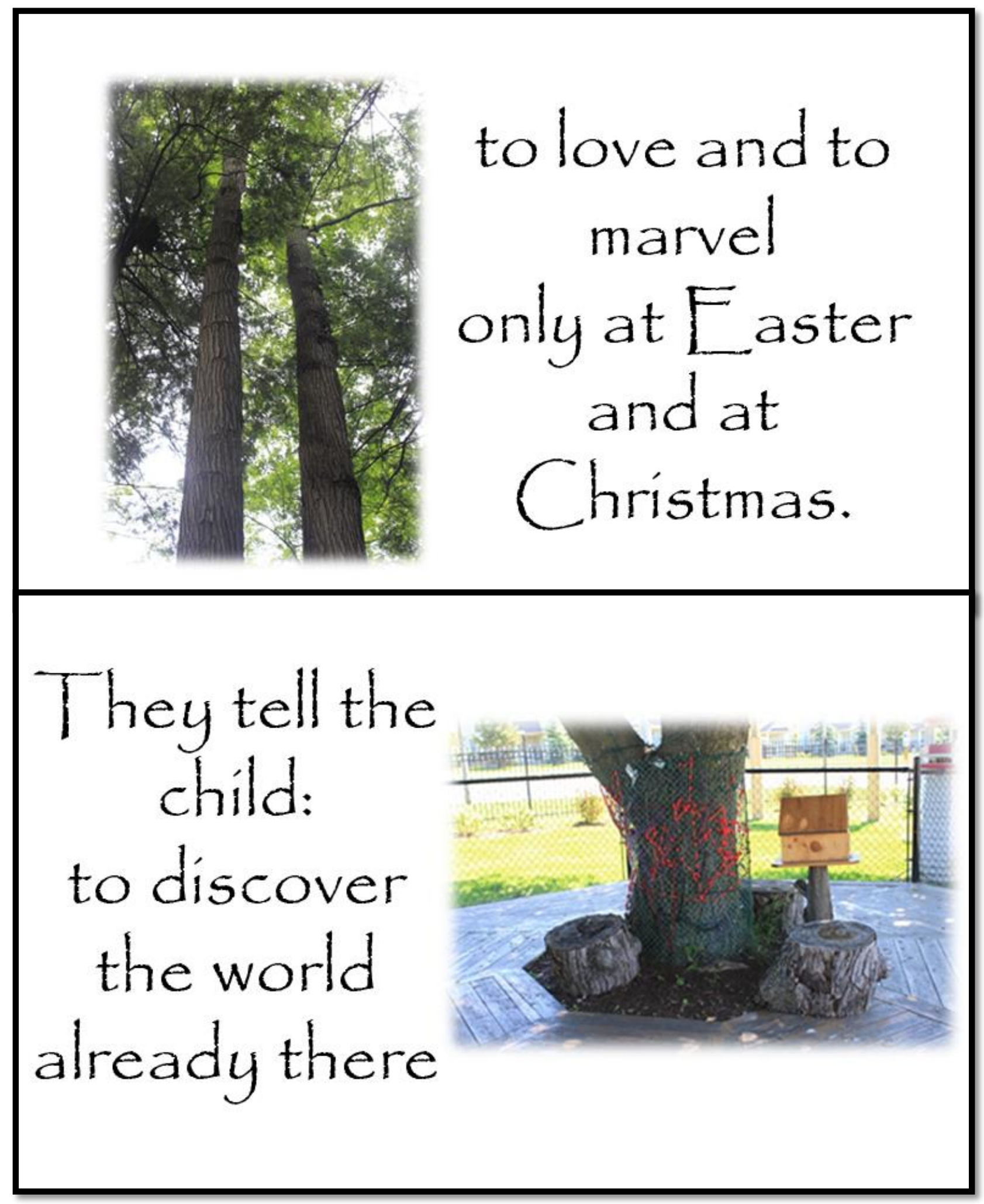




$$
\begin{aligned}
& \text { and of the } \\
& \text { hundred } \\
& \text { they steal } \\
& \text { ninety-nine. }
\end{aligned}
$$

\section{They tell the child:}

that work and play

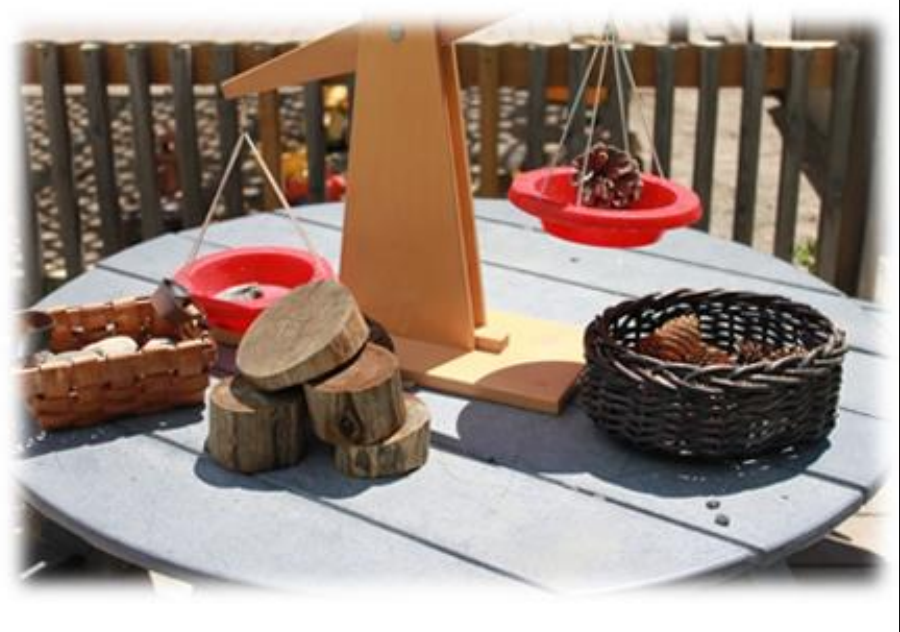




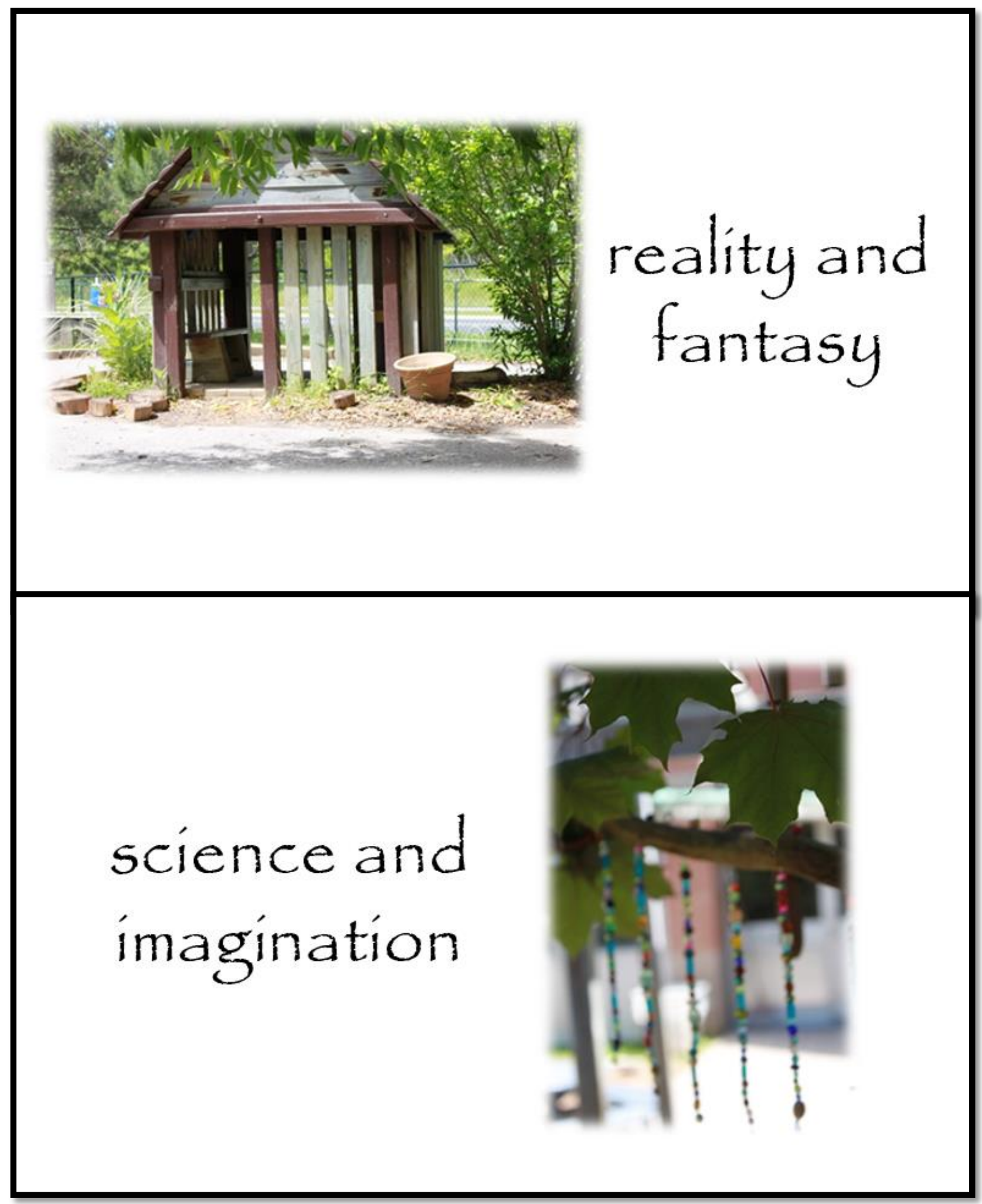




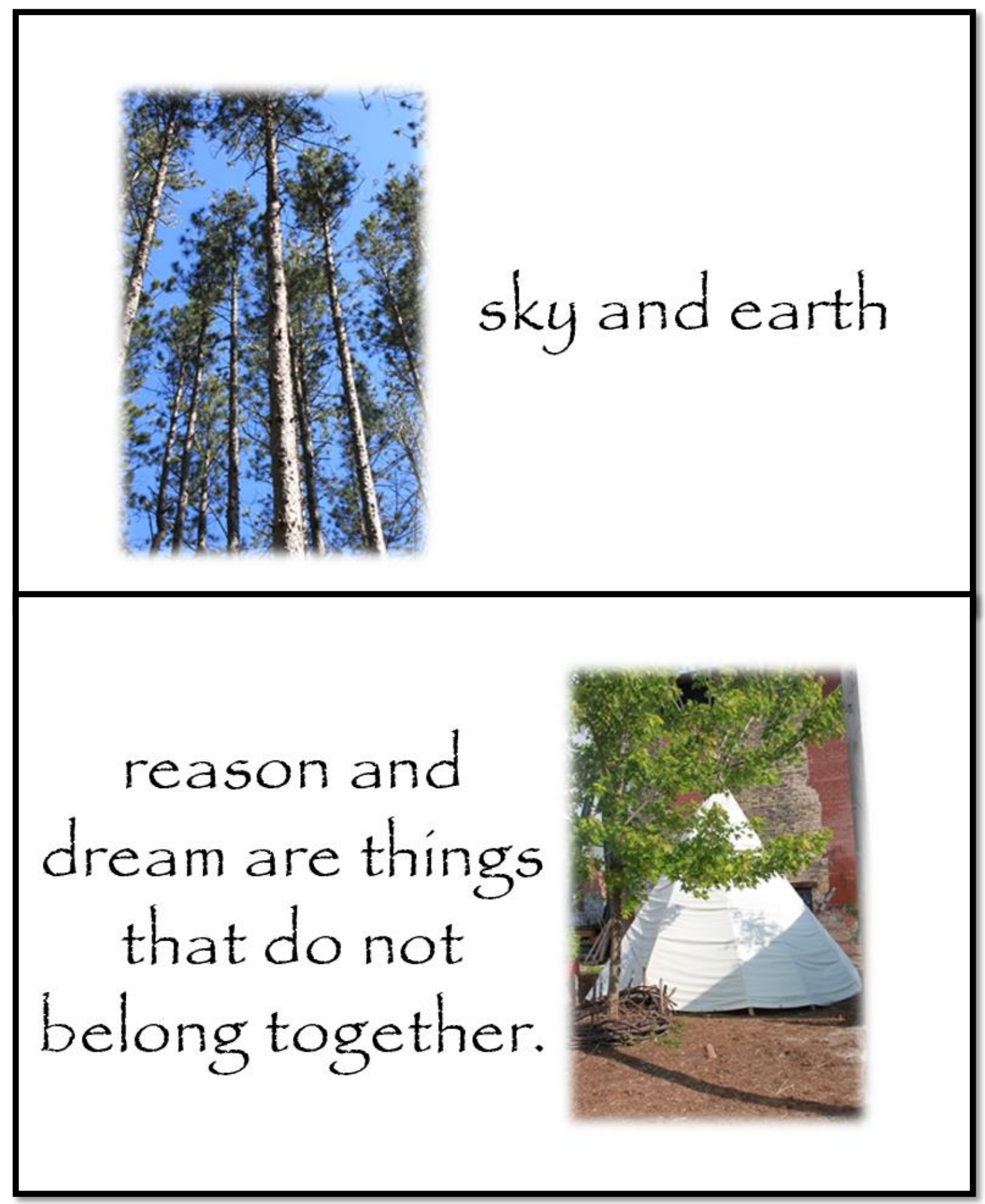




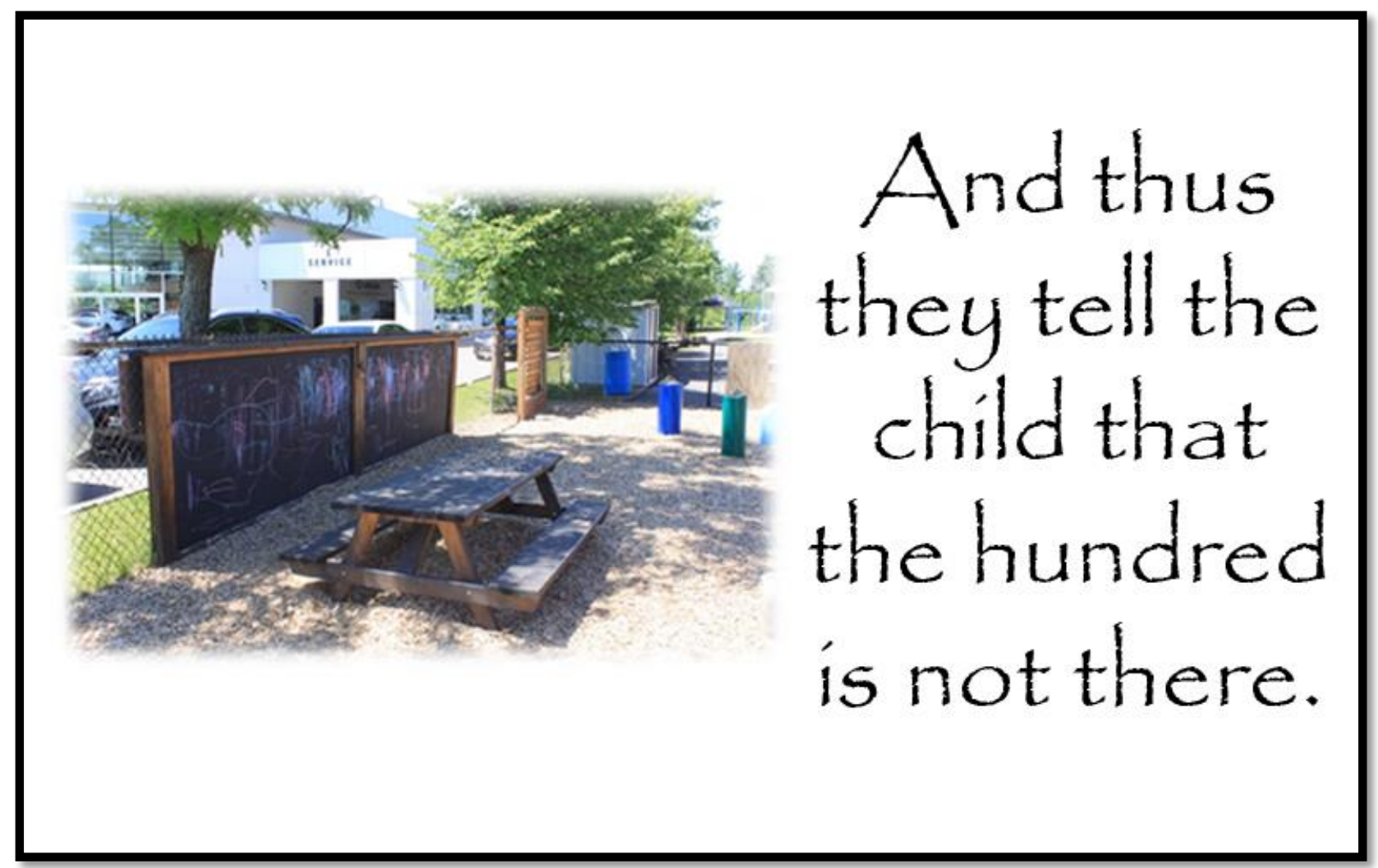




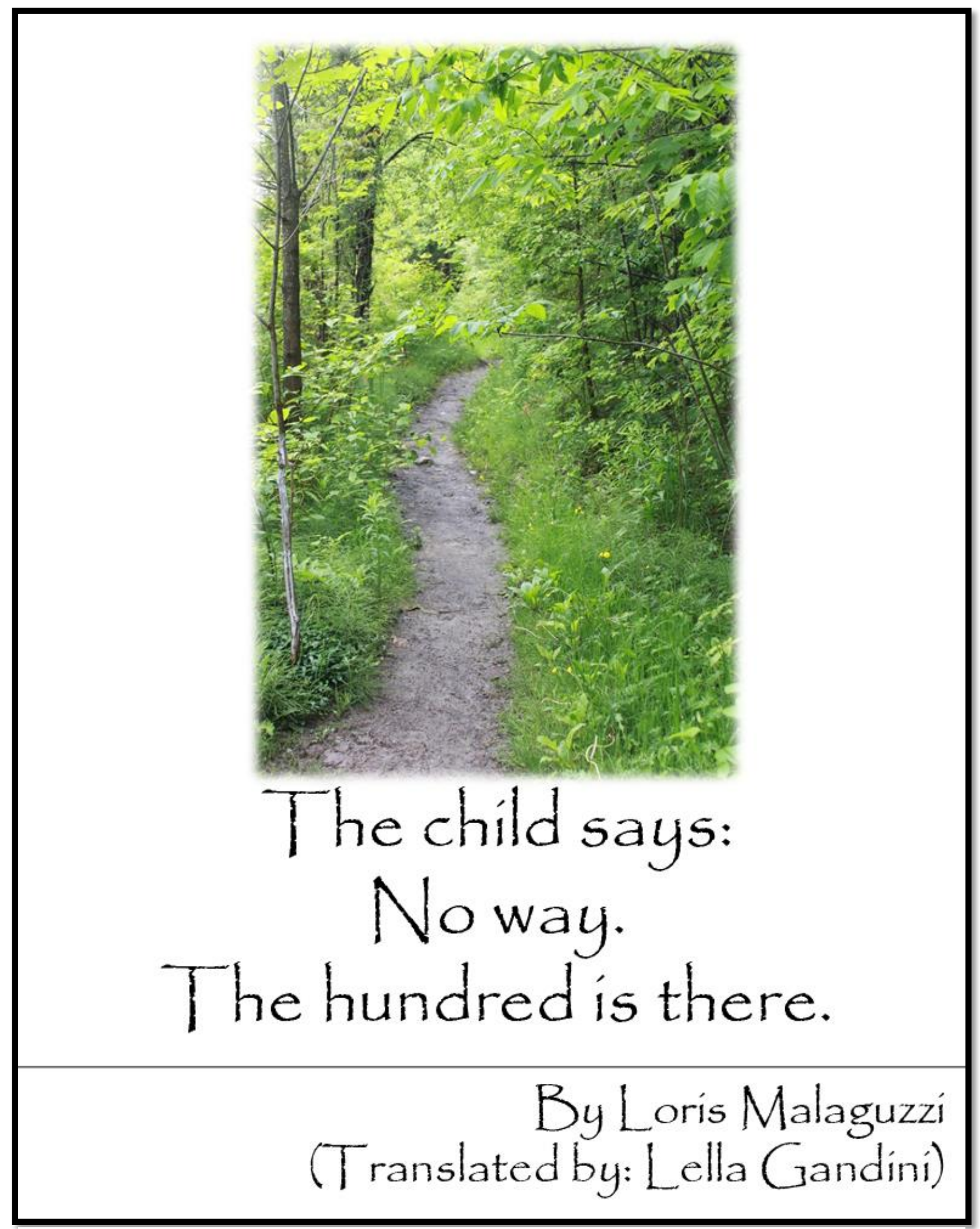

Figure 53. Hundred Languages Poem (Gandini, 2012. p. 3.) 


\section{RYERSONUNIVERSITY}

SCHOOL OF EARLY CHILDHOOD STUDIES FACULTY OF COMMUNITY SERVICES

Research Study:

Nature \& Reggio Inspired Outdoor Learning Environments

Is your early learning setting Reggio Inspired?

Do you incorporate natural elements or nature in the outdoor

Learning Environment?

Does your centre believe in the significance of the outdoor learning environments?

If you answered yes to any of the above questions, your early learning centre may be interested in participating in this study.

We are presently looking for early learning settings in Ontario to be a part of our study, which is being conducted as part of a Masters

Research project.

What does the study involve?

Participating sites will agree to have their outdoor learning environments photographed for data collection. Images will be shared in the dissemination of the research. The estimated time commitment is 1-3 hours on site for the photo shoot.

If interested please contact Tanya Farzaneh at Tanya.farzaneh@ryerson.ca 


\section{Appendix B}

\section{Consent Form}

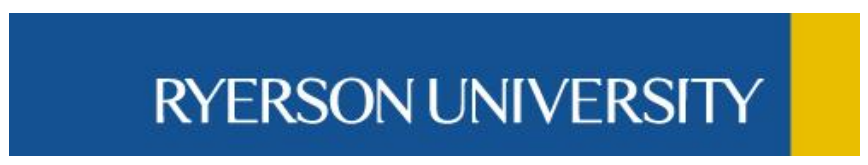

SCHOOL OF EARLY CHILDHOOD STUDIES

FACULTY OF COMMUNITY SERVICES

\section{Ryerson University \\ Consent Agreement}

You are being invited to participate in a research study. Please read this consent form so that you understand what your participation will involve. Before you consent to participate, please ask any questions to be sure you understand what your participation will involve.

Research Study: A photographic inquiry into Reggio inspired natural outdoor environments in Ontario early learning settings. This research study is being conducted by Tanya Farzaneh, student of Masters of Early Child Studies, and is supervised by Rachel Langford, director from the School of Early Childhood Education at Ryerson University.

If you have any questions or concerns about the research, please feel free to contact me, student researcher at tanya.farzaneh@ryerson.ca. In addition you may contact the faculty supervisor Rachel Langford 350 Victoria St, Toronto M5B 2K3, 416 979-5000 ext. 7635 or at rlangfor@ryerson.ca.

PURPOSE OF THE STUDY: This study seeks to explore the characteristics of Reggio inspired natural outdoor setting in Ontario context through photography based research methods. More specifically, this study will explore how Reggio Inspired practice translates in outdoor natural learning environments?

This study hopes to obtain 10-15 outdoor early learning setting that subscribe to Reggio Inspired practice and include nature and natural elements within their outdoor learning site. Early learning centres that do not include nature and other natural elements would be ineligible to 
participate. This major research paper is being completed in partial completion of degree requirements for the Masters of Child Studies at Ryerson University.

WHAT PARTICIPATION MEANS: If you volunteer your early learning centre to participate in this study, you will be asked to do the following things:

*Provide a convenient time to allow photographs to be taken of your outdoor learning environment during daytime hours

* Ensure closure of the outdoor environment and ensure the outdoor environment is free of children and people for 1-2 hours during the photo shoot/ data collection

* Site name and locations will be collected, however you will have choice to include this information in the data analysis.

* Prior to the use of photos, you will have access to review and omit photos if requested.

* Research findings and the study will be available to participating sites through email in the fall of 2015 upon study completion if requested.

* Images and research study may be shared in publication and or conference

POTENTIAL BENEFITS: By participating in this research study, you will be contributing to new research in the area of natural Reggio inspired outdoor learning setting within Ontario context. To date research is limited in this area. Through this research recommendations and potentials for practice will be discussed. Your site/ setting may help to contribute to these recommendations and potentially inspire other educators. I cannot guarantee, however, that you will receive any benefits from participating in this study.

\section{WHAT ARE THE POTENTIAL RISKS TO YOU AS A PARTICIPANT: The} potential risks of participating in this study are very low. Some participants may experience discomfort in having their outdoor learning sites photographed for research. To alleviate some of this discomfort, you will have the opportunity to review images taken and omit or delete photos that you do not wish to include in the data collection.

CONFIDENTIALITY: You will have the opportunity to indicate if you would like your setting to remain anonymous. For participants that choose to remain anonymous, no 
identifying factors such as name site and location will be used in the study. Your site identity will be protected throughout the process of this study. Site participants will be given an alphanumeric code such as Reggio-nature-1 as this will be used for the organization and coding of data, field notes, analysis and possible dissemination. Participants choosing to be acknowledged for their centre's outdoor learning space can indicate on the consent box below. Centres will be identified by Name and location only - ex. Apple Blossom -Toronto.

\section{DATA COLLECTED:}

Visual data collections will be stored in a secure password protected computer file to be viewed only by the researcher. Digital images will be destroyed once downloaded onto the secure password protected computer file. Digital images will be kept for 1 year following the completion of the research study. Consent forms will be stored in a separate secured locked file location to ensure confidentiality.

INCENTIVES FOR PARTICIPATION: There are no incentives offered in participating in this study

COSTS TO PARTICIPATION: There is no cost associated with participating in this study

\section{VOLUNTARY PARTICIPATION AND WITHDRAWAL:}

Participation in this study is completely voluntary. You can choose whether to be in this study or not. You may stop participating at any time. If you choose to stop participating, you may also choose to not have your data included in the study. You can choose to eliminate photos taken by June 30, 2015 to ensure these images are not used in data analysis. Your choice of whether or not to participate will not influence your future relations with Ryerson University or the investigators Tanya Farzaneh and Rachel Langford involved in the research.

QUESTIONS ABOUT THE STUDY: If you have any questions about the research now, please ask. If you have questions later about the research, you may contact.

Student researcher: Tanya Farzaneh 
tanya.farzaneh@ryerson.ca.

In addition you may contact the faculty supervisor Rachel Langford 350 Victoria St, Toronto M5B 2K3

416 979-5000 ext. 7635

rlangfor@ryerson.ca.

This study has been reviewed by the Ryerson University Research Ethics Board and does not require ethics approval. If you have questions regarding your rights as a participant in this study please contact:

\author{
Research Ethics Board \\ C/o Office of the Vice President, Research and Innovation \\ Ryerson University \\ 350 Victoria Street \\ Toronto, ON M5B 2K3 \\ 416-979-5042 \\ rebchair@ryerson.ca
}




\section{A photographic inquiry into Reggio inspired natural outdoor environments in Ontario early learning settings.}

\section{CONFIRMATION OF AGREEMENT:}

Your signature below indicates that you have read the information in this agreement and have had a chance to ask any questions you have about the study. Your signature also indicates that you agree to allow your site to participate in the study and have been told that you can change your mind and withdraw your consent to participate at any time. You have been given a copy of this agreement.

You have been told that by signing this consent agreement you are not giving up any of your legal rights.

Name of Participant (please print)

Signature of Participant

Date

I agree to allow photo images of the outdoor learning environments to be taken for the purposes of this study. I understand how these images will be stored and destroyed.

Signature of Participant

Date

\section{Please indicate level of confidentially you wish to maintain}

$\square$ I would like my site name/location to remain confidential, an alphanumeric code should be used

I give permission to use the site name and location in the final research study and dissemination of results

I would like to review photos upon data completion

Please send me a copy of the final research report by the Fall 2015 


\section{Appendix C}

\section{Photo Shoot Script}

\section{Guiding Questions:}

What aspects grab your attention?

Aesthetically?

Visually?

Sensorial?

Textures?

Beauty?

Where and in what ways is nature found?

How is the hundred languages represented? In what ways is it represented?

Is there evidence is the image of the child as competent, strong creative?

Are there provocations or areas to provoke children's imaginations?

How is the environment being translated as a third teacher? 


\section{References}

Best Start Expert Panel on Early Learning. (2007). Early learning for every child today: A framework for Ontario early childhood settings. Retrieved February 15, 2015, from http://www.children.gov.on.ca/htdocs/English/documents/topics/earlychildhood/early_lea rning_for_every_child_today.pdf

Buckingham, D. (July 2009). 'Creative' visual methods in media research: possibilities, problems and proposals. In J. Hughes (Ed.), Visual Methods, 31, 227- 247. London: SAGE Publications

Childcare Canada Childcare, (n.d). Bringing the outdoors into early childhood education Resource and Research Unit. Retrieved from: http:// www.childcarecanada

Cadwell, L. (2003). Bringing learning to life: The reggio approach to early childhood education. London: Teachers College Press.

Callaghan, K. (2013). The environment is a teacher. In Ontario Ministry of Education. Think, feel, act: Lessons from research about young children, (11-15). Toronto: Ministry of Education, Ontario.

Creswell, J. (2013). Qualitative inquiry and research design: Choosing among five approaches (3rd ed.). Thousand Oaks, CA: SAGE Publications.

Creswell, J. (2014). Research design: qualitative, quantitative, and mixed methods approaches (4th ed.). Thousand Oaks, CA: SAGE Publications.

Cooper, M. (2012). Is beauty a way of knowing? In Edwards, C., \& Gandini, L., \& Forman, G. (Eds.) The Hundred Languages of Children: The Reggio Emilia Experience in Transformation, (3 ${ }^{\text {rd }}$ ed). (295-302). Santa Barbara, CA: Praeger.

Dahlberg, G. (2012). Pedagogical documentation: a practice for negotiation and democracy. In Edwards, C., \& Gandini L., and Forman, G. (Eds.) The Hundred Languages of Children: The Reggio Emilia Experience in Transformation ( $3^{\text {rd }}$ ed), (225-231). Santa Barbara, CA: Praeger.

Dewey, J. (1963). Experience as Education (1 $\left.{ }^{\text {st }} \mathrm{ed}\right)$. New York, N.Y: Collier Books.

Dodd-Nufrio, A. (2011). Reggio Emilia, Maria Montessori, and John Dewey: dispelling teachers' misconceptions and understanding theoretical foundations. Early Childhood Education Journal, 39. 235-237.

Edwards, C. (2012). Teacher and learner, partner and guide: the role of the teacher. 
In Edwards,C., \& Gandini, L., \& Forman, G. (Eds.) The Hundred Languages of Children: The Reggio Emilia Experience in Transformation ( $3^{\text {rd }}$ ed), (147-172). Santa Barbara, CA: Praeger.

Edwards, C., \& Gandini, L. \& Forman, G. (2012). Introduction: background and starting points. In Edwards, C., \& Gandini, \& Forman, G. (Eds.) The Hundred Languages of Children: The Reggio Emilia Experience in Transformation ( $3^{\text {rd }}$ ed), (295-302). Santa Barbara, CA: Praeger.

Elliot, E. (2010). Thinking beyond a framework: entering into dialogues. In Pacini-Ketchabaw, V. (Ed.). Flows, Rhythms, \& Intensities: Early Childhood Education Curriculum. (3-20). New York, NY: Peter Land Publishing.

Ernest, J. (2014). Early childhood educators' use of natural outdoor settings as learning environments: an exploratory study of beliefs, practices, and barriers. Environmental Education Research, 20(6), 735-752, DOI: 10.1080/13504622.2013.833596.

Fiore, A. (2013). The reggio emilia approach to early childhood, Retrieved from http//: lascuoladitalia.org.s98094.gridserver.com.

Fjortoft, I. (2001). The natural environment as a playground for children: the impact of outdoor play activities in pre-primary school children. Early Childhood Education Journal, 29, (2) 111-117.

Fraser, S. (2000). Authentic Childhood: Experiencing Reggio Emilia in the classroom. Scarborough, Ontario, Canada: Nelson.

Frumkin, H. (2014). Forward In Nature Play \& Learning Places. Creating and managing places where children engage with nature. Natural Learning Initiative and Reston, VA: National Wildlife Federation. Version 1.2.

Forest School Canada (n.d) Forest and Nature School in Canada: A Head, Heart, Hands Approach to Outdoor Learning (2014). Retrieved: from: http//www.forestschoolscanada.ca

Forest School Canada (n.d.). Defining Forest School. Retrieved from: http://www.forestschoolcanada.ca

Fu, V., \& Stremmel, A., \& Hill, L. (2002). Teaching and learning: Collaborative exploration of the Reggio Emilia approach. Upper Saddle River, NJ: Pearson Education.

Gandini, L. (2012). History, Ideas, and Basic Principles: An Interview with Loris Malaguzzi. 
In Edwards, C., \& Gandini, L., \& Forman, G. (Eds.) The Hundred Languages of Children: The Reggio Emilia Experience in Transformation ( $3^{\text {rd }}$ ed). (27-71). Santa Barbara, CA: Praeger.

Gandini, L. (2012). The Observant Teacher: Observation as a Reciprocal Tool of Professional Development: An Interview with Amelia Gambetti. In Edwards, C., \& Gandini, L., \& Forman, G. (Eds.) The Hundred Languages of Children: The Reggio Emilia Experience in Transformation ( $3^{\text {rd }}$ ed). (173-185). Santa Barbara, CA: Praeger.

Gleave, J. \& Hamilton-Cole, I. (2012). A world without play: a literature review on the effects of a lack of play on children's lives. Retrieved: http:// wwwplayengland.org.uk.

Hall, E. (2012). Malaguzzi's Story, Other Stories, and Respect for Children. In Edwards, C., \& Gandini, L., \& and Forman, G. (Eds.) The Hundred Languages of Children: The Reggio Emilia Experience in Transformation ( $3^{\text {rd }}$ ed). (225-231). Santa Barbara, CA: Praeger.

Haas, C. \& Ashman, G. (2014). Kindergarten children's introduction to sustainability through transformative, experiential nature play. Australasian Journal of Early Childhood, 39 (2).

Herrington, S. \& Lesmeister, C. (2006). The design of landscapes at child care centres: seven Cs. Landscape Research, 31 (1). 63-82.

Jackson, R. Drummod, D. \& Camara, S. (2007). What is qualitative research? Qualitative research reports in communication, 8(1) 21-28.

Kenny, R. (2009). Involve, enjoy, achieve: a forest school evaluation project. Retrieved from: http://forestofavon.org.uk

Keyte-Hartland, D. (2010). Aesthetics of learning: landscapes of expressivity. Retrieved: debikeytehartland.file.wordpress.com/2011/08/aesthetics-of-learning.pdf

MacEachren, Z. (2013). The Canadian forest school movement, Learning Landscapes, 7 (3), 219-233.

Malaguzzi, L. (1994). Your image of the child: where teaching begins, Exchange, (3). Retrieved from: http: www.reggioalliance.org/downloads/malaguzzi:ccie:1994.pdf

Marion, M. (2015). Guidance of Young Children ( $9^{\text {th }}$ ed). Upper Saddle River, NJ: Pearson.

Mason, P. (2005). Visual Data In Applied Qualitative Research: lessons from experience. Qualitative Research, 5 (3). 325-346. 
Maynard, T. \& Waters, J. \& Clement, J. (2013). Moving outdoors: further explorations of 'child-initiated' learning in the outdoor environment. Education, 41(3) 282-299.

Maynard, T. \& Waters, J. (2007). Learning in the outdoor environment: a missed opportunity? Early Years: An International Research Journal, 27(3), 255-265, DOI: 10.1080/09575140701594400.

Merewether, J. (2015). Young Children's Perspectives of Outdoor Learning Spaces: What Matters? Australasian Journal of Early Childhood, 40(1), 99-110.

Moore, R. (2014). Nature play \& learning places: creating and managing places where children engage with nature. Raleigh, NC: Natural Learning Initiative and Reston, VA: National Wildlife Federation. Version 1.2.

New, R. (2000). Reggio Emilia: catalyst for change and conversation, Clearing house on Elementary and Early Childhood Education (1-7).

Nielson, D.S. (2001). Overview of qualitative research methods. Bone, 48(2) 51-60.

Nimmo, J \& Hallett, B. (2008). Childhood in the garden: a place to encounter natural and social diversity. Young Children the Journal of National Association of Early Childhood Education, (NAYEC). 32-38.

O'Brien, L. (2009). Learning outdoors: the forest school approach. International Journal of Primary, Elementary and Early Years Education, 37(1), 45-60, DOI: 10.1080/03004270802291798.

O'Brien, L. \& Murray, R. (2007). Urban forest school and its impact on young children: a case study from Britain, Urban forestry and Urban Greening, 6, 249-265.

Ontario Ministry of Education (n.d) How Does Learning Happen? Pedagogy for the Early Years (2014). Retrieved from: http:// www.ontario.ca/edu.ca

Pacini-Ketchabaw, V. (2010). Curriculum's Flows, Rhythms, and Intensities: A Beginning. In V. Pacini-Ketchabaw (Ed.), Flows, Rhythms, \& Intensities: Early Childhood Education Curriculum. (XI-XVIII). New York, NY: Peter Land Publishing.

Pauwels, L. (2010). Visual sociology reframed: an analytical synthesis and discussion of visual methods in social and cultural research. Sociological Methods \& Research, 38(4), 545581. doi:10.1177/0049124110366233 
Pelo, A. (2008). Introduction: Embracing Social Justice in Early Childhood Education. In Pelo,

A. (Ed). Rethinking Early Childhood Education (ix-xiii). Milwaukee, Wisconsin: Rethinking Schools.

Pelo, A. (2008). A Pedagogy for Ecology In Pelo, A. (Ed). Rethinking Early Childhood Education (132-130). Milwaukee, Wisconsin: Rethinking Schools.

Pink, S. (2006). Doing visual ethnography: images, media, and representation in research. London: Sage Publications.

Prosser, J. (1998). The status of image-based research. In Image-based Research: A sourcebook for Qualitative Research (86-100): New york, NY. Routledge.

Prosser, S \& Schwartz, D. (1998). Photography within the sociological research process. In Image-based Research: A sourcebookfor Qualitative Research (101-115): New York, NY: Routledge.

Prosser, J. (2007). Visual methods and the visual culture of schools. Visual studies, 22 (1), 13-30.

Rinaldi, C. (2012). The pedagogy of listening: the listening perspective from Reggio Emilia. In Edwards, C., \& Gandini, L., \& Forman, G. (Eds.) The Hundred Languages of Children: The Reggio Emilia Experience in Transformation (3 ${ }^{\text {rd }}$ ed). (233-246). Santa Barbara, CA: Praeger.

Rose, G. (2007). Visual methodologies: An introduction to the interpretation of visual materials (2nd ed.). London: SAGE Publications.

Rose, G. (2013). On the relation between visual research methods and contemporary visual culture. The Sociological Review, 62 (24-46).

Sears, A., \& Carins, J. (2010). A Good Book, In Theory: Making Sense Through Inquiry (2 $2^{\text {nd }}$ Edition). Toronto, ON: University of Toronto Press Incorporated.

Slade, M., \& Lowery, C. \& Bland, R. (2013). Evaluating the impact of forest schools: a collaboration between University and primary school, British Journal for Learning Support, 28 (2), 66-72.

Strong-Wilson, T. \& Ellis, J. (2007). Children and place: Reggio Emilia's environment as third teacher, Theory in Practice, 46 (1) 40-47.

Sobel, D. (1995). Reclaiming the Heart in Nature Education. Nature Study, 49(3) 4-12.

Sobel, D. (2004). Place-based education: connecting classroom and community. Nature and Listening. Retrieved from http://antiochne.edu 
Swarbrick, N., \& Eastwood, G. \& Tutton, K. (2004). Self-esteem and successful interaction as part of the Forest School Project. Support for Learning, 19 (3), 142-146.

Waller, T. (2007). 'The trampoline tree and the swamp monster with 18 heads': Outdoor play in the foundation stage and foundation phase. Education, 3-13, 35(4), 393-407. doi:10.1080/03004270701602657

Weber, S. (2008). Visual Images in Research: In Knowles J. G. \& Cole’s A. L. (41-54) Thousand Oaks, California: Sage Publications.

Weigand, R. (2011). A Garden of Learning: Exploring Critical Place-Based Pedagogy in Kindergarten: thesis submitted to Master of Arts Department of Curriculum, Teaching and Learning Ontario Institute for Studies in Education University of Toronto.

Weise, Lisa. (2012). "Get 'Em Outside: a Recaptured Natural Area on School Grounds becomes an Outdoor Classroom where Learning Opportunities Abound." Science and Children 36. 